\title{
THE ROLE OF POSTGRADUATE EDUCATION FOR REGISTERED NURSES WORKING IN THE AGED CARE SECTOR
}

\author{
By \\ Susan Elizabeth Tansley
}

A thesis submitted to the Victoria University of Wellington

in fulfilment of the

requirements for the degree

Master of Nursing

Victoria University of Wellington

2016 


\begin{abstract}
This New Zealand based study explored the perspectives of registered nurses working in aged residential care and their views and experiences on postgraduate education. There is very little research in the area of aged care in New Zealand and none involving postgraduate education. This was a qualitative study using mixed method data triangulation which included a document review, focus groups and interviews. The study was conducted at four aged care facilities in the lower North Island. Focus groups and face to face interviews were carried out with Nurse Managers $(n=5)$ and Registered Nurses $(n=15)$ who had $(n=7)$ and had not $(n=13)$ engaged in postgraduate education. The study found development of nursing knowledge was important for improving quality of older person's care, and career prospects and progression were the main reason nurses engage in postgraduate education. External agencies such as the local District Health Board and tertiary education providers play a role in postgraduate opportunities and how these agencies communicate with nurses plays a significant role in the uptake of postgraduate education. In addition work place support and personal factors such as choices and timing affect the uptake of postgraduate education. A multipronged approach is therefore needed to address postgraduate education in aged care.
\end{abstract}

\title{
Key Words
}

Postgraduate education, Registered Nurse, Aged Care, New Zealand 


\section{Acknowledgements}

This thesis is dedicated to both my Mums, Gladys Richards and Margaret Hing

When I began the journey of writing my thesis in 2013, I didn't realise it would not only be an academic journey but also a life journey. Somehow the significant things that happened in my life over this time period weaved and intermingled with my thesis and became one. Eight months into my research, my lovely little Mum who had dementia died. I know that throughout writing my thesis Mum has been with me, standing beside me, encouraging and supporting me every step of the way as she would have done if she had been alive and well. I also know that she is extremely proud of me at this moment. Thank you Mum for all your support. Margaret, my birth Mother died the same year. I know Margaret has also been with me on this journey and is proud of me. Thank you Margaret for your support.

There are many people I would like to acknowledge and thank who have helped me along the way through the process of researching and writing this thesis.

Firstly, I would like to acknowledge and thank all of the nurses who participated in this study for volunteering their time and sharing their thoughts and experiences with me, as without them this would not have been possible.

Most importantly, I would like to acknowledge and say a big thank you to my supervisor Kathy Nelson for all her wise words, support and mentoring over the last two years and eight months.

I also want to acknowledge and thank all of my work colleagues in the Practice Development Unit at Hutt Valley DHB for supporting me through all my ups and downs, providing advice, helping me with aspects of my thesis and just having that understanding of what researching and writing a thesis is all about.

Most of all though, I want to say a huge thank you to my husband Garry who said to me right at the beginning "your thesis is a marathon not a sprint" well it sure has been a marathon, two years and eight months later! Thank you Garry for all your support, your patience, your advice and proof reading. For those 6.30 a.m. motivational talks over breakfast, for sharing those woohoo moments when I've made some progress, for listening to me when I've been frustrated and annoyed with my thesis and totally understanding where I was at, I love you heaps.

To my Brother David, thank you for your support especially over the last three months. 
To all my friends who have supported me, a big thank you, in particular to Bernadine for listening to me talking about my thesis during our Saturday walks and for encouraging me to carry on. To Trish 'Mother', Trevor "Bob", Robyn and Mike..

Finaly I would like to acknowledge, the many others who have supported me through writing this thesis and who I haven't named (of which there are many), thank you.

'Vision without action is merely a dream

Action without vision just passes the time

Vision with action can change the world'

J.A.Barker 


\section{Table of Contents}

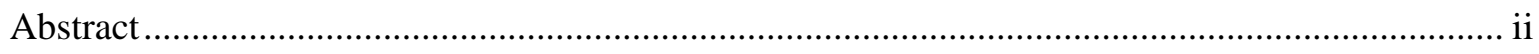

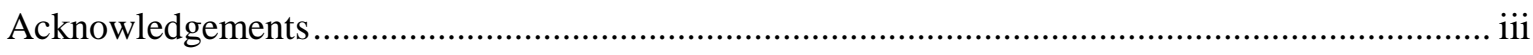

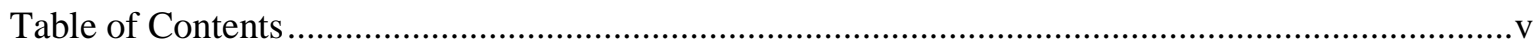

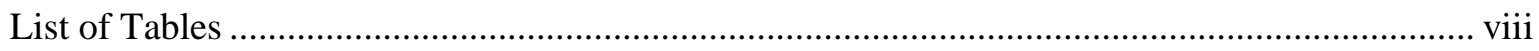

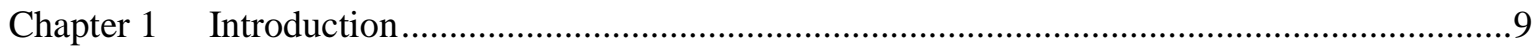

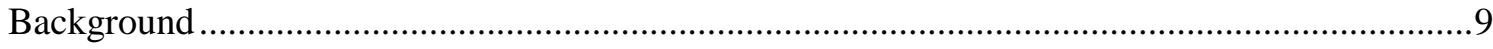

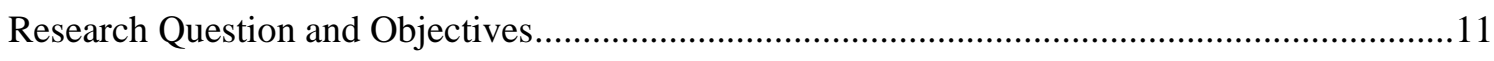

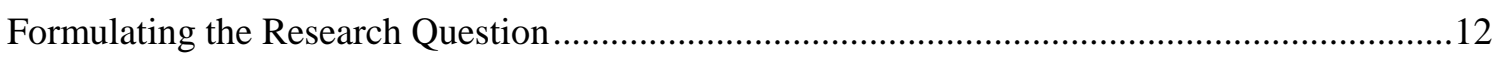

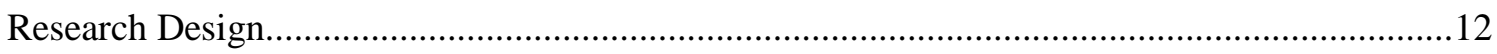

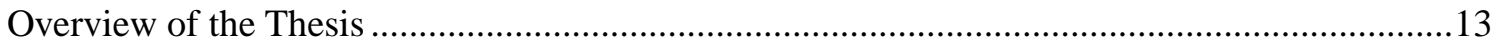

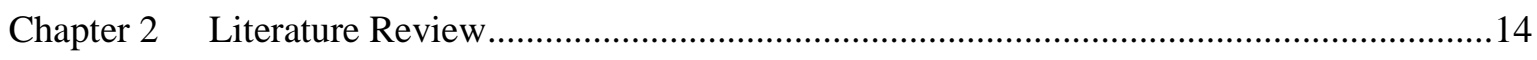

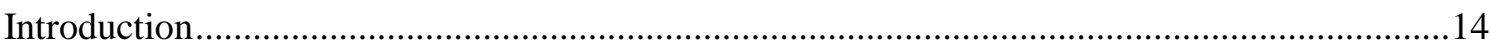

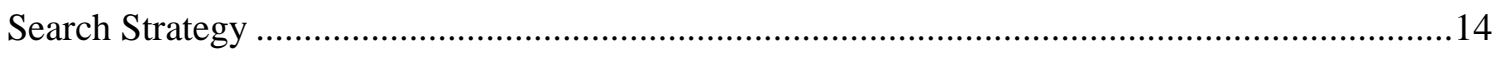

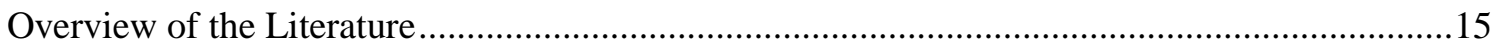

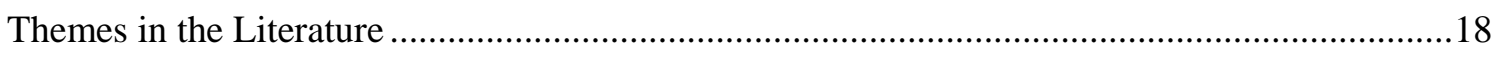

Registered Nurse's Motivation Before Commencing Study ….........................................18

Expectations of Registered Nurses Before Commencing Study ...........................................21

Barriers to Registered Nurses Commencing study ........................................................22

Support to Registered Nurses Before Commencing Study …..............................................24

Support to Registered Nurses During and to Completion of Postgraduate Study.....................25

Challenges for Registered Nurses Undertaking Postgraduate Study ....................................26

Benefits of Study During and Following Completion of Postgraduate Education ...................27

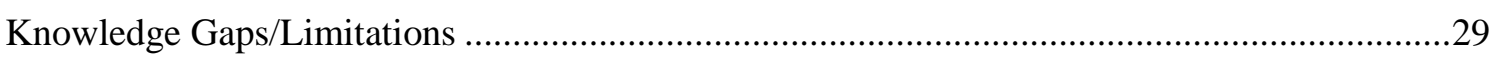

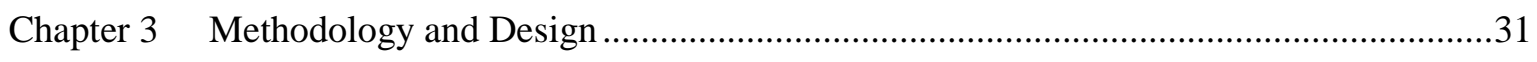

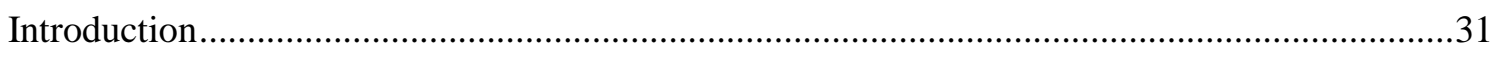

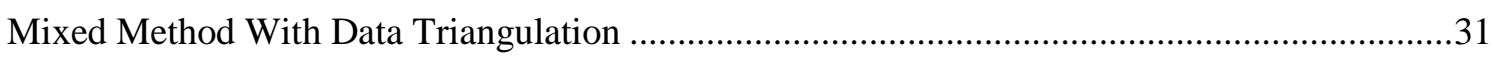

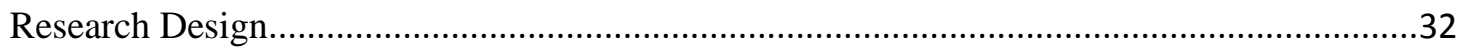

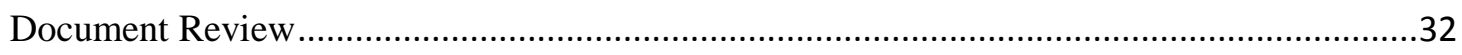


Focus Groups

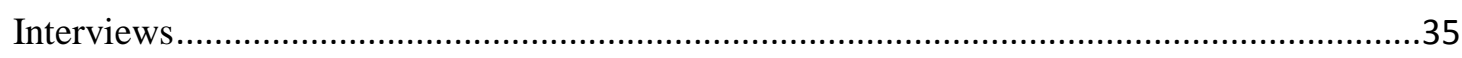

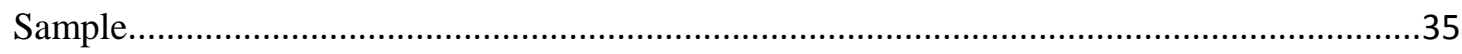

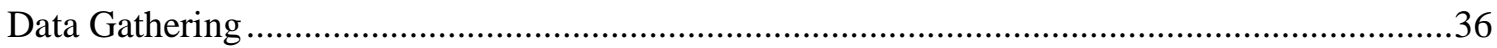

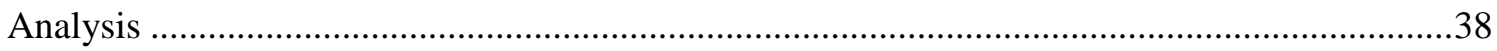

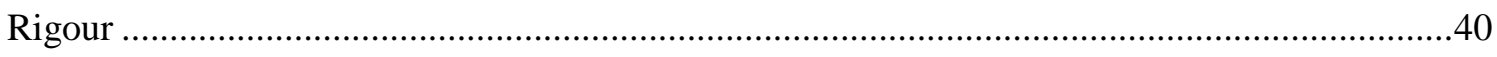

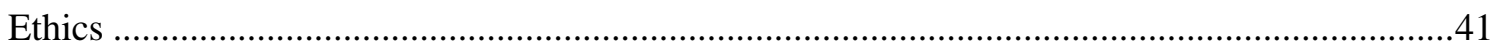

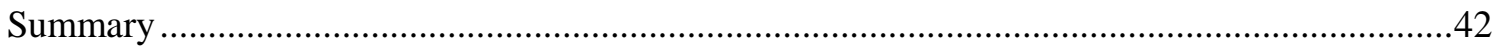

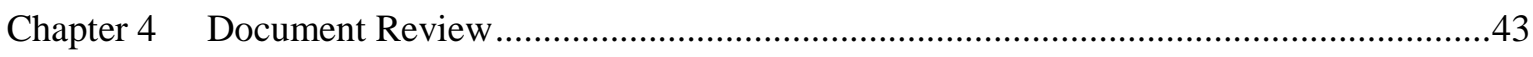

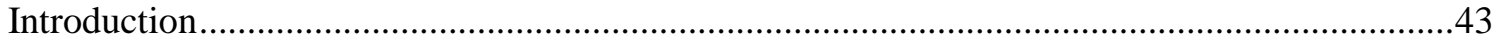

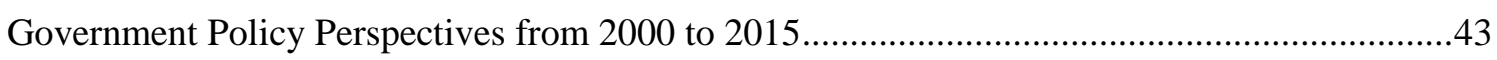

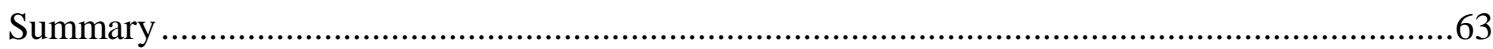

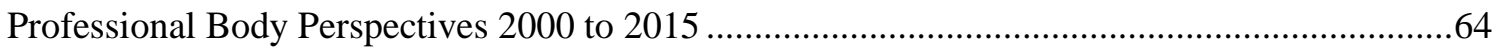

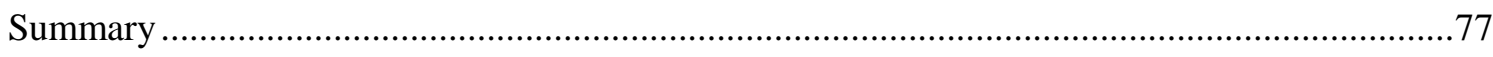

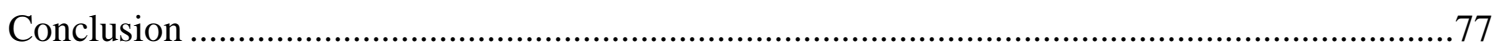

Chapter 5 Registered Nurses and Nurse Managers in Aged Care Perspectives on Postgraduate

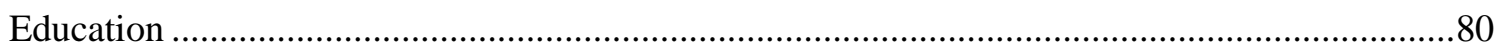

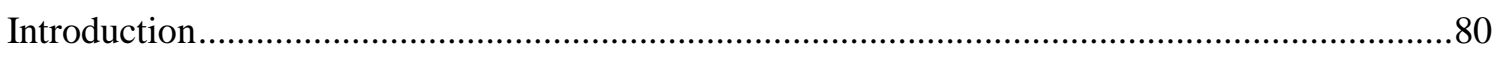

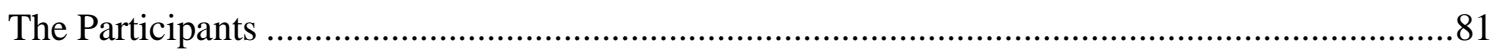

Overview of Postgraduate Education and the Aged Care Sector...............................................83

Nursing knowledge: Important for improving quality of older persons care.............................84

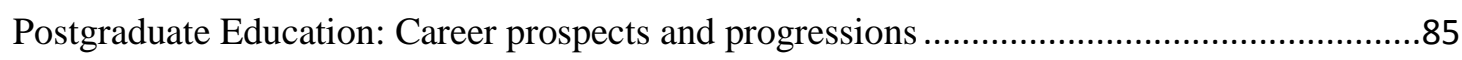

System Influences: The role of external agencies in providing postgraduate opportunities .....87

Workplace Factors: Influences on the uptake of postgraduate education ...............................87

Personal Factors: Choices and timing regarding up taking of postgraduate education..............89

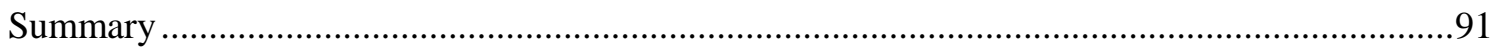

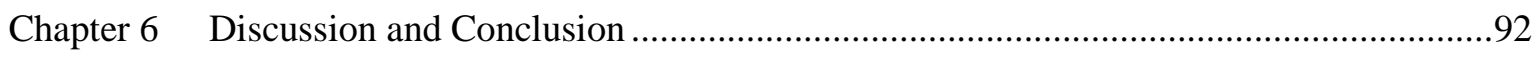

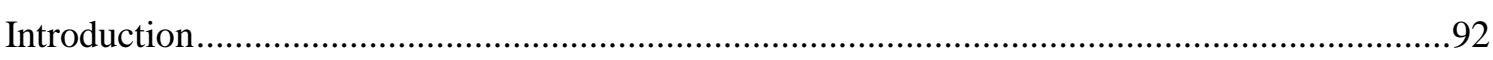

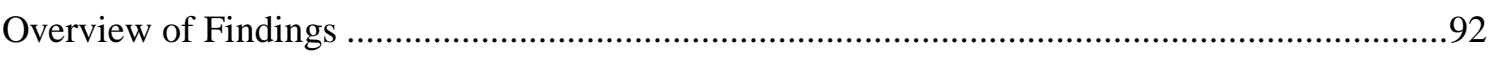

Significance of Postgraduate Education for Aged Care ...........................................................94

Enablers to Engaging in Postgraduate Education ....................................................................95 


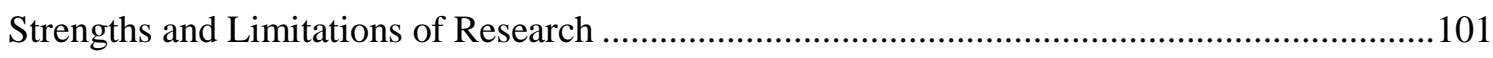

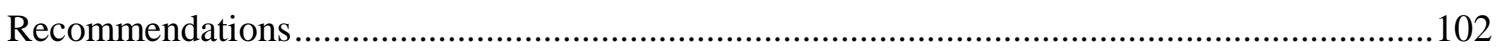

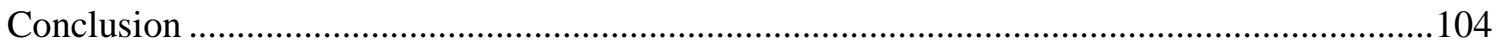

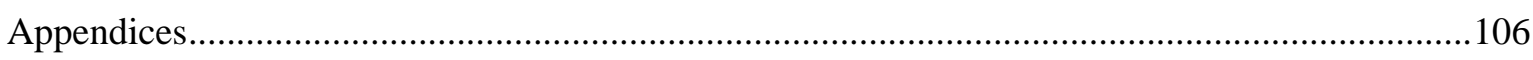

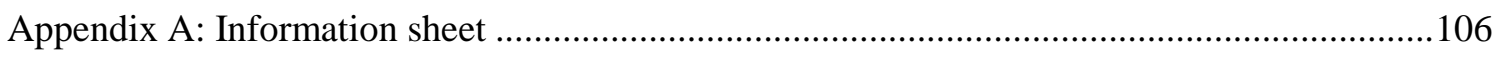

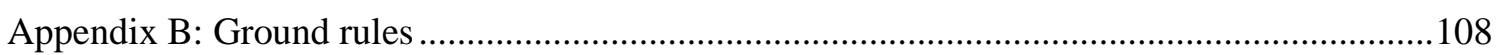

Appendix C: Interview questions for focus groups and interviews ..........................................109

Appendix D: Demographics and professional characteristics template ....................................110

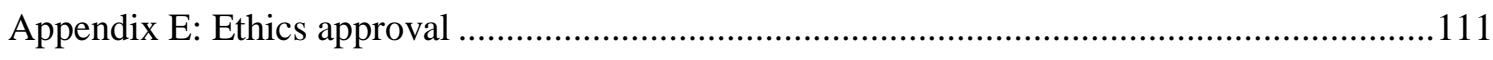

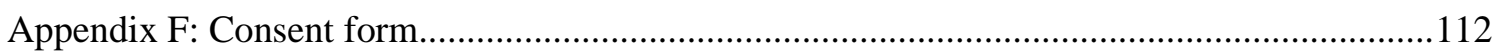

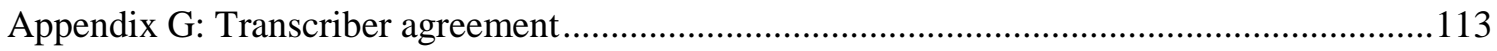

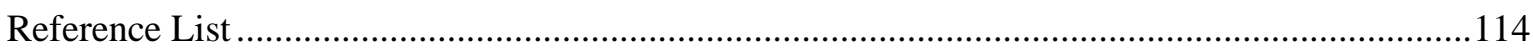




\section{List of Tables}

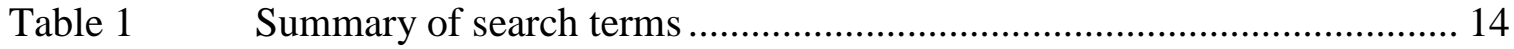

Table 2 Example of summary table used for critiquing literature .......................... 16

Table 3 Motivational factors related to RNs before engaging in

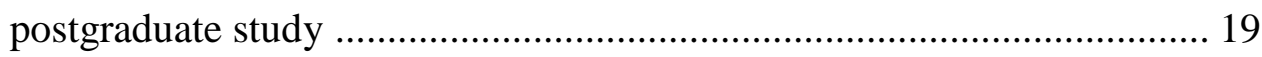

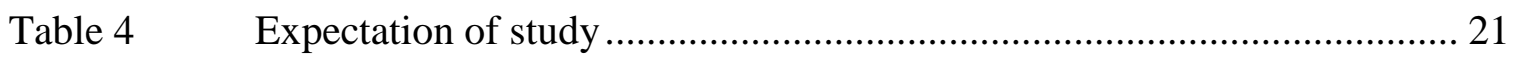

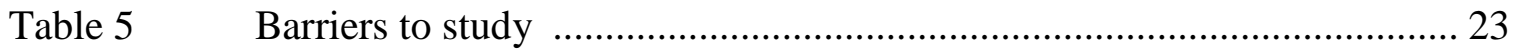

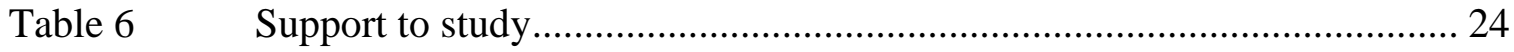

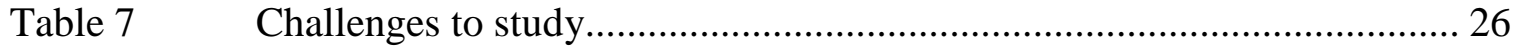

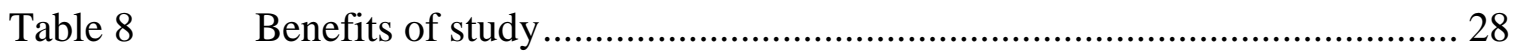

Table 9 Example of table used to categorise and interpret interview data ............ 40

Table $10 \quad$ Historical timeline of government policy documents from 2000 to 201344

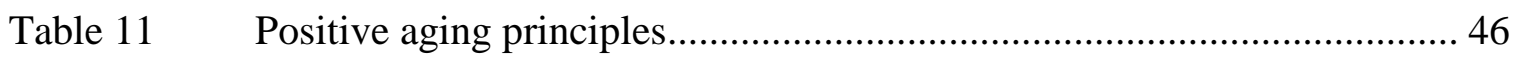

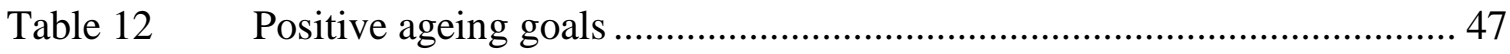

Table 13 Objectives of the Health of Older People Strategy .................................. 49

Table 14 Recommendations to meet priority on workforce development ............... 51

Table $15 \quad$ Action priorities identified by sector networks ....................................... 58

Table 16 Findings from evaluation of Nurse Practitioners role in workforce......... 60

Table 17 Historical timeline of professional body documents 2000-2015.............. 64

Table 18 Scenario results and possible effect on aged care RN workforce ............. 68

Table 19 NZNO recommendations for postgraduate education .............................. 70

Table 20 Summary of participants by facility, data collection format and engagement

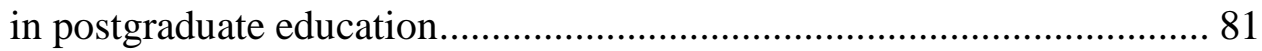

Table 21 Demographic and professional characteristics of participants .................. 82

Table 22 Level of postgraduate education and career plans of participants............. 83

Table 23 NCNZ percentage of RN's age and rest home/residential care setting compared to participants in this study................................................. 93 


\section{Chapter 1 Introduction}

New Zealand's older person's population is growing rapidly, as it is internationally. By 2061 it is predicted $26 \%$ of New Zealand's population will be aged 65 or older (Statistics New Zealand, 2012). This will have a significant impact on the health sector, in particular the nursing workforce. As people age their health needs become more complex, leading to the need for nurses to be trained in advanced practice such as Nurse Specialists and Nurse Practitioners (NPs) in care of the older person. Training in the area of advanced practice commonly comes from completing postgraduate qualifications at a university. The Ministry of Health $(\mathrm{MoH})$ have been addressing this need through policies, strategies and working groups since the release of the New Zealand Health Strategy in 2000. The purpose of this thesis is to investigate the role of postgraduate education in the aged care sector, through exploring the perceptions, views and experiences of registered nurse's (RN's) working in aged residential care.

This chapter presents the background to the study explaining the reason why this research took place. It is followed by the research aims and objectives culminating in the research question, the research design, and finally an overview of the thesis. This study is important for two reasons. First, there is limited New Zealand (NZ) literature about postgraduate education in the aged care sector, suggesting there is little known about the experiences of NZ RNs with postgraduate education in aged care. However, there is international literature that is drawn upon. Secondly, there has been little progress made in the number of NPs employed in the area of the older person. NPs need to complete a Master's degree, to gain an understanding of the role, so postgraduate education in this sector is important.

\section{Background}

The author of this research has been in the role of Nurse Coordinator for Health Workforce New Zealand (HWNZ) Postgraduate Nursing Funding at a local DHB for six years. HWNZ is responsible for leading and supporting training and development of the health and disability workforce and is a part of the National Health Board (MoH, 2015). The National Health Board works with the $\mathrm{MoH}$, to further improve the safety, quality and sustainability of health care for the NZ public. The following is the researcher's first person account of her role working in the health sector that culminated in producing this thesis: 
Part of my role involves marketing HWNZ funding to DHB employed RNs, as well as those in aged care and primary health care. I am also involved in the application and selection process for approving funding and provide support and guidance for those wanting to engage in postgraduate education and to those already studying. After three years in the role, I made the observation, very few RNs employed in the aged care sector take up the opportunity of postgraduate funding. Historically, there would only be one to two applications annually.

In 2012 I adopted a multipronged approach to increase the number of aged care nurse applications. I visited five rest homes in the area with the intention of actively promoting the funding programme. I also offered to assist those interested with completing the application form. Three information sessions were run at the local hospital, with Tertiary Education Providers present to provide information on courses to the $23 R N$ from aged care who attended. When funding applications closed the following month, there were only three applications. Of these three, two were approved as having met the criteria. It is unclear why others did not apply, as nurses in other sectors, such as primary health regularly apply for funding. This situation sparked my interest and I began to think about why nurses working in residential care were not taking up these funding opportunities. Were there barriers contributing to this, if so what were they, and how could these barriers be addressed to enable those RNs to apply for funding and become engaged in postgraduate education?

Internationally the population is aging. The World Health Organisation (2012) predicts the world's population of those 60 years and older $(60+)$ will grow to two billion by 2050 . The 65 years and older (65+) population in NZ, is also growing at a rate of just over 50\% over the last 20 years (Statistics NZ, 2012). Most people over the age of 60 keep well and live independently in their own home with various levels of family and social support (Statistics NZ, 1998). A small group develop health needs necessitating a move to live in an environment where there are various levels of health practitioner support. Residential 
care options for the older person in NZ consist of retirement villages and rest homes providing different levels of care such as: residential homes (lowest level of care), through to continuing care hospital (requiring 24 hour nursing supervised care). There are also some specialised facilities for people with psychiatric disorders or with dementia. For the older person living in their own home, home support services are available as their needs increase. Throughout the past decade, the number of home support services has grown to manage the increase in demand for aged care services (Aged Residential Care Service Review, 2010).

New Zealand government agencies predict that as the population ages, there will be insufficient community-based support services to meet the demand (Thornton, 2010). This will lead to more demand for residential care. The nursing sector needs to be prepared for the increased numbers of older persons in the community and in residential care settings. This will require a suitably qualified nursing workforce. Recent nursing workforce developments have involved the general nursing workforce upskilling into nurse specialists and NPs who are now being employed in the aged care sector. An example of this was in 2012 when there was a shortage of General Practitioners (GPs) in the Midcentral region. A model of care was implemented in which a NP was employed to work collaboratively with aged care staff, acute and specialist services and the primary healthcare team (HWNZ, 2012). The combination of the future aging population, the importance of education and the author's observation of the limited uptake of funded postgraduate education from nurses in the aged care sector, were the drivers for conducting this research.

\section{Research Question and Objectives}

The objectives of the research were:

1. Identify the place /role of postgraduate education for advancing nursing practice in residential care

2. Ascertain the place/role of postgraduate nursing education for aged care nurses' careers

3. Investigate and explore aged care nurses' experiences of postgraduate nursing education through the nurse observing his/her self-experiences and those of other nurses

4. Identify nurses' experiences of enablers and barriers to completing postgraduate study 
5. Find out ways of working with barriers and enablers to empower future nurses through their postgraduate education.

\section{Formulating the Research Question}

To formulate the research question a search of international literature was conducted using the Cumulative Index to Nursing and Allied Health Literature Plus (CINAHL Plus) and Public/Publisher/Medline (PubMed) from January 2000 to March 2013. Search term combinations consisted of; i) aged care, gerontologic, long term care, geriatric; ii) nurses, nursing, registered nurse; iii) postgraduate education, master's education, graduate education, continuing education, staff development; iv) attitudes and perceptions; and v) barriers and enablers were used. Literature from the United States of America (USA), Canada, England, Scotland, Spain, South Africa and Finland was located. No NZ research was found specifically in the area of RNs working in aged care undertaking postgraduate study. There was however one article which described concern about undergraduate nursing students having minimal interest in working in aged care. Clendon (2011) recommended Bachelor of Nursing programmes need to provide more appropriate aged care content.

Seven themes emerged from the literature search regarding nurses' experiences of postgraduate education in the aged care sector. These consisted of: i) the need for continuing education including postgraduate education in aged care; ii) the culture of learning in the aged care facility from managers; iii) self-belief of the $\mathrm{RN}$ in being able to manage academically; iv) the need for further collaboration between aged care facilities universities in setting up postgraduate programme content and support; v) the impact of the nurses working hours on managing postgraduate study requirements; vi) nurses with English as a second language and the extra supports required for them to complete; and vii) the financial situation of the aged care facility in being able to support nurses undertaking postgraduate study. The results of this literature search showed there was a gap in NZ literature around postgraduate education and RNs who work in residential aged care. The literature search as well as the themes led to the research question; what is the role of postgraduate education in the aged care sector?

\section{Research Design}

A qualitative descriptive approach was used for the study. Data were collected from a document review, focus groups and interviews using semi structured questions. A document review from 2000 to 2015 was carried out to obtain a baseline/foundation about 
historical and current regulation around postgraduate education for RNs working in aged care. This was done to inform questions for the focus groups and interviews and to contribute to the research as a whole. The documents reviewed were from NZ government policy relating to the health sector and from professional bodies such as the Nursing Council of New Zealand (NCNZ) and the New Zealand Nurses Organisation (NZNO). The documents concerned health workforce development and consisted of policy and strategies for health of the older persons, nursing workforce development, education for the health sector and annual reports.

The setting for this study was four aged residential care facilities in an urban area in the North Island of New Zealand. Three of the facilities provided rest home care, all four facilities provided hospital care, and two facilities specifically catered for people with dementia. All the participants were RNs.

\section{Overview of the Thesis}

This chapter has introduced the background to the research, the research question and objectives of the study. It has provided information on the relevance of the study, how the research question was formulated, and then presented a brief overview of the research design and an overview of the thesis. This thesis is comprised of six chapters. Chapter Two contains a review of NZ literature on postgraduate education and nursing, from this, gaps in the literature were identified. The methodology for this research is explained in Chapter Three along with the methods and design considerations. Chapter Four comprises the findings from the document review. Documents reviewed were about changes in the health sector, health workforce development and aged care. Findings from the interviews and focus groups are described and reported in Chapter Five through providing demographics and professional characteristics and the five themes which emerged through analysing the data. Chapter Six presents a discussion of the findings, along with implications from the research. 


\section{Chapter 2 Literature Review}

\section{Introduction}

This chapter presents the findings of a literature review on postgraduate education for RNs. The initial search was undertaken in 2013 and updated in 2016. The review involved the exploration of international and national research on nursing in general. This chapter begins with the search strategy and an overview of the findings of the literature. Following this the six themes identified in the review are introduced. The chapter concludes with an outline of knowledge gaps or areas of inquiry concerning postgraduate education and nursing in the aged care sector.

\section{Search Strategy}

The literature search was carried out using Cumulative Index to Nursing and Allied Health Literature (CINAHL) Plus, Proquest and Scopus to identify international and national research on postgraduate education and nursing. Searches were limited to: research articles, peer reviewed articles, abstracts and the English language. Search terms such as nursing, motivation, expectation, enablers, influence and barriers were used. There was no set date restriction on the literature as the aim was to explore what and how much research had been carried out overall. The search terms and the number of articles found are summarised in Table 1.

\section{Table 1: Summary of search terms}

\begin{tabular}{|l|l|r|}
\hline & Search Terms & No. Articles \\
\hline & $\begin{array}{l}\text { Postgraduate or Post Graduate or Post- } \\
\text { Graduate or Post Basic }\end{array}$ & 570 \\
\hline And & Nursing & 420 \\
\hline And & Motivation & 24 \\
\hline Or & Expectation & 3 \\
\hline Or & Enablers & 0 \\
\hline Or & Influence & 36 \\
\hline Or & Barriers & 32 \\
\hline Or & Aged Care & 0 \\
\hline Or & Gerontologic & 20 \\
\hline Or & Aged residential care & 1 \\
\hline
\end{tabular}

Of the 535 articles initially located, titles and abstracts were briefly read through to establish that the article focus linked to the research topic. From this, the abstracts of 79 articles were read in detail to ascertain suitability, of which 18 were finally selected for in- 
depth review. Reference lists from articles were reviewed and a further three articles added. Articles were excluded at the abstract stage because they did not have the primary focus about nurses and postgraduate education.

Each of the 18 articles were summarised in a table that contained information concerning; the author, country the research was undertaken, year article was published; journal name; article title; aims of the research; methodology; and findings and themes as identified by the author of the article. As most of the literature was qualitative, each article was critiqued using a critical appraisal tool for qualitative research (CASP). The implications were then summarised into a table (Table 2).

\section{Overview of the Literature}

The 18 reviewed studies reported on research from 11 countries including: Australia; England; Hong Kong; Ireland; Jordan; Malaysia; New Zealand; Norway; South Africa; Sweden and United States of America (USA). The highest numbers of studies were from Australia with four, followed by the USA, Ireland, England and New Zealand with two each. The remaining countries had one study each. All studies involved nurses studying in their own country apart from one study which consisted of nurses from Hong Kong, studying at a university in Australia (Simsen, Holroyd \& Sellick, 1996). Settings of the studies varied including: general hospital inpatient areas such as paediatrics, surgical, emergency department, theatre, outpatient clinics, nursing home, and the community. Two studies had very specific settings which consisted of specialty nurses working in intellectual disability (Sweeney \& Dalton, 2007), and in clinical trials in haematology and oncology (Scott, White \& Roydhouse, 2013). The first NZ based study (McDonald, Willis, Fourie \& Hedgecock, 2009) involved graduate nurses who had completed a Nursing Entry to Practice Programme (NETP), with a postgraduate paper integrated into the programme. The second NZ based study (Barnhill, MKillop \& Aspinall, 2012) concerned the impact of postgraduate education on RNs working in an acute area.

Dates spanned from 1987 to 2013, with 12 of the 18 studies published between 2009 and 2013. Generally all studies focused on RNs and their experience of postgraduate education through exploring participant motivation, attitudes, support, expectations, benefits, barriers and challenges to undertaking education. 
Table 2: Example of summary table used to critique literature

\begin{tabular}{|c|c|c|c|c|c|}
\hline $\begin{array}{l}\text { Author \& } \\
\text { Journal }\end{array}$ & $\begin{array}{l}\text { Research } \\
\text { Aim }\end{array}$ & Methodology & $\begin{array}{l}\text { Findings \& } \\
\text { Themes }\end{array}$ & Critique & Implication \\
\hline $\begin{array}{l}\text { Black, } \\
\text { K.E., \& } \\
\text { Bonner,A. } \\
\text { (2011) } \\
\text { Employer } \\
\text { based } \\
\text { support for } \\
\text { registered } \\
\text { nurses } \\
\text { undertaking } \\
\text { postgraduat } \\
\text { e study via } \\
\text { distance } \\
\text { education } \\
\text { Nurse } \\
\text { Education } \\
\text { Today, } \\
31(2), 163- \\
167 \\
\text { Australian } \\
\text { research }\end{array}$ & $\begin{array}{l}\text { To } \\
\text { establish } \\
\text { different } \\
\text { methods of } \\
\text { employer } \\
\text { based } \\
\text { support for } \\
\text { RNs } \\
\text { undertaking } \\
\text { postgraduat } \\
\text { e distance } \\
\text { education } \\
\text { To } \\
\text { investigate } \\
\text { participant' } \\
\text { s } \\
\text { perceptions } \\
\text { of whether } \\
\text { or not the } \\
\text { existence or } \\
\text { absence of } \\
\text { this support } \\
\text { has any } \\
\text { influence } \\
\text { on the } \\
\text { uptake, } \\
\text { ease or } \\
\text { difficulty of } \\
\text { undertaking } \\
\text { and } \\
\text { completing } \\
\text { the } \\
\text { programme }\end{array}$ & $\begin{array}{l}\text { Design } \\
\text { Qualitative } \\
\text { exploratory } \\
\text { descriptive } \\
\text { design } \\
\text { Sample: } \\
\text { Convenience } \\
\text { sample of } 270 \\
\text { Registered } \\
\text { Nurses drawn } \\
\text { from medical, } \\
\text { surgical, } \\
\text { emergency } \\
\text { department } \\
\text { (selected to } \\
\text { provide a range } \\
\text { of nursing } \\
\text { contexts) and } \\
\text { theatre in a } \\
\text { major hospital } \\
\text { in Tasmania } \\
\text { Response Rate } \\
\text { Response rate } \\
\text { was } 34 \% \text { with } \\
28 \% \text { currently } \\
\text { enrolled in } \\
\text { distance } \\
\text { education and } \\
54 \% \text { planning } \\
\text { further study. } \\
\text { Data Collection } \\
\text { Self-reported } \\
\text { questionnaire, } \\
\text { piloted previous } \\
\text { to use. } \\
28 \% \text { who had } \\
\text { done or where } \\
\text { currently } \\
\text { undertaking } \\
\text { distance } \\
\text { education had } \\
\text { received no } \\
\text { support to do } \\
\text { this. Of those, } \\
59 \% \text { had sought } \\
\text { support and for } \\
71.4 \% \text { no } \\
\text { support was } \\
\text { offered. }\end{array}$ & $\begin{array}{l}\text { Strong } \\
\text { differences } \\
\text { between } \\
\text { support } \\
\text { wanted by } \\
\text { nurses and } \\
\text { support } \\
\text { offered by } \\
\text { employers. } \\
\text { Supports most } \\
\text { frequently } \\
\text { received: } \\
\text {-Course fees } \\
\text {-Roster } \\
\text { requests } \\
\text {-Study leave } \\
\text { Supports } \\
\text { sought most } \\
\text { frequently: } \\
\text {-study buddy } \\
\text {-Mentorship } \\
\text { Supports most } \\
\text { frequently } \\
\text { offered were: } \\
\text {-Study leave } \\
\text {-Study groups } \\
\text {-Emotional } \\
\text { Supports most } \\
\text { liked by RNs: } \\
\text {-Course fees } \\
\text {-Study leave } \\
\text {-Roster } \\
\text { requests } \\
\text { Supports RNs } \\
\text { thought should } \\
\text { be mandatory } \\
\text { were: } \\
\text {-Study leave } \\
\text {-Roster } \\
\text { requests \& } \\
\text {-Clinical } \\
\text { placement } \\
\text { - 64\% initially } \\
\text { tertiary } \\
\text { educated } \\
\text {-83\%held a } \\
\text { minimum } \\
\text { bachelor } \\
\text { degree. }\end{array}$ & $\begin{array}{l}\text { - Low } \\
\text { response rate } \\
\text { of } 34 \% \\
\text { - Med, Surg, } \\
\text { Ed and theatre } \\
\text { selected to } \\
\text { participate but } \\
\text { not any } \\
\text { geriatrics/aged } \\
\text { care. } \\
\text {-Interesting } \\
\text { that study } \\
\text { leave, (65\%), } \\
\text { roster requests } \\
\text { (52\%) and } \\
\text { clinical } \\
\text { placements(54 } \\
\%) \text { were } \\
\text { identified by } \\
\text { nurses that } \\
\text { they should be } \\
\text { mandatory } \\
\text { rather than } \\
\text { Course } \\
\text { fees(27\%) yet } \\
64 \% \text { identified } \\
\text { course fees as } \\
\text { being what } \\
\text { they would } \\
\text { like as support. } \\
\text {-the study was } \\
\text { undertaken at } \\
\text { one hospital in } \\
\text { Tasmania, it } \\
\text { may have been } \\
\text { beneficial to } \\
\text { undertake the } \\
\text { study at more } \\
\text { than one } \\
\text { hospital to } \\
\text { compare the } \\
\text { culture of the } \\
\text { hospital/emplo } \\
\text { yers around } \\
\text { postgraduate } \\
\text { education. }\end{array}$ & $\begin{array}{l}\text { _Geriatrics/a } \\
\text { ged care not } \\
\text { selected for } \\
\text { study } \\
\text {-In NZ what } \\
\text { would be } \\
\text { considered as } \\
\text { support for } \\
\text { studying? } \\
\text { What would } \\
\text { be the most } \\
\text { liked method } \\
\text { of support? } \\
\text {-What do } \\
\text { employers/m } \\
\text { anagers } \\
\text { consider to } \\
\text { be supportive } \\
\text { for nurses } \\
\text { undertaking } \\
\text { postgraduate } \\
\text { education? } \\
\text { - Would } \\
\text { distance } \\
\text { education be } \\
\text { preferable? } \\
\text {-Are there } \\
\text { many } \\
\text { postgraduate } \\
\text { distance } \\
\text { education } \\
\text { courses in } \\
\text { NZ. }\end{array}$ \\
\hline
\end{tabular}


The experiences were categorised into: before, during and post education. Seven studies consisted of RNs either in the process of, or having completed postgraduate study at universities and institutes. Two of these (Hoffman \& Hester, 2012; Olsson, Persson, Kaila, Nilsson \& Boström, 2012), recruited from inter professional qualifications of which there was a significant representation of RNs.

A mixture of quantitative and qualitative methodologies and designs were used to conduct the 18 studies which included: descriptive cross sectional, case study, ethnographic, interpretive, and exploratory descriptive. In four studies (Johnson \& Copnell, 2002; Simsen et al.,1996; Sweeney \& Dalton, 2007; Watson \& Wells, 1987) the design of the research was not specifically named. Some studies did not provide a lot of detail about how the research was conducted; they concentrated on other aspects such as a specific postgraduate programmes the participants were involved in. All studies had gained ethics approval. Sample sizes varied depending on the methodology ranging from 10 (Clerehan, McCall, McKenna \& Alsharami, 2011) that involved a qualitative descriptive design and purposeful sampling technique, to 686 (Simsen et al., 1996) that did not state the research design or sampling technique. Hoffman and Hester (2012) undertook a cross sectional, descriptive design, using a convenience sampling technique of 372 students resulting in a $15.2 \%$ response rate. Of the 18 studies, 12 did not specify what type of sampling technique was used. Two quantitative studies used random sampling and three qualitative studies used convenience, snowballing and purposeful sampling.

Questionnaires were used to gather data in the majority of the studies. There was variation in how the questionnaires were disseminated including postal, email or on-line. Almost half the questionnaires were piloted using smaller groups not participating in the main study. This resulted in minor changes to some questions. In four studies (Chiu, 2005; Clerehan et al., 2011; Watkins, 2011; Zahran, 2012) semi-structured interviews were used, generally taking between 30 and 60 minutes. Interviews were mostly one-on-one, however, in two studies (Chiu, 2005; Johnson \& Copnell, 2002) focus group interviews were also conducted. In all studies demographic descriptions were provided of the sample. Demographic information varied and in most instances included; age distribution; ethnicity; gender; marital status; employment setting; previous postgraduate education; nursing speciality and years registered. Depending on the study other demographic characteristics such as language, location of undergraduate experience, years in a specific country, primary wage earner, time allowed off work, work hours and number of dependents were reported. Data were mostly analysed according to the methods and methodology used, such as inductive qualitative content analysis, the use of statistical 
software packages, transcribing, coding, theming and categorising. In one study (Zahran, 2012) interviews were transcribed from Arabic to English.

It was found in most of the studies, participants identified financial support, to some degree, as a motivator for undertaking postgraduate study. It was also commonly identified that although participants had completed or were about to complete a postgraduate qualification, this was not recognised by employers for remuneration or career advancement. Enablers and barriers to study were identified in all the studies, however they were not always overtly described, and some studies contained both enablers and barriers while others contained one or the other.

\section{Themes in the Literature}

Six key themes emerged from the literature and were categorised as occurring before commencing postgraduate study, during study, and following completion of postgraduate study. Within the themes there were different points of foci, these included personal, progress, practice, postgraduate programme and financial. The themes which emerged from the literature were: i) motivation to study; ii) expectation of study; iii) barriers to study; iv) support to study; v) challenges to study; and vi) benefits of study. These themes were then categorised and subthemes were developed. Summaries of the themes, categories and subthemes are presented in table format at the beginning of each of theme.

\section{Registered Nurse's Motivation Before Commencing Study}

The review identified the two most common motivators for RNs before commencing postgraduate study were 'personal and professional development' (Table 3) (Chiu, 2005; Hoffman \& Hester, 2012; Olsson, Persson, Kaila, Wikmar \& Bostrom, 2013; Simsen et al., 1996; Sweeney \& Dalton, 2007; Watkins, 2011; Watson \& Wells, 1987; Zahran, 2013).

In reporting the research on motivation, some researchers highlighted quotations from the nurses' responses. The 'need for a challenge' was identified as the key motivating factor in personal development for research conducted in England, Malaysia and Sweden (Chiu, 2005; Olsson et al., 2013; Watkins, 2011). The challenge was described by one nurse as being due to "not previously achieving at school" (Watkins, 2011, p. 33). Another nurse who had previously completed some postgraduate education found it to be a personal challenge to complete the rest of the qualification (Olsson et al., 2013). 
Table 3: Motivational factors related to RNs before engaging in postgraduate study

\begin{tabular}{|c|c|c|}
\hline Theme & Category & Sub Theme \\
\hline $\begin{array}{l}\text { Motivation } \\
\text { to Study }\end{array}$ & $\begin{array}{l}\text { Before } \\
\text { commencing } \\
\text { postgraduate } \\
\text { study }\end{array}$ & $\begin{array}{l}\text { Personal } \\
\text { - Personal development } \\
\text { - Ambition } \\
\text { - } \text { Reaching self-actualisation } \\
\text { - Needed a challenge (stimulation, self-growth) } \\
\text { - Influence of family or friends postgraduate } \\
\text { Professional } \\
\text { - Professional development (includes career } \\
\text { - } \text { puthway) } \\
\text { - Increased credibility } \\
\text { - Compliance with management requirements } \\
\text { Practice } \\
\text { - Skill development } \\
\text { - Specialty training } \\
\text { - Better patient care } \\
\text { - Impact on practice } \\
\text { Postgraduate Programme } \\
\text { - Content of course } \\
\text { - Structure of course } \\
\text { - Relates to practice } \\
\text { Financial } \\
\text { - Course funded/reimbursement } \\
\text { - Attend study days }\end{array}$ \\
\hline
\end{tabular}

In a Jordanian-based study, described ambition as being a driving factor in undertaking postgraduate study, "my ambition is more than a bachelor degree" (Zahran, 2013, p. 1053). The 2012 South African based study, using a cross sectional research design to explore and describe academic transitional experiences of Master's degree students, found one nurse's personal motivation was that she would be able to meet influential people through completing postgraduate study (Hoffman \& Hester 2012). Similarly a study conducted in the USA in 1987 using an Educational Attitude Questionnaire, explored nurse's attitudes to postgraduate education and found of the 524 who participated, $86 \%(n=450)$ considered postgraduate study was a way of meeting new and interesting people (Watson \& Wells, 1987).

A case study conducted in Ireland in 1996 explored motivation and expectations of RNs in a postgraduate programme using open-ended questions and a seven point ordinal scale. The study found the reasons 25 of the 30 participants engaged in the advanced programme 
was due to the structure and content of the course, individual and professional development and that the course related to practice (Boore, 1996). The participants were all students in the first two cohorts of the programme.

Employers also have an influence on nurse's motivation to study according to findings in a case study conducted in Malaysia in 2005 looking at 12 nurse's reasons for undertaking postgraduate study. It was found that where there was an expectation from the nurse managers to complete a postgraduate qualification, the nurse was more motivated, enrolled in and completed a qualification (Chiu, 2005). Similarly, research undertaken in the USA in 2009 found organisational incentives motivated nurses, who already had degrees or diplomas, to return to postgraduate education (Warren \& Mills, 2009). It was also identified that being paid to attend study days, and reimbursement for tuition, were among the top three ranked incentives by participants in the study. In contrast, Watson and Wells (1987) found nurses received no encouragement or incentive from their employers to complete a postgraduate qualification. Similarly Zahran (2013) noted nurses reported there was no recognition from hospital management or nursings professional bodies for nurses undertaking or having completed a postgraduate qualification. Although career advancement has been highlighted as a motivating factor (Sweeney \& Dalton, 2007; Watkins, 2011; Zarahn, 2013), it has also been considered as a barrier due to unclear career pathway structures (Scott, White \& Roydhouse, 2013) and the trusted availability of jobs for nurses with a Master's degree (Watson \& Wells, 1987).

Motivation to undertake postgraduate education, because other family members had, was identified in a qualitative descriptive study conducted in Ireland in 2009 (Tame, 2009). Percentages of those participants' motivation was not provided. The study explored perceptions and experiences of 23 perioperative nurses from one NHS Trust. The participants were all currently engaged in or had competed postgraduate study. Similarly, Watson and Wells (1987) found 41\% ( $\mathrm{n}=215)$ of the 524 respondents believed completing a Masters degree was something their families would like them to do. Providing better patient care was identified as a motivation to engage in study by participants in a qualitative study conducted in Sweden in 2011 (Olsson et al., 2013). The study explored the expectations of 42 participants from six different health professions. Twelve of the participants were nurses. All participants were enrolled in an inter-professional Master's degree at one institute. A wish to improve direct patient care rather than improving selfdevelopment was a motivation for some participants in Jordan (Zahran, 2013). Also a 2007 qualitative study conducted in Ireland, exploring the educational requirements of RNs in the specialty of intellectual disability, found the primary motivation of $17 \%(n=36)$ of the 
210 participants was to provide better services for those with an intellectual disability (Sweeney \& Dalton, 2007). Five hundred questionnaires were distributed to organisations that provided services to people with an intellectual disability, with a $42 \%(n=210)$ return rate. Of note the other primary motivator for engaging in postgraduate education from this study was skill development $40 \%(\mathrm{n}=84)$.

\section{Expectations of Registered Nurses Before Commencing Study}

Expectations before commencing postgraduate study (Table 4) came not only from nurses but also from employers (Chiu, 2005; Tame, 2009). The expectations from nurses varied, commonly including an increase of knowledge, skills, professional development and personal development (McDonald et al., 2009; Olsson, et al., 2013; Simsen, et al., 1996; Watkins 2011).

While research has not identified explicitly employer expectation, research does indicate expectation from nurses engaging in postgraduate study (McDonald et al., 2009; Zahran, 2012). For example employers expect RNs at the end of the NETP programme to be confident and competent practitioners. Other expectations were found in nurse specialists with masters degrees with the expectation that these nurses will be capable of providing high quality health care and be role models for others (Zahran, 2012).

Table 4: Expectation of study

\begin{tabular}{|c|c|c|}
\hline Theme & Category & Sub Theme \\
\hline $\begin{array}{l}\text { Expectation of } \\
\text { Study }\end{array}$ & $\begin{array}{l}\text { Before } \\
\text { commencing } \\
\text { postgraduate } \\
\text { study }\end{array}$ & $\begin{array}{l}\text { Personal } \\
\text { - Personal development } \\
\text { Professional } \\
\text { - Enhance inter professional collaboration } \\
\text { - Role model } \\
\text { Practice } \\
\text { - Increase professional competence for clinical } \\
\text { - } \text { practice \& research } \\
\text { - Enprove quality of care } \\
\text { Postgraduate knowledge \& understanding of } \\
\text { - Flexibility around assignments \& extensions } \\
\text { - due to work and study (NETP graduates only) } \\
\text { - More communication about course } \\
\text { - Clarity around how to access support } \\
\text { Financial } \\
\text { - Expenses i.e. expecting to be paid for } \\
\text { - Time off to attend course }\end{array}$ \\
\hline
\end{tabular}


Research looking at the expectations and motivations of British and German nurses undertaking postgraduate education found that reasons for nurses applying to study was linked to their academic expectations (Watkins, 2011). The nurses expected to gain some understanding as to how to improve their practice using evidence based practice. In a NZ qualitative study, McDonald et al. (2009) investigated 40 NETP nurses using open and closed questions found flexibility and an extension around assignments was an expectation of $18 \%(n=7)$ of the participants due to working and studying simultaneously. However, $31 \%(n=12)$ of the participants commented there should be better communication around the course requirements at the start of the course as well as making it clearer how to access support. It is not clear however, what type of support the participants were referring to.

Nurses expressed two other types of expectations. Sweeney and Dalton (2007) found 61\% ( $n=124)$ of the 203 study participants, had an expectation they would be given study leave to attend classes; however they had to use annual leave instead. For others, expectations concerned nursing colleagues, as Zahran (2013) identified, some nurses' colleagues had an expectation, nurses engaged in postgraduate study would be better role models and share their new knowledge to improve practice.

\section{Barriers to Registered Nurses Commencing study}

The identification of financial aid was a common barrier within the literature (Table 5) as to why nurses did and did not undertake postgraduate study (Black \& Bonner, 2011; Boore, 1996; Johnson \& Copnell, 2002; Scott et al., 2013; Tame, 2009; Warren \& Mills, 2009; Watson \& Wells, 1987).

A qualitative study using a self-administered questionnaire to explore the benefits and barriers of undertaking postgraduate education by Paediatric nurses, found 90\% ( $\mathrm{n}=352)$ of the 391 respondents identified reduced hours and loss of salary as a barrier, $89 \%(\mathrm{n}=$ $348)$ identified course costs as a barrier, and 70\% $(n=274)$ chose no direct remuneration for qualifications as a barrier (Johnson \& Copnell, 2002). Research undertaken in Maryland USA, exploring the motivation of RNs to return to postgraduate study, reported older age, family and money were key barriers to nurses in completing education. Demographics from the study were compared to national demographics of RNs from a 2004 national survey of RNs. The comparison showed 54.4\% $(\mathrm{n}=161)$ of the 297 nurses were in the 45 to 50 year age group, compared to $17.5 \%$ of nurses in the same age group in the 2004 national survey (demographic data numbers not provided for 2004 national survey); revealing a significant difference (Warren \& Mills, 2009). These results are not 
accurate however, as the data from the 2004 national survey is completed annually by nurses renewing their licensure and is optional. Meaning, as not all nurses are required to complete demographics to renew their licensure, the 2004 national survey demographic data are not representative or accurate of all nurses.

\section{Table 5: Barriers to study}

\begin{tabular}{|c|c|c|}
\hline Theme & Category & Sub Theme \\
\hline $\begin{array}{l}\text { Barriers to } \\
\text { Study }\end{array}$ & $\begin{array}{l}\text { Before } \\
\text { commencing } \\
\text { postgraduate } \\
\text { study }\end{array}$ & $\begin{array}{l}\text { Personal } \\
\text { - Separation from family \& friends } \\
\text { Professional } \\
\text { - Unclear or no career pathway } \\
\text { Practice } \\
\text { - Other nurses attitudes } \\
\text { - Work environment, lack of support } \\
\text { Postgraduate Programme } \\
\text { - Perceived academic ability } \\
\text { Financial } \\
\text { - No funding; expense if living away; fees } \\
\text { - Reduced working hours therefore loss of } \\
\text { - salary } \\
\text { - } \text { No direct remuneration for postgraduate } \\
\text { High cost of study }\end{array}$ \\
\hline
\end{tabular}

Watson and Wells (1987) reported family financial commitments were an issue to preventing $50 \%(\mathrm{n}=262)$ of 524 respondents returning to further postgraduate study with high tuition costs also being a key concern. Similarly a 2013 study conducted in Australia exploring the advancing clinical pathway of clinical trial nurses, highlighted the significant cost of postgraduate study, lack of time to study and an unclear career pathway as barriers needing to be addressed by employers, nursing organisations, educators and funding organisations (Scott et al., 2013). However, Tame (2009) identified that although funding was an issue, some nurses felt that it would not be a barrier for them personally if their motivation was strong enough. In the same study, the physical environment of the university was described as a barrier; this was not the case in any of the other studies. Tame (2009) also identified three participants who had engaged in postgraduate study secretly for two reasons. First, due to managers and colleagues negative attitudes toward postgraduate education, resulting in participants feeling they were unable to discuss study progress in the workplace. Second, because of the participants' perceptions of their ability to complete a postgraduate qualification, and if they failed, they did not want anyone to know. Participants' perceptions of their academic ability were considered to be a barrier, 
especially from those who had not studied at a university before. Comments from some of those nurses were that they "would rather not study than be unsuccessful" (p. 259).

There are also barriers to nurses engaging in postgraduate study in a country other than their own. Chiu (2005) found participants from Malaysia undertaking education in Australia considered the high cost and separation from their families could stop them from studying overseas. However, with little opportunity for quality postgraduate education in Malaysia, a high value was placed on postgraduate education overseas.

\section{Support to Registered Nurses Before Commencing Study}

With regard to support to RNs before commencing postgraduate study (Table 6), two common types of support were evident in the literature. These were, employer support, which was mostly financial and covered the period before commencing education and academic support (Black \& Bonner, 2011; Clerehan et al., 2011; Hoffman \& Hester, 2012; Sweeney \& Dalton, 2007; Tame, 2009). Academic support covers the period of time from commencing through to completion of postgraduate study.

\section{Table 6: Support to study}

\begin{tabular}{|c|c|c|}
\hline Theme & Category & Sub theme \\
\hline $\begin{array}{l}\text { Support to } \\
\text { Study }\end{array}$ & $\begin{array}{l}\text { Before, during } \\
\text { and to } \\
\text { completion of } \\
\text { postgraduate } \\
\text { study }\end{array}$ & $\begin{array}{l}\text { Personal } \\
\text { - Emotional } \\
\text { - Time management i.e. study/work/life } \\
\text { - Family } \\
\text { Professional } \\
\text { - Work colleagues } \\
\text { Practice } \\
\text { - More supportive environment (graduates) } \\
\text { Postgraduate Programme } \\
\text { - Mentorship } \\
\text { - Orientation programme (not as many } \\
\text { - } \text { attending as thought would) } \\
\text { Financial } \\
\text { - Courientation } \\
\text { - Roster requests } \\
\text { - Study leave }\end{array}$ \\
\hline
\end{tabular}


Black and Bonner's (2011) study investigating Australasian employer based support for RNs completing or who had completed postgraduate education through distance education, found there were differences between employers and the RNs in what support was wanted and what was offered. The study sample was recruited using convenience sampling. A questionnaire was sent to $270 \mathrm{RNs}$ from a large hospital in Tasmania resulting in a $34 \%$ (n $=92$ ) response rate. Using an exploratory descriptive design then identified, $94 \%(n=86)$ of the RNs thought there should be some support, $84 \%(n=77)$ felt some support should be mandatory, and 34\% $(\mathrm{n}=31)$ had received no support. Support the RNs would have liked were: course fees, study leave, availability of resources and roster requests, mentorship, preceptorship and emotional support. The top three forms of support RNs identified that should be mandatory were: study leave at $65 \%(\mathrm{n}=60)$, roster requests at $52 \%(\mathrm{n}=48)$ and clinical placements at 54\% $(\mathrm{n}=50)$. Having course fees paid for was also identified as supportive to the RNs in undertaking further postgraduate education. Black and Bonner (2011) recommended that if employers are advocating postgraduate study for RNs, then support systems need to be in place. Similarly, Sweeney and Dalton (2007) found funding from the employer, and time off work, were highlighted as a support; however the study did not describe what type of funding employers would provide.

\section{Support to Registered Nurses During and to Completion of Postgraduate Study}

A South African study conducted in 2012 looked at academic transitional experiences of Masters' students, which included nurses, at the faculty of Community Health Sciences. An exploratory, descriptive research design was utilised. Convenience sampling was used and a questionnaire was emailed to 374 students, the response rate was low at $15.2 \%(\mathrm{n}=$ 57). Results of the study found there were several support systems in place to assist the students with their transition into postgraduate education (Hoffman \& Hester, 2012). The support systems included: an orientation programme, library services, an academic writing centre and individual academic support, writing coaches and mentors. Through conducting the study it was established, the least used academic support system was the academic writing centre. This had not been utilised as expected. It was suggested the limited use of the writing centre was due to "English being the home language of only a third of the respondents" (p. 6). In contrast, other supports such as individual academic support with a supervisor had been made use of by $91.2 \%(n=52)$ of students.

The Australian study by Clerehan et al. (2011), exploring 10 Saudi Arabian nurses and their experiences of undertaking postgraduate study in Australia identified on-going support was vital in helping nurses transition through a different social and learning 
environment. The research also identified that support around balancing study time and time with family was required. Tame (2009) found support from many sources such as family, work colleagues and the university, during postgraduate study was considered vital by nurses participating in the study; however, some of those nurses would not approach their work colleagues for support due to the culture of the work place toward postgraduate study.

\section{Challenges for Registered Nurses Undertaking Postgraduate Study}

Challenges to study experienced while undertaking postgraduate education (Table 7) included, academic, studying overseas, time management and balancing work, study and life (Clerehan et al., 2011; Johansen \& Harding, 2013; McDonald et al., 2009).

\section{Table 7: Challenges to study}

\begin{tabular}{|c|c|c|}
\hline Theme & Category & Sub Theme \\
\hline $\begin{array}{l}\text { Challenges to } \\
\text { study }\end{array}$ & $\begin{array}{l}\text { During } \\
\text { postgraduate } \\
\text { study }\end{array}$ & $\begin{array}{l}\text { Personal } \\
\text { - In a good way } \\
\text { - Personal - lack of self-belief } \\
\text { - Personal development } \\
\text { - Previous under achieving } \\
\text { - } \quad \text { Baltural } \\
\text { Professional } \\
\text { - Improve knowledge \& skills } \\
\text { - Credibility } \\
\text { - Profession/career enhancement } \\
\text { Practice } \\
\text { - Unrelated to work place } \\
\text { Postgraduate Programme } \\
\text { - Academic writing } \\
\text { - Transition to study } \\
\text { - Relationships with lecturers } \\
\text { - Academic - focus on style not content } \\
\text { - Approaches to study } \\
\text { Finances } \\
\text { - Expensive if living away from home }\end{array}$ \\
\hline
\end{tabular}

Clerehan et al. (2011) found the main challenges to studying in another country were differences between the two countries education systems, relationships with lecturers and family/study balance. In their study, challenges with family and study balance were related to cultural expectations of participants, many of whom were married and had children. Those participants had a cultural belief that they ought to spend time with their family 
before study. This was challenging and had an impact on their study. One participant described the impact as being with the family, but thinking and planning study at the same time, "I am with my body with them, but my soul and mind absent really" (p. 218). McDonald et al. (2009) identified 41\% $(\mathrm{n}=16)$ of the 40 participants described time management as a challenge, with one participant expressing "time constraints and the workload was difficult, found it tough fitting it all in as well as doing shift work" (p. 22), while Olson et al. (2012) found respondents described taking on postgraduate education generally as a personal challenge, (no numbers or percentages were provided). Similarly, Watkins (2011) found participants were either personal or professional challenge seekers. The professional challenge seekers related to; professional and career enhancement, improving knowledge and skills, credibility and catching up with new developments in nursing. Personal challenge seekers related to personal development, previous under achievement and having the opportunity to engage in a Master's degree (no numbers or percentages were provided).

Academic requirements were also identified as challenging in a small Norwegian based study by Johansen and Harding (2013). The study using descriptive design, explored 17 nurses' experiences and attitudes to academic writing in postgraduate education. Most of the nurses identified, they had little experience with postgraduate education, found academic writing to be challenging and described it as being "difficult, time consuming and of little relevance to their clinical practice" (p. 366). The study also found that students who had little experience with postgraduate education tended to focus on the expected academic style as opposed to the learning or content. It was argued the lack of writing skills may be due to the lack of support from the Norwegian nursing education system. The study is limited however due to the small number of participants involved. Hoffman and Hester (2012) argued that some of the research participants' academic transitional challenges from their study were related to the students' motivation to undertake postgraduate study which was influenced by participants' experiences with prior learning and academic successes.

\section{Benefits of Study During and Following Completion of Postgraduate Education}

Benefits of study to RNs during and following completion of postgraduate education were many and varied throughout the literature (Table 8). The location of where postgraduate education was being held was identified as more of a benefit if it was held locally (Johnson \& Copnell, 2002; Simsen et al., 1996; Sweeney \& Dalton, 2007). 
Table 8: Benefits of study

\begin{tabular}{|c|c|c|}
\hline Theme & Category & Sub Theme \\
\hline $\begin{array}{l}\text { Benefits of } \\
\text { study }\end{array}$ & $\begin{array}{l}\text { During and } \\
\text { following } \\
\text { completion } \\
\text { of } \\
\text { postgraduate } \\
\text { study }\end{array}$ & $\begin{array}{l}\text { Personal } \\
\text { - Increased self confidence } \\
\text { - Doing more with lives } \\
\text { Professional } \\
\text { - Increase employment opportunity } \\
\text { Practice } \\
\text { - Study \& practice at the same time } \\
\text { - Improved practice } \\
\text { - Learning to link theory to practice } \\
\text { - Collaborative practice } \\
\text { Postgraduate Programme } \\
\text { - Gain tertiary qualification } \\
\text { - Continue with postgraduate education } \\
\text { - Postgraduate education appropriate for first } \\
\quad \text { year of practice although wait } 3-4 \text { months } \\
\text { - before introducing it (graduates). } \\
\text { Financial } \\
\text { - Nothdy locally }\end{array}$ \\
\hline
\end{tabular}

A NZ study conducted in 2012 found 53 (92.6\%) of RNs identified an increase in knowledge and understanding of human biology, the disease process, pathophysiology and patient assessment following completion of postgraduate education. As well as this, 46 $(80 \%)$ identified an increase in application of knowledge (Barnhill et al., 2012). Johnson and Copnell (2002) identified being able to link theory to practice as a significant benefit by respondents. Results of their study identified benefits to the 391 respondents is largely focused on how the individual nurses would benefit and not on how the clinical area/service or patients would benefit. Benefits with the highest percentage included: being able to link theory to practice $336(86 \%)$; increased employment opportunities $277(71 \%)$; increased self-confidence 250 (64\%); and gaining a tertiary qualification $242(62 \%)$. Although this study was about benefits and barriers of undertaking postgraduate study, its focus was considerably more on barriers. Conversely, Boore (1996) highlighted benefits of a postgraduate programme as being around personal attributes; intellectual abilities, theoretical understanding, research understanding, and nursing care. Nursing care included: having a positive effect on practice; introducing innovations and more questioning about care given, demonstrating nurses were also thinking about benefits to patients and the service not only to themselves. 
Zahran (2013) found some colleagues of the participants researched, perceived there was a positive impact on practice for nurses undertaking postgraduate study. In contrast, other colleagues perceived, the purpose of postgraduate education was for personal advancement only; was not applicable to practice settings; and had no practice value. However, McDonald et al. (2009) found 61\% ( $\mathrm{n}=24)$ of NETP nurses considered it appropriate to engage in postgraduate education in the first year of practice, and 78\% ( $\mathrm{n}=31)$ of NETP nurses in the study identified an improvement in nursing skills. The NETP nurses described postgraduate study within the NETP programme as a positive experience encouraging them to pursue education in the future. Similarly Simsen et al. (1996) found that of the 705 respondents in their study, 50\% $(\mathrm{n}=352)$ planned to continue with postgraduate education in the following two to five years, with married and male nurses more likely to want to continue with study. In contrast, senior and older nurses remained undecided or did not wish to continue. A benefit Tame (2009) identified during the period of time participants were students, was that participants' perceived they were doing more with their lives and described this as "accessing CPE removed participants at least temporarily, from traditional female roles" (p. 260). Other benefits from the Tame study included; an increase in confidence and in practice knowledge leading to a more collaborative relationship with medical staff enabling participants to challenge and suggest changes to medical decisions, moving away from the image of nurses being handmaidens to the medical staff.

\section{Knowledge Gaps/Limitations}

Three knowledge gaps were identified from this literature review. The first gap is the minimal research that has been produced from New Zealand around not only postgraduate education in nursing but also in aged care. The literature search resulted in two NZ research articles in the area of postgraduate education and nursing. The two NZ research articles were both held within one DHB each.This indicates some limitation and the research would benefit in being conducted wider in NZ. It also shows a significant gap in research within New Zealand. The second knowledge gap is in the international literature, where although there is more literature around postgraduate education and nurse's attitudes, barriers, motivation and benefits, there was minimal research involving nurses working in aged care. Most participants and respondents involved in the 18 studies were working in other areas of health such as, medical, surgical, theatre or paediatrics. This also shows a gap in the research around postgraduate education for nurses in aged care. The third gap in knowledge is around employer expectation from nurses engaging in 
postgraduate education. Much of the literature was around what nurses expected from employers, or from engaging in postgraduate study. However, there was minimal literature (one study) specifically identifying what employers expected. Including employer expectations would have added to the knowledge in this area and given a more balanced picture. These gaps were all considered important to address in this research. The next chapter of the thesis presents the methodology and design for the research. 


\section{Chapter 3 Methodology and Design}

\section{Introduction}

The purpose of this research is to examine the role of postgraduate education in the aged care sector. The research includes an exploration of the perspectives of RNs employed in aged care and to capture their views and experiences of postgraduate education. The chapter commences with a brief overview of the mixed methods methodology used for this study. The chapter then proceeds to describe the research design, including the sample, the three methods of data collection, document review, focus groups and interviews, and analyses techniques. Rigour strategies are then summarised, and finally the process for ethics and managing ethical issues is presented.

\section{Mixed Method With Data Triangulation}

A qualitative approach was used for this research. Qualitative research comes from a post positivist approach, the purpose of which is to explore and explain in depth phenomena by guiding researchers in understanding phenomena which occur naturally through investigating participant's values, meanings, experiences, beliefs, and attitudes (Schneider, et al., 2007). A case study approach was initially considered as the methodology because of its use in examining individuals, groups, organisational, social, political and related phenomena (Yin, 2009). A case study can be described as a "collection of detailed, relatively unstructured information from several sources, usually including the reports of those being studied", and is often used by the researcher to understand "complex phenomena about which little is known" (Lo Biondo-wood \& Haber, 2002, p. 132). Due to the challenge of defining the phenomena of the case, and the related units of analysis, a decision was made not to continue with case study. However, what I valued from the case study approach was the expectation to use different methods and perspectives, which I considered was important for this study. I therefore chose mixed methods with data triangulation.

A mixed method approach enables the researcher to elicit different perspectives from the data collected, and to give a holistic view of the research topic (Williamson, 2005). Typically a mixed methods methodology is an integration of quantitative and qualitative approaches of which, according to Cresswell (2014), delivers a further comprehensive understanding of the research under question. This study mainly focused on a qualitative aspect using minimal quantitative data. More of a qualitative aspect was been chosen as this study is of a qualitative nature exploring opinions, perceptions and experiences of 
individuals. Mixed method data triangulation is carried out through "the use of a variety of data sources" (Schneider et al., 2008, p. 250). In this study, sources were a document review, focus groups and interviews covering three groups of nurses; those who have engaged in postgraduate education; those who have not engaged in postgraduate education; and Nurse Managers. Using data triangulation as a research approach can be undertaken in three ways (Kimchi, Polivka \& Stevenson, 1991). These are: i) time triangulation - where data about the same phenomena is collected over separate times for example days, weeks or months; ii) person triangulation - where data is collected from two or three levels of people, this could be groups or individuals or both; and iii) space triangulation - where data is collected at several sites of the same phenomena. In this study all three types of triangulation are used. Time triangulation is used for the document review. Person triangulation for sample selection, as data was collected from three different groups of RNs, and space triangulation, as the sample was recruited from four different older persons facilities.

\section{Research Design}

This section details the methods and procedures used in this research.

\section{Document Review}

A document review was undertaken to gather information about what key stakeholder groups had written and proposed about postgraduate education, nursing, and aged care. This information was considered important for investigating policy direction and examining trends and influences. Documents were obtained between the years 2000 to 2015. This period captures when strategic documents were released concerning the growth of NZ's population, and the changes required for the health workforce to effectively meet the needs of the growing population.

The document search involved searching websites from organisations including the $\mathrm{MoH}$, Health Workforce Advisory Committee (HWAC), HWNZ, NCNZ, NZNO, and the College of Nurses Aotearoa, as well as a general Google search using terms similar to those used in the literature review. An initial search on health workforce and older persons, from the MoH, Ministry of Social Development, and from the HWAC, resulted in the selection of 25 policy documents. A further 17 documents from professional bodies such as NCNZ and NZNO were added. These documents focused on nursing education, funding, NPs, the nursing workforce and annual reports. The findings of this collection of 40 documents located over the 15 year time period are provided in Chapter Four. 


\section{Focus Groups}

Focus groups are qualitative in nature (Doody, Slevin \& Taggart, 2013a), and have been used by researchers in health care for the last two decades to collect information about participants perceptions, attitudes, knowledge, opinions and beliefs (Then, Rankin, \& Ali, 2014). The main purpose of a focus group is to enable the researcher to gain a better understanding of a topic or issue through observing, listening and collecting information, in-depth knowledge and experiences from a group (Krueger \& Casey, 2009; Then et al., 2014). Powell and Single (1996), advise that participants for focus groups are chosen for their individual experiences relating to the research. In this research, focus groups were chosen to explore and find out from RNs about their personal experiences of postgraduate education.

The intention was for each group to have been five to eight participants and to be organised as a homogenous unit. Homogeneity, with regard to focus groups, means participants within a group have something in common which is of interest to the researcher (Krueger $\&$ Casey, 2009). A key point is that homogeneity is present in a group's background, not in their attitudes (Morgan, 1997). However, due to problems encountered with recruitment, groups were heterogeneous.

Focus groups require a facilitator who has a good understanding of the purpose of the research as well as knowledge of the topic of the study (Krueger, 2009). The key role of the facilitator is to facilitate the discussion (Doody et al., 2013b). There are also responsibilities the facilitator needs to carry out before, during and after the focus group session to ensure its success. Responsibilities before a focus group include preparing prompts and questions for the discussion (Curtis \& Redmond, 2007). During the focus group, it is the facilitating of free flowing and open discussion that is important (Powell \& Single, 1996). The facilitator needs to communicate clearly with the group, have good listening skills, be able to control any personal reactions, be open and not defensive, and respect participants in the group (Krueger \& Casey, 2009; Powell \& Single, 1996). Krueger and Casey also suggest respect of participants is one of the most significant factors influencing the quality of focus group results. The facilitator keeps the group focused and on track and should ensure every group member has an opportunity to have their say. Powell and Single (1996), also advise that a notetaker or observer is present at the focus group to capture the interaction and dynamics of the group. In this research this advice was not adopted given the difficulties in arranging groups. 
Morgan (1997) argues "strengths and weaknesses of focus groups flow directly from their two defining features: the reliance on the researcher's focus and the group's interaction" (p. 13). Focus groups also rely on the interaction of participants to generate data related to their opinions and experiences. Although this can be a strength (Kitzinger, 1995), it can also be a limitation, as group interaction can lead to conformity within the group, meaning that some participants can withhold valuable information (Curtis \& Redmond, 2007). A group process is an opportunity for those who are shy or do not think they have much to share on the topic (Kitzinger, 1995). A further strength of focus groups is that the researcher can collate similarities and differences in opinions and values expressed by participants (Freeman, 2006).

A limitation of focus groups is that they are not naturalistic because of the facilitator's influence on the interactions (Morgan, 1997). This may have a negative effect on the quality of the data. Also a group may be very quiet and not provide much data. Facilitation skills include monitoring of the group, such as being aware that participants do not trust each other, or managing dominant or aggressive behaviour of individuals and being sensitive if participants become upset. Data from focus groups is challenging to analyse. The interpretation of comments from the group must be carried out, not only within the context of the groups dynamics, but also the environmental and social context from which they took place (Then et al., 2014).

Information sheets containing details about the research, what participation would involve, and details on confidentiality, data storage and dissemination were developed for participants to inform their decisions about participating (Appendix A). In addition to the questions, the focus group schedule contained detail such as the ground rules (Appendix B), advice for the group to ask questions, and to remind them that the session would be audiotaped. The opening question "Tell me what you enjoy most about nursing older people?" was purposeful. As such this was an easy question that dealt with facts and did not require a lot of thinking. It was used to encourage group members to talk and have some discussion at the very start so they were more likely to contribute during the group session (Krueger \& Casey, 2009). The focus group sessions were expected to take between 60-90 minutes each. There were nine questions to ask for each focus group and 10 for the Nurse Manager group (Appendix C). The questions covered i) the place of postgraduate education in aged care; ii) benefits to RNs undertaking postgraduate education and outcomes for residents; iii) benefits and barriers of postgraduate education to the RN; iv) observations of RNs of those who have undertaken postgraduate education; and v) culture of and support provided by the residential facility. Nurse Managers were also asked to 
share their experiences of postgraduate education. This topic was specifically added to find out if they had personally attempted, or completed any postgraduate education, and how that influenced their belief in the importance, need and value of postgraduate education for the $\mathrm{RN}$ working in their aged care facility.

\section{Interviews}

Interviews involve the researcher asking structured, semi-structured or unstructured questions, for the purposes of investigating an area of interest to the researcher (Roberts \& Taylor, 2002). Semi-structured and unstructured questions are commonly used in qualitative research as they allow for a more flexible exploration of topics that come up throughout the interview (Roberts \& Taylor, 2002). Semi-structured interviews were considered appropriate when it became evident it was not possible to convene a focus group. This allowed some individuals to share their perspective on a topic. Interviews are commonly used in mixed method designs (McIntosh \& Morse, 2015). Whiting (2007) identifies five phases to the semi-structured interview. These are; i) building rapport; ii) apprehension, iii) exploration; iv) co-operative; v) participation; and vi) concluding. The information sheet, consent form and schedule, previously used for the focus groups, was modified for the interviews. In the focus groups and interviews participants were asked to complete a simple questionnaire regarding their demographic and clinical background (Appendix D).

\section{Sample}

The population chosen for this research is RNs working in residential aged care. The rationale for this was that in order to be eligible to undertake postgraduate education in nursing in NZ, nurses are required to have nursing registration. Three groups of nurses were recruited: i) those who had engaged in postgraduate study; ii) those who had not; and iii) Nurse Managers. These groups were chosen because I wanted to explore RNs decisions as to why they did or did not undertake postgraduate study; and to explore benefits and barriers to undertaking, or not undertaking, postgraduate study; as well as obtaining Nurse Manager's perspectives on the topic.

The only inclusion criteria was that the RNs needed to have worked in aged care for two or more years. This was to ensure the RNs would have sufficient experience in aged care and time to be engaged in postgraduate study. The exclusion criteria were i) Enrolled nurses working in aged care, as to be eligible for postgraduate education in nursing and for HWNZ funding nurses must be RNs; and ii) casual nurses working in aged care, as these 
nurses work across different aged care facilities, and would have difficulty answering some of the questions.

Purposive sampling was mainly used to recruit participants. Purposive sampling is when the researcher recruits people most likely to have the characteristics and experience of the phenomena under investigation (Higginbottom, 2004). Convenience sampling was also utilised as this enabled recruitment of those "conveniently available" in relation to readiness, time, access and location (Schneider et al., 2007, p. 124). In selecting the sample it was important that people had time to consider whether to participate, as this should help ensure the depth of information required for the study (Schneider et al., 2007).

To recruit participants, I consulted with Nurse Managers from five rest homes in the Lower North Island and asked if they would give permission for their facilities to participate in the research. All five Managers were in agreement. A total of 56 packs (containing the information sheet, consent form and stamped addressed envelope) were collated, one for each RN in the facilities including Nurse Managers. These packs were given to each Nurse Manager to distribute out to their nursing staff at meetings, or placing them in staff mail slots or the staff rooms. The potential participants were given two weeks to return the consent forms to me. Over those two weeks I was contacted by two RNs willing to volunteer their time to participate in the research. I waited another week in case other potential participants contacted me however I received no other contact.

I then contacted the Nurse Managers again and made arrangements with each of them to go to the rest home to conduct either focus groups or interviews with their RNs depending on what the Nurse Manager was able to arrange due to staffing numbers. This process took another two weeks to complete, and due to the difficulties of talking with the Nurse Managers, only four facilities participated in the research. I contacted the two RNs who had originally responded to my invitation about what was happening regarding when I would be at their facility so they could participate. I did not know until I arrived at each individual facility as to how many RNs would be participating.

\section{Data Gathering}

The first facility I went to, I had arranged with the Nurse Manager to conduct a homogenous focus group with those participants who were currently engaged in postgraduate education. On arrival, there were three RNs waiting for me. Two who were engaged in postgraduate education and one who was not. I did not think it would be appropriate to turn the RN who had not engaged in any postgraduate education away. I 
therefore conducted the group with all three RNs present and adapted the questions to include the RN not engaged in postgraduate study. The room we were in was a dining room with no carpet. The lack of carpet on the floor meant the room had a lot of echo which impacted on the quality of the audio recording making it difficult later to transcribe.

I commenced the group session by introducing myself and I then completed the research formalities such as advising how the group would run and revisited the consent process to ensure everyone was familiar with expectations, and to complete the demographics and professional characteristics form. As this was being completed I realised I had made a mistake on the form concerning age groupings. I had written 20 to 25,25 to 30 , and 30 to 35 which meant anyone who was exactly 25 or 30 could be in one of two groups. I asked participants who were in this predicament to write down their actual age.

Following completion of the form I went over the ground rules. Participants were asked if they were in agreement and if they had anything to add. No new rules were added and all were in agreement. I then commenced asking the group the pre constructed questions. The group dynamics were positive and there was a light hearted atmosphere. All three RNs knew each other. The two who were currently participating in postgraduate education, contributed well and were able to answer all questions. The RN who had not completed any postgraduate education was quieter, until towards the end when she became more vocal increasing her contribution. Following completion of the focus group I provided some refreshments and thanked everybody for their time. As I was about to leave, an RN who had missed the focus group arrived. She was very keen to participate in the research, so I interviewed her at that time. Once away from the facility I wrote notes about my thoughts concerning what I had heard and how the group and interview went.

I went to the second focus group with less of an expectation of it being homogenous. On arrival at the facility there were four RNs waiting for me. One who was currently engaged in postgraduate study and three who had never engaged in postgraduate study. The room used for this focus group was a lot quieter, as it had carpet on the floor and arm chairs to sit on. I went through the same process as the first focus group regarding preparation and the order of questions. During this focus group there were several interruptions from one participant's pager going off which resulted in the participant leaving the room on two occasions. The participants all knew each other and were very vocal; they all interacted well and answered and discussed all the questions. 
I conducted a further 12 interviews. It was unknown each time I went to a facility how many RNs I would be interviewing so I went prepared with questions to cover all three possibilities I undertook a similar preparatory stage as I had done with the focus groups with the exception that there was no need to review the ground rules. In both focus groups, the audio recorder was only turned on following those formalities.

Settings for the interviews varied, if the interview was with a Nurse Manager it was generally held in their office. This did cause some interruption at one interview with people knocking on the door and the phone ringing. I paused the audio recorder to maintain confidentiality during those interruptions. I found the interruptions impacted on the focus and flow of the interview. Other settings used for the interviews were a whānau room, a recreation room, a staff meeting room and a staff office. Due to 11 of the 13 interviews being held during work hours, the interviews were shorter ranging in length from 9 to 32 minutes. Given the limited time some interviews were rushed and participants did not always engage in deep conversation. I found the Nurse Managers to be more engaged in the interviews, which could possibly be because they did not have a patient load to get back to.

Every interview was different I found some participants opened up more than others and would share personal information, which sometimes was unrelated to my research. Difficulties encountered with the interviews were mainly the limited time each RN felt they could give to the interview. Another issue arose with the demographics and professional characteristics form, when one participant had trouble with the question asking for the year of their nursing registration. The participant had immigrated to NZ and asked if I wanted the date of their initial nursing registration or when they got their NZ nursing registration. I clarified it was their initial nursing registration, but did ask that they also put the NZ date down. I subsequently made this clearer.

\section{Analysis}

Data analysis was carried out on the document review, focus groups and interviews. A transcriber who had signed a confidentiality agreement (Appendix D) was used for transcribing one focus group and 11 interviews, and I transcribed the other focus group and two interviews. Data analysis for the document review followed three steps. First, the documents were separated into two clusters, government policy perspectives and professional body perspectives and put into a historical timeline. Second, the content of each document was reviewed for what it reported regarding nursing workforce 
development, postgraduate, postgraduate education, aged care, older persons, residential care and continuing care, postgraduate funding, NP and Nurse Specialist. Third, overall trends in the documents were then analysed over time.

Data analysis for the focus groups and interviews was carried out using a descriptive process, through content extraction, categorising and interpreting the data. Sandelowski (1995) considers analysis starts the moment data have been collected. The process was conducted in five steps and focused on the content of what was shared. First I collated the demographics and professional characteristics these were summarised in table format. Percentages for each group were developed; this assisted in describing differences amongst the group; for example, the proportion of people by ethnicity who had completed postgraduate education.

Secondly, I listened to the audiotapes of each interview several times, I then read the transcriptions to become very familiar with and get a sense of the data. Sandelowski (1995) considers re reading of transcriptions as being an essential part of the process for the researcher to get a "sense of the whole", to eventually move on to the next part of the analytical process (p. 373). Similarly Creswell (2014) advises researchers about reading through the data multiple times and reflecting on what has been read to get an overall meaning and idea of what the participant is saying. As I did this I cleaned the transcriptions by removing words such as "umm" and de identifying the data to ensure confidentiality of the facilities, group participants and others who were named. Thirdly, I transferred the data from each focus group and interview into table form. During this exercise I re-read the transcripts and listened to what was said.

The fourth step involved categorising what each question meant and then interpreting its meaning (Table 9). Interpretation of the data involves the researcher determining their assessment of what is being said (Sandelowski, 1995). Creswell (2014) refers to interpretation of data analysis as "peeling back the layers of an onion" in order to find the meaning (p. 195). As an overlap between the answers became apparent, I made the decision to cluster questions. The clusters were; questions one and eight which captured the big picture of aged care in general, questions two and three which captured workplace, questions four, five and nine were about benefits of postgraduate education, question six which captured the barriers to postgraduate study and question seven the personal factors around postgraduate study. 
Table 9: Example of table used to categorise and interpret interview data

\begin{tabular}{|c|c|c|c|}
\hline Q8 & \multicolumn{3}{|c|}{$\begin{array}{l}\text { What do you think are the potential benefits to the residents of RNs completing } \\
\text { postgraduate education? }\end{array}$} \\
\hline $\begin{array}{l}\text { Interview } \\
\text { Number }\end{array}$ & Content & Category & Interpretation \\
\hline $\begin{array}{l}\text { RN12D } \\
\text { Not } \\
\text { engaged } \\
\text { in PG }\end{array}$ & $\begin{array}{l}\text { "Well I think the benefits for } \\
\text { them are, they are assured } \\
\text { that there are competent } \\
\text { nurses to take care of them. } \\
\text { New updates to their current } \\
\text { trends and standards of care'. }\end{array}$ & $\begin{array}{l}\text { Residents can feel } \\
\text { confident that the RNs } \\
\text { engaged in postgraduate } \\
\text { education have advanced } \\
\text { and current skills and } \\
\text { knowledge to care for } \\
\text { them. }\end{array}$ & $\begin{array}{l}\text { Being up to date with } \\
\text { standards of care and } \\
\text { current trends in } \\
\text { nursing is essential to } \\
\text { providing skilled and } \\
\text { competent care to } \\
\text { residents. }\end{array}$ \\
\hline
\end{tabular}

The fifth and final step involved further re reading of the data and finalising my interpretation. From this five themes emerged. In developing the interpretation, attention was given to identify the similarities and differences in what was shared. The triangulation of the document review with that of the focus group and interview data was part of the discussion.

\section{Rigour}

Rigour in qualitative research is necessary as it makes evident the integrity and credibility of the research process (McBrien, 2008). Rigour has been ensured during the course of this research and has been carried out in two main ways. Firstly, through using triangulation and secondly through an audit trail. The main types of triangulation are: multidisciplinary, theory, data, investigator, and methodological, this study has used data triangulation, meaning several sources of data have been used (Schneider et al., 2007). In this study data sources were from the document review, the focus groups and interviews with the RNs and Nurse Managers. An audit or decision trail refers to the record of what and why decisions were made in the research. The trail is important for demonstrating that the research is trustworthy (Schneider et al., 2007). In this study the audit trail consisted of detailing the steps taken about managing the focus groups and interviews and the analysis process including how the raw data was handled in order to create the themes. The findings include the use of some quotations to demonstrate the credibility of the terms that emerged.

Sandelowski (1986) states a good audit trail is when "A study and its findings are auditable when another researcher can clearly follow the "decision trail" used by the investigator in the study" (p. 33). 


\section{Ethics}

For this research, ethics approval was obtained from the Human Ethics Committee at Victoria University (Appendix E). Key aspects of this application were consent, confidentiality and de-identifiability. A signed consent form was needed by all participants (Appendix F). All care was taken to ensure demographics and professional characteristics were grouped so as others could not readily identify participants contribution. This was important as people who participated in the group sessions were familiar with who was involved. The interviews and focus groups all took place at facilities, of which others were aware that research was taking place. All participants and residential facilities were deidentified in the writing of this thesis for example, RN1, RN 2 or Facility A, Facility B.

Following data collection, the transcriber completed and signed a confidentiality agreement (Appendix G). The only people to listen to the audio recordings and read the transcription were the transcriber, my thesis supervisor and myself. The transcriber no longer has the audio recordings and has deleted copies of the transcriptions from her computer. Once this thesis has been completed, audio recordings and scanned copies of written transcriptions will be transferred to a USB stick for storage for two years and then destroyed.

Four ethical issues occurred during focus groups and interviews. The first issue happened at the first focus group, where I was expecting only nurses who had engaged in postgraduate education and a participant who had not completed any postgraduate education arrived. As the information sheet noted that there were going to be different types of participants I considered it appropriate for the person to stay. The participant had come voluntarily and had stayed back after work to attend. I did not seek approval from the group for this decision.

The second issue involved someone who did not meet the inclusion criteria arriving for a focus group. In this group a RN who had not worked for two or more years arrived: she came because she was undertaking postgraduate study. Again I made a decision to allow this nurse to stay. This decision was influenced because others were present when this nurse arrived, I was conscious of not embarrassing her regarding eligibility, given that she had made the effort to attend. As this was a focus group situation it was not possible to postpone the group to get ethical clearance to include her. The other three nurses in the group were in agreement for her to be involved. The ethics committee has since been notified. 
The third issue concerned a participant debriefing with me about their work and the facility due to my role at the DHB. I listened to and acknowledged what they had to say which brought up some conflicting issues relating to my professional role. I acknowledged what the participant had to say at the time and spent some time reflecting on it once I returned home. Nothing about this debriefing has been used in this research.

The fourth issue concerned a participant sharing personal information about themselves during the interview. This information clearly caused her some distress. I acknowledged at the end of the interview and I debriefed with my supervisor. A decision was made to utilise some of this information in the analysis as the experiences of this $\mathrm{RN}$ had a direct impact on her thinking regarding postgraduate education and nursing.

\section{Summary}

This chapter has presented the methodology used for this research. It has also outlined the research design used to implement this research. The data collection consisting of a document review, focus groups and interviews has been described followed by how analysis of the research was carried out. The processes used to ensure rigour throughout the research has been explained and ethical situations have been identified and explained. In the following two chapters the findings are presented, commencing in the next chapter with a document review. 


\section{Chapter 4 Document Review}

\section{Introduction}

This chapter presents findings from the document review beginning in 2000 with the New Zealand Health Strategy $(\mathrm{MoH}, 2000)$ through to 2015. The document review was limited to NZ resources and achieved through researching specific internet sites such as the Ministry of Health (MoH), Nursing Council of New Zealand (NCNZ), the New Zealand College of Nurses and the New Zealand Nurses Organisation (NZNO). Prior to the interviews, 37 documents between the years 2000 and 2013 were obtained and reviewed. Following data collection, three documents released in 2015 were added to the review as they were considered important. The year 2000 was selected because this was the time strategic documents were released concerning the future growth of NZ's population and changes required for the health workforce to effectively meet the needs of the growing population.

Following a review of the initial 37 documents, a decision was made to cluster these into two groups. The first group consists of policy documents generated by the government. The second group consists of documents by professional bodies. A literature review commissioned by Careerforce was also included in the second cluster. An historical approach was used to present each of the two clusters. In presenting this review, a decision was made to use an annotated approach to present the contents related to each document regarding what the document said about older persons, the nursing workforce and postgraduate education. It was considered this approach would work best given the many different styles of documents. A summary is presented at the end of each group.

\section{Government Policy Perspectives from 2000 to 2015}

The first cluster of documents consists of 25 government policy documents (Table 10). Most documents come from the $\mathrm{MoH}$. The $\mathrm{MoH}$ leads and has overall responsibility for the management and development of NZs health and disability systems. The role of the $\mathrm{MoH}$ is to "improve, promote and protect the health and wellbeing of New Zealanders" (MoH, 2016, I1). This is done through leading the health and disability system; providing advice to the Government and Minister of Health; providing payment services and health sector information; and purchasing national health and disability support services. These documents had a different emphasis, six were specifically focused on the older person, 10 on the health workforce generally, seven on the nursing workforce and two on the general health system. 
Table 10: Historical timeline of Government policy documents from 2000 - 2015

\begin{tabular}{|c|c|c|}
\hline Year & Document & Focus \\
\hline 2000 & New Zealand Health Strategy & General \\
\hline 2001 & New Zealand Positive Aging Strategy & Older Persons \\
\hline 2001 & $\begin{array}{l}\text { The New Zealand Health Workforce: A Stock Take of Issues } \\
\text { and Capacity } 2001\end{array}$ & Health Workforce \\
\hline 2002 & $\begin{array}{l}\text { The New Zealand Health Workforce Framing Future } \\
\text { Directions: Discussion Document }\end{array}$ & Health Workforce \\
\hline 2002 & $\begin{array}{l}\text { Health of Older People Strategy, Health Sector Action to } \\
2010 \text { to Support Positive Aging }\end{array}$ & Older Persons \\
\hline 2002 & $\begin{array}{l}\text { Health of Older People in New Zealand: Statistical } \\
\text { Reference Report }\end{array}$ & Older Persons \\
\hline 2003 & $\begin{array}{l}\text { The New Zealand Health Workforce Framing Future } \\
\text { Directions: Analysis of Submissions and Draft } \\
\text { Recommendations to the Minister of Health for Health } \\
\text { Workforce Development (unpublished) }\end{array}$ & Health Workforce \\
\hline 2003 & $\begin{array}{l}\text { The New Zealand Health Workforce Future Directions: } \\
\text { Recommendations to the Minister of Health }\end{array}$ & Health Workforce \\
\hline 2004 & $\begin{array}{l}\text { Impact of Population Aging in New Zealand on the Demand } \\
\text { of Health \& Disability Support Services \& Workforce } \\
\text { Implications }\end{array}$ & Older Persons \\
\hline 2004 & $\begin{array}{l}\text { Aging New Zealand and Health Disability Services Demand } \\
\text { Projections } 2010-2021\end{array}$ & Older Persons \\
\hline 2005 & $\begin{array}{l}\text { Health Workforce Advisory Committee Strategic Principles } \\
\text { for Workforce Development in NZ }\end{array}$ & Health Workforce \\
\hline 2005 & Future Workforce 2005-2010 & Health Workforce \\
\hline 2005 & $\begin{array}{l}\text { Strategic Principles for Workforce Development in New } \\
\text { Zealand }\end{array}$ & Health Workforce \\
\hline 2006 & $\begin{array}{l}\text { Health of Older People Information Strategic Plan: } \\
\text { Directions to } 2010 \& \text { Beyond }\end{array}$ & Older Persons \\
\hline 2006 & Health Workforce Development: An Overview. & Health Workforce \\
\hline 2006 & $\begin{array}{l}\text { Report of the Safe Staffing/Healthy Workplaces Committee } \\
\text { of Inquiry }\end{array}$ & Health Workforce \\
\hline 2006 & Nursing Workforce Strategy & Nursing Workforce \\
\hline 2009 & Our Health Workforce Today and the Future & Health Workforce \\
\hline 2009 & $\begin{array}{l}\text { A Nurse Education \& Training Board for NZ: A Report to } \\
\text { the Minister of Health }\end{array}$ & Nursing Workforce \\
\hline 2011 & Workforce for the Care of Older People: phase 1 report & Nursing Workforce \\
\hline
\end{tabular}




\begin{tabular}{|l|l|l|}
\hline 2011 & Postgraduate Nursing Training Specification & Nursing Workforce \\
\hline 2013 & Evaluation of Nurse Practitioner in Aged Care & Nursing Workforce \\
\hline 2014 & Service Specification Nursing Entry to Practice Programme & Nursing Workforce \\
\hline 2014 & $\begin{array}{l}\text { Aged Residential Care Nursing Entry to Practice Evaluation } \\
\text { Report }\end{array}$ & Nursing Workforce \\
\hline 2015 & $\begin{array}{l}\text { Update of the New Zealand Health Strategy: All New } \\
\text { Zealanders Live Well, Stay Well, Get well: Consultation } \\
\text { Draft }\end{array}$ & General \\
\hline
\end{tabular}

\section{The New Zealand Health Strategy}

The New Zealand Health Strategy $(\mathrm{MoH}, 2000)$ released by the Minister of Health, the Honourable Annette King, outlines the government's strategic direction for New Zealand's health sector. The Strategy included the principles, goals, priority objectives and service delivery areas for the health sector. The document also identified key quality issues, one of which was workforce development. In the introduction, the document was described as a "living Strategy" (MoH, 2000, p. 1), as it was expected to be further developed and built on over the coming years. An updated health strategy is presently being consulted on. The New Zealand Health Strategy included four objectives relating to aged care and the workforce. These were: i) "support policies and programmes that promote positive aging"; ii) "reduce the impact of dementia"; iii) "reduce the incidence and impact of falls in older people"; and iv) "ensure accessible and appropriate services for older people" (p. 12).

Future workforce issues were named as needing to be addressed in aged care. The document reported that as the population ages, health needs will change and there will be a need for increased training and support for carers, volunteers and additional community nursing support. It also identified there would be an increased need to provide support and supervision of health professionals around pre-registration, post-registration and on-going education training. The government was to establish an independent Health Workforce Advisory Committee (HWAC) to address how needs would be met, monitor changing needs, and address workforce needs with the delivery of suitable training and education (Health Workforce Advisory Committee [HWAC, 2005]).

\section{New Zealand Positive Ageing Strategy}

The New Zealand Positive Ageing Strategy (Ministry of Social Development, 2001) was designed to strengthen the government's commitment to positive aging by providing better 
opportunities for the older person to choose how they want to be involved and participate in the community. This was to be achieved through identifying the barriers to older people participating, and addressing those barriers through collaborating with sector services and developing actions. The Strategy included 10 broad principles (Table 11) that were expected to assist with directing and developing policies and services.

\section{Table 11: Positive Ageing Principles}

\begin{tabular}{|c|c|}
\hline Principles & Action \\
\hline Principle One & $\begin{array}{l}\text { Empower older people to make choices that enable them to live a } \\
\text { satisfying life and lead a healthy lifestyle. }\end{array}$ \\
\hline Principle Two & $\begin{array}{l}\text { Provide opportunities for older people to participate in and contribute } \\
\text { to family, whānau and community. }\end{array}$ \\
\hline Principle Three & Reflect positive attitudes to older people. \\
\hline Principle Four & $\begin{array}{l}\text { Recognise the diversity of older people and ageing as a normal part } \\
\text { of the lifecycle. }\end{array}$ \\
\hline Principle Five & $\begin{array}{l}\text { Affirm the values and strengthen the capabilities of older Māori and } \\
\text { their whānau. }\end{array}$ \\
\hline Principle Six & $\begin{array}{l}\text { Recognise the diversity and strengthen the capabilities of older } \\
\text { Pacific people. }\end{array}$ \\
\hline Principle Seven & $\begin{array}{l}\text { Appreciate the diversity of cultural identity of older people living in } \\
\text { New Zealand. }\end{array}$ \\
\hline Principle Eight & Recognise the different issues facing men and women. \\
\hline Principle Nine & $\begin{array}{l}\text { Ensure older people, in both rural and urban areas, live with } \\
\text { confidence in a secure environment and receive the services they } \\
\text { need to do so. }\end{array}$ \\
\hline Principle Ten & $\begin{array}{l}\text { Enable older people to take responsibility for their personal growth } \\
\text { and development through changing circumstances. }\end{array}$ \\
\hline
\end{tabular}

Source; Ministry of Social Development (2001), New Zealand Positive Aging Strategy, Wellington: NZ Government.

The Ministry of Social Development sought feedback on the 10 principles through consultation with members of national community groups including Aged Concern, Māori groups and other ministries, such as the Ministry of Pacific Island Affairs. The groups identified priority areas for government action. From this consultation 10 Positive Aging Goals (Table 12) together with recommended actions were identified. The key goal for health was to provide the older person with affordable, timely, equitable and accessible health services. There was no specific reference in the Strategy towards workforce 
development in the health sector, which would be necessary to enable meeting the goal for health of the older person.

Table 12: Positive Ageing Goals

\begin{tabular}{|c|c|}
\hline Goals & \\
\hline Income & Secure and adequate income for older people \\
\hline Health & $\begin{array}{l}\text { Equitable, timely, affordable and accessible health services for older } \\
\text { people }\end{array}$ \\
\hline Housing & Affordable and appropriate housing options for older people \\
\hline Transport & Affordable and accessible transport options for older people \\
\hline Ageing in Place & Older people feel safe and secure and can age in place \\
\hline $\begin{array}{l}\text { Cultural } \\
\text { Diversity }\end{array}$ & $\begin{array}{l}\text { A range of culturally appropriate services allows choices for older } \\
\text { people }\end{array}$ \\
\hline Rural & $\begin{array}{l}\text { Older people living in rural communities are not disadvantaged when } \\
\text { accessing services }\end{array}$ \\
\hline Attitudes & People of all ages have a positive attitude to ageing and older people \\
\hline Employment & Elimination of ageism and the promotion of flexible work options \\
\hline Opportunities & $\begin{array}{l}\text { Increasing opportunities for personal growth and community } \\
\text { participation }\end{array}$ \\
\hline
\end{tabular}

Source; Ministry of Social Development (2001), New Zealand Positive Aging Strategy, Wellington: NZ Government.

\section{The NZ Health Workforce: A Stocktake of Issues and Capacity}

The NZ Health Workforce: A Stocktake of Issues and Capacity 2001 (Health Workforce Advisory Committee [HWAC], 2002a) was written following the establishment of HWAC. Based on the data up to 2001 and submissions from health sector organisations, HWAC identified six priorities for workforce development. These were; i) The workforce implications of implementation of the Primary Health Care Strategy; ii) Building Māori health workforce capacity; iii) Building Pacific health workforce capacity; iv) Promoting a healthy hospital workforce environment; v) Building health and support workforce capacity for people who experience disability; and vi) Education to meet workforce needs.

In this Stocktake, HWAC refer to all strategies under the umbrella of the New Zealand Health Strategy, including Health of Older People Strategy. The document identified two workforce initiatives for the nursing sector, these are: i) to develop regulations for nurse prescribing, including in aged care; and ii) "options for developing the health aid workforce, which will include providing training options specialising in particular clinical 
and support setting, and a pathway to move to more advanced training" (p. 15). The nurse practitioner (NP) role is described in the document as "Nurse practitioners will be unique health care providers, making independent and collaborative health care decisions in partnership with individuals, families and communities across a number of settings" (p. 35). At the time this document was released, regulations were being developed for NPs to have prescribing rights.

\section{The New Zealand Health Workforce Framing Future Directions: Discussion Document}

The New Zealand Health Workforce: Framing Future Directions (HWAC, 2002b) is a discussion document that addresses the six priorities for workforce development identified in The New Zealand Workforce: A Stocktake of Issues and Capacity (HWAC, 2002a). Workforce development priorities were covered in depth, followed by questions for discussion and consultation. The document does not specifically address workforce development priorities for aged care. It does however refer to the need to address the workforce implications of the Primary Health Care Strategy including the benefits of the NP role. The workforce development priority relating to "Educating a Responsive Health Workforce" considers the effect the Tertiary Education Strategy (MoH, 2002) could have on this priority.

\section{Health of Older People Strategy: Health Sector Action to 2010 to Support Positive Aging}

The primary aim of the Health of Older People Strategy: Health Sector Action to 2010 to Support Positive Aging (MoH, 2002a); from here-on-in referred to as the Health of Older People Strategy was to be responsive to the diverse needs of older people through developing a combined approach to health and disability support services. Eight objectives were listed outlining the actions and key steps needed to implement the Strategy (Table 13).

One step particularly relevant to this research, is step 2.4, "policy and service planning will support quality health and disability support programmes integrated around the needs of older people" (p. 71). Achieving this step would require development of the workforce, including the $\mathrm{MoH}$ implementing a planned approach to strengthen the health workforce, in order to meet the needs of the older person. The Strategy referred to the $\mathrm{MoH}$, specifically stating there was a need for "an education system that responds effectively to health sector needs" (p. 23), of which the MoH were to advise the Ministry of Education of 
by mid-2003. This should include implementation of the NP role, development of regulations for nurse prescribing; and the inclusion of NP in aged care. A framework for primary health care nursing and possibilities for growing the unregulated workforce (caregivers in rest homes or health care assistants in DHBs) were also referred to.

Table 13: Objectives of the Health of Older People Strategy

\begin{tabular}{|c|c|}
\hline Objectives & Action \\
\hline Objective One & $\begin{array}{l}\text { Older people, their families and whānau are able to make informed } \\
\text { choices about options for healthy living, health care and/or } \\
\text { disability support needs. }\end{array}$ \\
\hline Objective Two & $\begin{array}{l}\text { Policy and service planning will support quality health and } \\
\text { disability support programmes integrated around the needs of older } \\
\text { people. }\end{array}$ \\
\hline Objective Three & $\begin{array}{l}\text { Funding and service delivery will promote timely access to quality } \\
\text { integrated health and disability support services for older people, } \\
\text { family whānau and carers. }\end{array}$ \\
\hline Objective Four & $\begin{array}{l}\text { The health and disability support needs of older Māori and their } \\
\text { whānau will be met by appropriate integrated health care and } \\
\text { disability support services. }\end{array}$ \\
\hline Objective Five & $\begin{array}{l}\text { Population based health initiatives and programmes will promote } \\
\text { health and well-being in older age. }\end{array}$ \\
\hline Objective Six & $\begin{array}{l}\text { Older people will have timely access to primary and community } \\
\text { health services that proactively improve and maintain their health } \\
\text { and functioning. }\end{array}$ \\
\hline Objective Seven & $\begin{array}{l}\text { Admission to general hospital services will be integrated with any } \\
\text { community based care and support that an older person requires. }\end{array}$ \\
\hline Objective Eight & $\begin{array}{l}\text { Older people with high and complex health and disability support } \\
\text { needs will have access to flexible, timely and coordinated services } \\
\text { and living option that take account of family and whānau carer } \\
\text { needs. }\end{array}$ \\
\hline
\end{tabular}

Source: Ministry of Health (2002). Health of Older People Strategy: Health Sector Action to 2010 to Support Positive Ageing. Wellington: NZ Government.

\section{Health of Older People in New Zealand a Statistical Reference Report}

The Health of Older People in New Zealand A Statistical Reference Report (MoH, 2002b) was developed to inform the implementation of the Health of Older People Strategy into action. The aim was to help the Ministry, service providers and DHBs with planning and delivering services to existing and future older persons. The document covers NZ's aging population; the sociodemographics and health status of older people; provides an overview 
of health and disability support services including an examination of the expenditure relating to utilisation of health and disability services and the Accident Compensation Corporation; and the future need for health services for the older person.

In relation to aged residential care it was identified that approximately five percent of people aged 65 and over are in residential care. Throughout 2000/2001 there was an estimated 29,100 people in residential care, of whom, $72 \%$ were aged 65 to 74 and $84 \%$ were aged 75 and over, and had some form of disability for which help was needed on a daily basis. The document included no statistics or discussions about current or future workforce development in or for aged care.

\section{The New Zealand Health Workforce Future Directions: Recommendations to the Minister of Health}

The New Zealand Health Workforce Future Directions: Recommendations to the Minister of Health (HWAC, 2003) consolidates information and recommendations made in The New Zealand Health Workforce Framing Future Directions (HWAC, 2002b). These recommendations followed analysis of consultation from the 2002 discussion document including a national summit in 2003, attended by "leading thinkers on health and disability workforce issues" (HWAC, 2003, p. 1). The document built on the six priorities for workforce development in The NZ Health Workforce: A Stocktake of Issues and Capacity (HWAC, 2002) and added a seventh priority regarding research and evaluation. The HWAC workforce priority for education "To facilitate the evolution and further development of health workforce education" (p. 13) included five recommendations (Table 14).

Three of the recommendations were to be implemented as a priority. These were; i) the review of the Clinical Training Agency funding role; ii) the review of existing postgraduate education frameworks; and iii) to meet the needs of the health and disability sector, the MoH, HWAC and DHBs need to work with the Tertiary Education Committee on health education courses. It was clearly outlined that the key to success for all these recommendations was for collaboration between the health and education sectors. 
Table 14: Recommendations to meet priority on workforce development

\begin{tabular}{|c|c|}
\hline Priority & Recommendation \\
\hline 3.1 & $\begin{array}{l}\text { The MoH in collaboration with HWAC and DHBs: } \\
\text { 3.1.1 Reviews the strategic framework around the CTA funding role in health } \\
\text { workforce training by June } 2005 \text {. } \\
\text { 3.1.2 Reviews the appropriateness of current postgraduate education } \\
\text { frameworks and vocational training in order to meet the future workforce } \\
\text { requirements and health needs of New Zealanders by June } 2005 \text {. } \\
\text { 3.1.3 Works with TEC to ensure that health education courses meet the needs } \\
\text { of the health and disability sector. }\end{array}$ \\
\hline 3.2 & $\begin{array}{l}\text { DHBs and other health service providers acknowledge and support their role } \\
\text { as educators in collaboration with education providers and professional bodies } \\
\text { as provided for in their workforce development plans by June } 2005 \text {. }\end{array}$ \\
\hline 3.4 & $\begin{array}{l}\text { The TEC and tertiary education organisations (TEOs), in collaboration with } \\
\text { the health and disability sector, introduce mechanisms to ensure that: } \\
\text { 3.4.1 Collaborative planning, information sharing and teaching between the } \\
\text { health sector and tertiary education providers is strengthened. } \\
\text { 3.4.2 Wherever possible, delivery of educational programmes is made flexible } \\
\text { to improve access. } \\
\text { 3.4.3 Health workforce education is responsive to changes in required skills } \\
\text { for the diverse range of health practitioners. } \\
\text { 3.4.5 Students and graduates are actively recruited to better represent the } \\
\text { diversity of the New Zealand population using broad selection criteria. }\end{array}$ \\
\hline 3.5 & $\begin{array}{l}\text { TEOs, in consultation with the health and disability sector, introduce } \\
\text { mechanisms to ensure that: } \\
\text { 3.5.1 The teaching capability of staff, both academic and clinical, is supported } \\
\text { and strengthened. } \\
\text { 3.5.2 Clinical and community placements are better coordinated and aligned } \\
\text { to the New Zealand Health Strategy and the New Zealand Disability Strategy. }\end{array}$ \\
\hline
\end{tabular}

Impact of Population Aging in New Zealand on the Demand for Health and Disability Support Services and Workforce Implications

The document, Impact of Population Ageing in New Zealand on the Demand for Health and Disability Support Services and Workforce Implications (MoH, 2004a) was completed by Cornwall and Davey, is a background paper prepared for the Ministry by the New Zealand Institute for Research and Ageing, and the Health Services Research Centre, Victoria University of Wellington. The document consists of a literature review on the projected impact of population ageing on health and disability support services (20112021) from selected countries in the Organisation for Economic Co-operation and Development, and the implications on health sector policy. Several issues were highlighted in the literature review including the future load that will be placed on health and disability 
services due to the ageing population, the impact this load will have on services, concerns about the impact about the impact and challenges for the health workforce.

The document identified that other countries are facing similar issues to NZ with regard to recruitment and retention of the aged care workforce. This is significant with regard to addressing the challenge of meeting the needs of the aging population. Two issues highlighted were the ageing nursing health workforce and the unpopularity by workers of caring for older people in long term care. Recruitment and retention into the aged care specialty for "medical professionals" and medical practitioners was noted (MoH, 2004, p. 80). However, there is no reference to recruitment and retention of nurses in aged care.

\section{Ageing New Zealand and Health Disability Services 2010-2021: Background Information. International Responses to Ageing Population}

The Ageing New Zealand and Health and Disability Services 2010-2021: Background Information. International Responses to Ageing Populations (MoH, 2004b) document outlines responses and recommendations from international literature on possible responses to the demand for health and disability services from the ageing population. Countries mainly focused on within this document are; Australia, Canada, the USA and the UK. It was identified that to manage the growing demand for health services, four particular areas in health would need to change. These areas are; i) the need for more health practitioners to cope with the increased number of older people; ii) the need for more specialist practitioners in the field of older people, to manage conditions related to aging, such as hip replacements; iii) the need for more knowledge in the area of the health of the older person; and v) the need for more services to provide support to older persons, such as assistance with daily living tasks.

The change to meet the demand on health services due to an increase in the population of the older person focused on the need for more practitioners, including the nursing sector. The discussion referred to the need for medical and nursing schools to increase the number of intakes. The possibility of recruiting additional nurses and doctors from overseas was also raised. The need for more specialist practitioners, more training of advanced practice geriatric nurses and NPs employed in rest homes was identified. Actual training or education programmes in support of aged care were not discussed. 


\section{Health Workforce Advisory Committee: Strategic Principles for Workforce Development in NZ}

The Health Workforce Advisory Committee: Strategic Principles for Workforce Development in New Zealand (HWAC, 2005) contained seven principles based on current workforce plans, strategies and other documents relating to the health and disability workforce. These principles were developed to provide guidance for future approaches to workforce development. The principles are; i) Equity and appropriateness - communities should be able to access services appropriate to their needs and receive fair and reasonable outcomes from the health and disability workforce; ii) Strategic and sustainable supply the health and disability workforce must be strategic, considering priorities and issues which they have identified. Numbers of health and disability practitioners need to be in plentiful supply, suitable, sustainable and affordable to meet the needs of the population; iii) Healthy workplaces - people working in the health and disability sector must work in a healthy and attractive environment; iv) Collaborative practice - the health and disability support workforce are to be supported and encouraged to work across disciplines and different settings; v) Effective education - there must be access for the health and disability support workforce to relevant, appropriate and continuing education, vi) Stakeholder involvement - health and disability support workforce development requires collaborative processes to work effectively; and vii) Informing and monitoring - enable health and disability support workforce development to work well, effective tools are required to make use of the information gained from monitoring and evaluating.

The principles are generic when referring to the health and disability workforce, and HWAC did not specifically comment on sectors such as aged care. In my assessment two principles in particular concern aged care and postgraduate education. These are i) Healthy workplaces; and ii) Effective education. The guiding principle of healthy workplaces encompasses cultural, social, emotional and organisational components and is not solely about health and safety. One aspect of developing a healthy workplace is that it should improve recruitment and retention of health practitioners (HWAC, 2005). There is potential that this guideline could improve recruitment and retention of staff in aged care.

In respect to the principle Effective Education, the HWAC recommended the need for strong links between regulatory bodies, educational bodies and employers in the health and disability workforce to enable the development of relevant programmes. Funding the health and disability workforce and ensuring there are sufficient resources to enable opportunities for training and study is also an important element of this guiding principle. 
This guideline could also strengthen the relevancy of postgraduate programmes and funding opportunities for nurses working in aged care.

\section{Future Workforce 2005-2010}

The document Future Workforce 2005 - 2010 (District Health Boards NZ [DHBNZ], 2005), is a high level strategic framework and plan developed by DHBNZ with support from HWAC and the MoH. Through consultation with workforce and service development specialists, this framework was designed to encourage and steer "collaborative workforce activity" (p. 2) to 2010.

Following a consultation process eight priorities and actions were identified, one of which related to education and training. Actions for this priority were around creating and building relationships with the education sector to work together on issues such as recognition of prior learning and access to education and competencies. Other actions for this priority were to develop e-learning systems and eliciting DHB agreement on competencies such as professional portfolios becoming transferable across DHBs and other disciplines. There was no specific reference to postgraduate education nor was there any reference to older persons.

\section{Health of Older People Information: Strategic Plan: Directions to 2010 and Beyond}

The Health of Older People Information Strategic Plan: Directions to 2010 and Beyond $(\mathrm{MoH}, 2006 \mathrm{a})$ was developed in consultation with service providers and DHBs to address gaps identified in the accompanying Health of Older Persons Statistical Reference Report $(\mathrm{MoH}, 2002)$. The gaps concerned information services. At the time, information on how older people used health and disability support services was not adequate. To address this gap the Strategy proposed "developing the information infrastructure, systems and services required to plan, deliver and monitor health and disability support programmes for older people as a population group" (p. 3). This Strategy links with the Health of Older People Strategy $(\mathrm{MoH}, 2006)$ released in the same year. Stakeholders included health practitioners, service providers and service users. Specific health practitioners are not referred to in this Strategy.

\section{Health Workforce Development: An Overview}

The document Health Workforce Development: An Overview (MoH, 2006b) provides an overview of workforce development since 2000 and was a resource for those involved in health workforce development to help with understanding existing issues and ways of 
managing workforce development. This report is based on priorities identified from the Future Workforce 2005 - 2010, and refers to earlier HWAC reports such as The New Zealand Health Workforce: a Stocktake of Issues and Capacity 2001 and The New Zealand Health Workforce: Framing Future Directions 2003.

The first section of the report focuses on "setting the scene" (p. 18) of health services and the changes they face. Section two examined past and current approaches that are useful to enable the health workforce to meet the future changing needs of the NZ population. The final section of the report summarises existing and proposed "national and workforce development activity" (p. 33) using an example from the mental health workforce development model.

\section{Report of the Safe Staffing/Healthy Workplaces Committee of Inquiry}

The document Report of the Safe Staffing/Healthy Workplaces Committee of Enquiry (Safe Staffing Healthy Workplaces Unit, 2006) was released following a committee of enquiry held following "national negotiations" for a Multi-Employer Collective Agreement between NZNO and the DHBs (p. 7). This report makes recommendations for safe staffing and healthy workplaces and addresses issues from NZNO members in relation to safe staffing and workplaces.

The Safe Staffing/Healthy Workplace Committee reported on seven elements of safe/staffing and healthy workplaces. The elements were; i) The requirement for nursing and midwifery; ii) The cultural environment; iii) Creating and sustaining quality and safety; iv) Authority and leadership in nursing and midwifery; v) Acquiring and using knowledge and skills; vi) The wider team; and vii) The physical environment, technology, equipment and work design. The fifth element acquiring and using knowledge and skills, reported that internal and external education, which includes tertiary education, was vital in "advancing practice and the overall body of nursing and midwifery" (p. 41). Other significant points in the fifth element were: nurses and midwives need protected time to be able to gain knowledge and skills and should be supported in this; greater opportunities and efforts need to be made in the workplace for gaining knowledge and skills; health and education providers need to collaborate to ensure practice drives education; and competencies need to be developed between managers and their teams to enable good team functioning and more flexible ways of working. 


\section{Nursing Workforce Strategy}

The Nursing Workforce Strategy (DHBNZ, 2006) discussion document was completed by the Nursing and Midwifery Strategy Group, one of the six groups formed as part of DHBNZs Future Workforce 2005-2010 strategic workforce plan. The Nursing and Midwifery Strategy Group was composed of members from DHBs with support from DHBNZs and external advisors. The purpose of the Strategy was to bring together an overview of both previous and current sector work on the nursing workforce as a foundation for action, and to report priorities for action. A draft discussion document was initially sent out for feedback to the education sector, DHBs, non-government organisations, professional groups and individuals. The released document incorporated changes as a result of the feedback which was then sent to the DHBs' National Chief Executives group for final recommendations.

This strategy discusses current and future nursing workforce matters. Issues of note in 2006 were: i) the ageing population and the need for increased care for those 65 years and over; ii) the demand that will be placed on primary health care following the goal, ageing in place, by the Ministry of Social Developments Positive Ageing Strategy in 2001; iii) the need to increase the 2004 small number of nurses working in aged care (13.6\%) and in primary health $(6.7 \%)$ to meet future demand; iv) the ethnic makeup of the nursing workforce needs to be more reflective of the population and communities; v) the health and education sectors need a more coordinated approach; and vi) the importance for nurses to have access to continuing training and education.

Of note specifically with regard to post registration / postgraduate programmes, nurses were able to access programmes. However, the access was unequal across various service areas and amongst individual nurses. In addition to clinically focused progammes, nurses also needed access to programmes in management, leadership, nursing education and research programmes. There was also demand for more interdisciplinary education and recognition of prior learning. The expertise of nurses needs to be recognised by education programmes in order to avoid them having to complete another qualification if their area of practice changes. Finally, the Strategy reported the need for improved alignment of nursing education priorities to the needs of the population.

In discussing the future of the nursing workforce, the Strategy noted that it is likely there will be new and expanded competencies for RNs in the future to enable RNs to meet the increased complex needs of patients. Competencies identified included: cultural, relationship management and leadership, expanded assessment skills, interdisciplinary 
practice and team work, working in partnership with patients, and the management of ethical issues, research and quality. One significant point made by the Nursing and Midwifery Strategic Group, with regard to education and the nursing workforce, was in order to improve development and promotion of retention in the nursing workforce, postgraduate programmes need to be "more comprehensive and health service responsive" (p. 31).

Four recommendations were made for priority action from the Nursing and Midwifery Strategy Group. These are; i) To develop the nursing workforce in primary health, rural and community based services; ii) To support development and retention of the nursing workforce; iii) To increase the ethnic diversity of the nursing workforce; and iv) To progress development of a coordinated sector wide nursing workforce strategy (DHBNZ, 2006, p. 33). There were no specific recommendations for developing the aged care nursing workforce.

\section{Future Workforce Our Health Workforce Today and the Future}

The document Future Workforce Our Health Workforce Today and the Future (DHBNZ, 2009) is a high level document that extends the earlier Future Workforce 2005-2015. This 2009 document adds to what has been achieved since 2005 and listed 10 overarching priorities (Table 15). The priorities and related actions were identified by sector networks for the short and long term. Some of the actions specifically refer to the nursing workforce, health of older people services and education. Three priority actions $(1,4$,and 10) are of interest here.

Priority action one concerns the development of new roles and responding to issues around health sector demands as well as numbers of health and disability practitioners within the workforce, has the intention to support, develop and expand new roles for health practitioners and includes the operating theatre workforce, Enrolled Nurses (ENs), NPs and Nurse Endoscopists. The fourth priority focuses on growing and developing the public health and primary health care (PHC) workforce including RNs in PHC and health of older people services and NPs. This action considers recruitment needs for RNs in PHC and health of older people as well as better support for new graduate nurses going into these areas.

The $10^{\text {th }}$ priority addresses education for the health and disability workforce. This includes i) forecasts of the number of graduates (medical and nursing) expected; ii) continuing to develop relationships with education providers locally, regionally and nationally; iii) 
encouraging the continued growth of a learning culture; and iv) ensuring postgraduate and on-going education for health practitioners. The document signalled the intention of strengthening the health and disability sectors input with the Clinical Training Agency regarding their priorities and strategic plans to increase alignment and provision of funding of postgraduate education.

\section{Table 15: Action priorities identified by sector networks}

\begin{tabular}{|c|c|}
\hline Priority & Action \\
\hline 1 & Identify and respond to whole sector workforce supply issues. \\
\hline 2 & $\begin{array}{l}\text { Value health and disability workforces by fostering supportive work } \\
\text { environments and positive cultures. }\end{array}$ \\
\hline 3 & $\begin{array}{l}\text { Support development of clinical leadership working in partnership for } \\
\text { improved retention, productivity, service quality and health outcomes. }\end{array}$ \\
\hline 4 & $\begin{array}{l}\text { Grow and develop the public health, primary health care, rural, and } \\
\text { community workforce including NGOs. }\end{array}$ \\
\hline 5 & Grow and develop Māori health and disability workforce. \\
\hline 6 & Grow and develop Pacific health and disability workforce. \\
\hline 7 & Grow and develop a sustainable care and support workforce. \\
\hline 8 & $\begin{array}{l}\text { Align the workforce, including developing new roles, to address population } \\
\text { health needs and service models (of prevention, early identification and } \\
\text { intervention). }\end{array}$ \\
\hline 9 & $\begin{array}{l}\text { Build a whole system unified approach to workforce development and } \\
\text { planning (including cross government activity). }\end{array}$ \\
\hline 10 & $\begin{array}{l}\text { Ensure health and disability service and workforce demand drives education } \\
\text { content and delivery. }\end{array}$ \\
\hline
\end{tabular}

Source: District Health Boards New Zealand, (2009). Future Workforce Our Health Workforce Today and the Future. Wellington: NZ Government.

\section{A Nurse Education and Training Board for New Zealand}

A Nurse Training Board in New Zealand (MoH, 2009), written by Len Cook for the Minister of Health, presents findings of an evaluation of the need for a Nurse Education and Training Board to oversee nursing training and education in NZ. In response to the document, the Minister of Health established a Committee on Strategic Oversight for Nursing Education. The review of nursing education and training was carried out involving consultation with nurse leaders, educators and others from the health service. The report made recommendations on the place of nurses in the health service, current education and 
training of nurses, the current and future demands on nurses, and leadership of the nurse education system. Postgraduate education and post-entry education for clinical nurse training were also addressed. The report identified postgraduate education issues including that senior nurse employment pathways were not reflective of their postgraduate qualification, and postgraduate qualifications would be better if they were linked to employment, roles or a financial reward system.

Cook recommended that the Minister of Health note; i) it would be considerably beneficial for nurse education training to develop a high level governance system; ii) there is a high commitment between nursing groups who were consulted on the need for an education and training board; and iii) there is a need for health professionals to collaborate more effectively in the oversight of the health workforce as a whole, in training and in the advancement of skills for providing treatment and care to New Zealanders.

\section{Workforce for the Care of Older People: Phase 1 Report}

The Workforce for the Care of Older People: Phase 1 Report (MoH, 2011a) was carried out by HWAC who at the time commissioned several service reviews for the purposes of informing future workforce development. This review of services for older people considered; the needs of older people, the way services were currently provided, how future services could be different, and what needs to change for the future, especially in relation to workforce development.

The review was carried out using model scenarios, i) prevention and restorative care; ii) leveraging the current workforce; and iii) designing services to meet the needs of older people. The review included five recommendations. The first was, there needed to be an increased focus on prevention and rehabilitation service choices for older people with the likelihood of older persons' independence being maximised using short term interventions. Secondly more work was needed to support formal and informal caregivers. It was also recommended that caregivers receive specific training and development as well as career paths. Thirdly it was recommended that clinical specialists whose role is in the needs of older people are recognised as an important resource. These clinical specialists, who include nurses, were noted to provide advanced knowledge and skills to other health and support workers in PHC and the community. The fourth recommendation was for acute care to be better prepared to meet the needs of the older person in service and facility design. The final recommendation concerned the need for improved integrated care for the older person. 


\section{Evaluation of the Nurse Practitioner in Aged Care}

The Evaluation of the Nurse Practitioner in Aged Care (MoH, 2013) provides results from an evaluation of a project on a Nurse Practitioner: Older Adult, who worked in aged residential care facilities in a district of New Zealand as part of a project. The project was sponsored by MidCentral DHB and Central PHO and involved three residential care facilities. The impetus for this project was from the strategic initiatives of two residential care organisations wanting to address the health of older people in aged residential care. These residential facilities simply wanted to change the model of care so older persons would have improved access and quality of care, timely and seamless access to health and social services, and clinical leadership and front line support to nurses and health care staff. The introduction of the NP Older Adult was one way of addressing those changes. Health Workforce New Zealand funded an evaluation of the pilot to determine the impact the NP had on the three residential facilities.Findings from the evaluation were positive (Table 16) and from this, several re commendations were made.

Table 16: Findings from evaluation of Nurse Practitioner role in aged residential care

Increased timely access to primary healthcare services.

Decreased fragmentation across primary and secondary services through a care coordination approach.

Decreased presentations to the emergency department and reduced hospital admissions.

Reduction in polypharmacy.

Highly collaborative care between Nurse Practitioner, General Practitioners and hospital specialists and aged care staff.

Advanced clinical nursing leadership that increased staff confidence and decreased anxiety.

Positive impact on the recruitment and retention of General Practitioners, who noted they were more attracted to working in the sector knowing they had the clinical support provided by the Nurse Practitioner role.

Source: Ministry of Health (2013, p. 8).Evaluation of Nurse Practitioner in Aged Care. Wellington, NZ Government.

Recommendations of note were; i) that the model of care with the NP be on-going; ii) strategies be developed to share this innovation via the MoH, HWNZ and Regional Training Hubs; iii) that prospective models of care for delivering PHC services to aged residential care facilities be scoped; and iv) "the improved workforce knowledge and move 
towards aged care settings as learning organisations through NP led practice development, is significant and should incorporate the interdisciplinary team to maximise resources and ensure sustainability" (p. 8).

\section{Update of the New Zealand Health Strategy: All New Zealanders Live Well, Stay Well, Get Well Consultation Draft}

The document Update of the New Zealand Health Strategy: All New Zealanders Live Well, Stay Well, Get Well Consultation Draft (MoH, 2015c) was released for consultation with analysis and feedback expected in 2015. Analysis and feedback from the consultation will be released mid 2016 (MoH, 2015). This is the first time the strategy has been updated since the original New Zealand Health Strategy was released in 2000. Issues to be addressed include, the population has continued to age and future needs will require more care and support; current services for some families are not as accessible as they should be and there is an increase in demand for the social needs of the most vulnerable. The consultation strategy is in two parts, future directions and a roadmap of actions. There is no specific reference to older persons, nursing workforce development or further education within the future themes or actions. Of note though, is action four of the roadmap which states "Remove legislative barriers to allow health practitioners, such as pharmacists and nurses, to prescribe under limited circumstances" (p. 36).

\section{Service Specification Nursing Entry to Practice}

Service Specification Nursing Entry to Practice (MoH, 2014c) describes the requirements of the Nursing Entry to Practice (NETP) Programme. It also provides criteria for Aged Residential Care (ARC) NETP. NETP is a partially funded programme by the $\mathrm{MoH}$ specifically for RNs in their first year of practice following successful completion of their Bachelor of Nursing and passing NCNZ state finals. The Nursing Entry to Specialty Programme (NESP) is also a partially funded programme and is specifically for nurses working in mental health and addiction. This NESP programme receives funding from Te Pou. The purpose of NETP and NESP Programmes is to provide a safe and supportive year for graduate RNs assisting them through their transition from a novice competent nurse to a more skilled, safe and competent $\mathrm{RN}$, and to increase recruitment and retention numbers of RNs. All NESP nurses complete a postgraduate certificate, however each individual DHB decides on the educational component for NETP nurses. This component can be a postgraduate paper undertaken through a university or a polytechnic, or a DHB designed educational component ( $\mathrm{MOH}, 2014 \mathrm{c})$. 
In 2009, as a way of encouraging graduate nurses, midwives and doctors to work in hard to staff communities and specialties, HWNZ released the Voluntary Bonding Scheme $(\mathrm{MoH}$, 2014b). Health practitioners who joined this scheme are paid a higher annual salary, which can go towards repaying their student loan or to top up their take home income for up to five years. Aged residential care is considered a hard to staff area.

\section{Aged Residential Care Nurse Entry to Practice (ARC NETP) Evaluation Report}

The document Aged Residential Care Nurse Entry to Practice (ARC NETP) Evaluation Report (MoH, 2015a) provides results from a programme pilot commissioned by the Office of the Chief Nurse, MoH. The pilot involved an Aged Residential Care (ARC) NETP programme for 15 graduate nurses working in 11 ARC facilities. Additional funding was attached to this programme to increase and improve support for those nurse graduates. The evaluation, conducted by Howard-Brown and McKinley (2014) included seven recommendations. Recommendations of note were; i) to improve how pilots are developed and implemented, as there had been a lack of clarity in the implementation of the Aged Residential Care pilot; ii) to promote ARC as a career option to improve the recruitment process for ARC; and iii) to strengthen preceptoring in ARC. Of importance to this research was a final consideration from the evaluation on whether or not it was cost beneficial to include a postgraduate paper in the NETP Programme taking into account the stress experienced by graduate nurses in taking on postgraduate study (MoH, 2014). Since the evaluation, ARC NETP-programmes have been introduced for all 20 DHBs.

Between 2013 and 2014 the MoH introduced one off additional funding for high need PHC practices who employed new graduate nurses on the NETP programme. The scheme was known as Very Low Cost Access (VLCA) Practice Sustainability. This was introduced because particular practices were known to have a high proportion of people with complex needs as well as infrastructure and resource issues. The funding of \$2.4 million dollars for 48 graduate nurse positions nationally, was to pay for the graduate nurses salaries for the 12 months of the NETP Programme. The additional funding was only available to those practices which qualified having a high proportion of high needs clients ( $\mathrm{MoH}, 2015)$. An evaluation carried out in 2015 showed there were positive results from the VLCA funding in all areas of sustainability issues. There were also positive results for the graduate nurses around employment retention and they were well supported in their learning and practice throughout the 12 months of the NETP Programme. 


\section{Postgraduate Nursing Training Specification}

The Postgraduate Nursing Training specification (MoH, 2011b) describes the criteria for postgraduate nursing funding for New Zealand DHBs. Postgraduate nursing funding is allocated to all 20 DHBs for nurses to undertake postgraduate education. Funding was originally provided for nurses working in hospital based services However, this has since changed and there are now four funding streams based on geographical or clinical area of work. These include RNs working in hospitals, aged care, PHC and rural areas. The funding pays for course fees and clinical release time so nurses can be released from their clinical area to attend study days. It also pays for travel and accommodation, clinical mentoring, professional supervision and Maori and Pacific cultural support.

\section{Summary}

Since the release of the New Zealand Health Strategy in 2000 many policy and workforce documents have been released from the government. These documents have become more specific over time about nursing workforce development. Yet, it has taken over 15 years to put these strategies into action. A strong theme running through the documents is the need for a more strategic approach to developing the health and disability workforce to further meet the demands of the current and future aging population in NZ. For nursing this means advancing and expanding nursing roles, such as Nurse Specialists and NPs with prescribing rights. This is especially relevant in PHC due to one of the priorities in the Positive Ageing Strategy, "ageing in place", which refers to older persons ageing in their homes for as long as possible rather than going into residential care. There will also be more pressure and demands placed on nurses caring for older persons in aged residential care as people live longer.

Another theme running through many of the documents is that the education and health sector need to be collaborative and work together to be more effective in meeting the workforce's needs. Education and training is important and needed for the health workforce as a whole including nursing. This encompasses undergraduate and postgraduate education. This is important for nursing, as nurses will need to be trained and educated to provide more advanced care, expand their roles, and to increase the number of NPs in PHC and aged residential care. This ends the document review on the group of 22 clustered documents on government policy perspectives. 


\section{Professional Body Perspectives 2000 to 2015}

The second group of 17 clustered documents from three professional bodies - NCNZ, the College of Nurses Aotearoa New Zealand, and NZNO. The documents, which vary in focus, are set out in a historical timeline (Table 17). Eight documents were on the nursing workforce, four on nursing education and two concerned NPs. There was one annual report, one document on aged care, and one concerning a membership group.

Table 17: Historical timeline of professional body documents 2000 - 2015

\begin{tabular}{|c|c|c|}
\hline Year & Document & Focus \\
\hline 2000 & $\begin{array}{l}\text { New Zealand Registered Nurses, Midwives and Enrolled } \\
\text { Nurses Workforce Statistics }\end{array}$ & Nursing Workforce \\
\hline 2006 & $\begin{array}{l}\text { National Gerontology: Section of New Zealand Nurses } \\
\text { Organisation Strategic Plan 2006-2011 }\end{array}$ & Aged Care \\
\hline 2008 & $\begin{array}{l}\text { Education Survey Report: Implications for Practice (New } \\
\text { Zealand Nurses Organisation) }\end{array}$ & Nursing Education \\
\hline 2010 & $\begin{array}{l}\text { The Future Nursing Workforce: Supply Projections 2010- } \\
2035\end{array}$ & Nursing Workforce \\
\hline 2010 & Clarifying Nursing Education Funding Issues & Nursing Education \\
\hline 2010 & $\begin{array}{l}\text { Education Programme Standards for the Registered Nurse } \\
\text { Scope of Practice }\end{array}$ & $\begin{array}{l}\text { Registered Nurse / } \\
\text { Education }\end{array}$ \\
\hline 2011 & Employment Survey (New Zealand Nurses Organisation) & Nursing Workforce \\
\hline 2012 & The New Zealand Nursing Workforce 2012-2013 & Nursing Workforce \\
\hline 2012 & $\begin{array}{l}\text { Competencies for the Nurse Practitioner Scope of } \\
\text { Practice }\end{array}$ & Nurse Practitioner \\
\hline 2013 & Employment Survey (New Zealand Nurses Organisation) & Nursing Workforce \\
\hline 2013 & $\begin{array}{l}\text { The Future Nursing Workforce: Supply Projections 2010- } \\
2035 \text { (Nursing Council New Zealand) }\end{array}$ & Nursing Workforce \\
\hline 2013 & College of Nurses Aotearoa Strategic Plan 2013-2016 & Nursing Group \\
\hline 2013 & $\begin{array}{l}\text { Education Policy Framework (New Zealand Nurses } \\
\text { Organisation) }\end{array}$ & Nursing Education \\
\hline 2013 & $\begin{array}{l}\text { Consultation on the Scope of Practice \& Qualifications } \\
\text { Prescribed for Nurse Practitioners }\end{array}$ & Nurse Practitioner \\
\hline 2014 & Annual Report (Nursing Council of New Zealand) & Annual Report \\
\hline 2015 & $\begin{array}{l}\text { The New Zealand Nursing Workforce: A profile of } \\
\text { Nurse Practitioners, Registered Nurses and Enrolled } \\
\text { Nurses } 2014-2015\end{array}$ & Nursing Workforce \\
\hline 2015 & Employment Survey (New Zealand Nurses Organisation) & Nursing Workforce \\
\hline
\end{tabular}




\section{New Zealand Registered Nurses and Midwives Workforce Statistics}

The New Zealand Registered Nurses, Midwives and Enrolled Nurses Workforce Statistics, (NCNZ, 2000) covers the period 1998 - 1999. The purpose of this report was to inform the health sector and aid policy development concerning the future of the nursing and midwifery workforce. Data collected on RNs and Midwives are difficult to separate, due to the way data from Annual Practicing Certificates were collected.

Nursing and midwifery workforce data at this time consisted of a total of 31,869 RNs and Midwives. There were 843 RNs/Midwives per 100,000 populations. At this time in NZ, pressures impacting on the nursing workforce included people living longer and their health needs becoming more complex as they age, an increase in mental illness, increase in diabetes and some cancers and infectious diseases. Other pressures on the nursing workforce included: an increased demand for more Māori nurses and an increase in demand for the unregulated workforce. In 1999 some designated nurses had been given extended prescribing rights through the Medicines Amendment Act 1999. This was initially limited to two scopes of practise, aged care and child/family health. The number of RNs employed in continuing care was 3,718, whereas the number of RNs employed in rest homes was 2,153.

In 1998 the average age of the RN/Midwife was 42.6 years. There were higher numbers of those aged 35 years or under employed in a hospital or in nursing agencies, whereas those aged 50 years or over were more inclined to be employed in rest homes or in hospital community services. Of the 2153 RNs employed in rest homes, 317 (14.7\%) were aged 50 to 54 years, and $302(14.2 \%)$ were aged 55 to 59 years.

Ethnicities of all RNs Nurses/Midwives in 1998 were composed of: European/Pākeha 25,786 (80.9\%), Māori 955 (3\%), Pacific people 618 (1.9\%), and other European 2903 (9.1 $\%)$. Those with other ethnicity not accounted for on the list were 1375 (4.3\%) and those not reported $232(0.7 \%)$. The number of nurses immigrating to NZ increased from 290 in 1994 to 1400 in 1998. In 1998, ethnicities of RNs employed in rest homes were: NZ European 1,706 (79.2\%), NZ Maori 56 (2.6\%), other European 150 (6.9\%), Pacific 22 (1\%), and other $158(7.3 \%)$ with not stated at 12 (0.5\%). In 1998, statistics on the RNs /Midwifes country of registration was referred to as country of graduation with: NZ 26,778 and overseas 5,091.

Although a postgraduate educational framework, guidelines and competencies had been developed by NCNZ in 1999 to assess, approve and monitor nursing practise programmes 
(from beginning practitioner to advanced nursing practice), there was no data provided in the report on the numbers of RNs with a postgraduate qualification.

\section{National Gerontology Section of New Zealand Nurses Organisation Strategic Plan 2006-2011}

The National Gerontology Section of the New Zealand Nurses Organisation 2006-2011, (National Gerontology Section NZNO, 2006) provided the goals and aspirations of the National Gerontology Section, a strategic plan to 2011, and a business and action plan from 2005 to 2007 . Throughout this document continuing education and professional development for members of the National Gerontology Section are addressed. One aim of the Section is to "Encourage, promote and provide the development of educational programmes / seminars for gerontology nurses and those interested in the care of older people" (p. 5). Although the above aim does not specify if the education is postgraduate, it is clear within the strategic plan that tertiary education is included, as the plan refers to developing relationships with tertiary education providers as a way of promoting gerontology as being a significant and worthwhile nursing specialty.

\section{New Zealand Nurses Organisation Education Survey Report: Implications for Practice 2008}

The New Zealand Nurses Organisation Education Survey Report (Brinkman, Wilson-Salt $\&$ Walker, 2008) published findings of a survey undertaken to explore issues surrounding attaining professional development hours for RNs to maintain their competencies, and to then be in a position to put improved systems in place. Of the 1650 surveys sent to a random sample of registered and enrolled nurses who were NZNO members, 720 (43.6\%) responded. Completion of the survey was voluntary and respondents were not identifiable. Of the 720 respondents, $47(6.5 \%)$ had a postgraduate qualification. The main findings from the survey were: i) percentages of professional development for workplace options were more popular than nursing tertiary education options, for example approximately $94 \%$ chose in-service education, and $20 \%$ chose to do a postgraduate certificate, ii) $54 \%$ of the respondents described having conflict with time and other commitments, iii) $18.6 \%$ of respondents reported a need for work life balance, and iv) taking time off work, the cost of fees, travelling distance and time were described as obstacles to professional development.

Findings also showed a proportion of respondents referred to being insufficiently prepared for specific areas of their role as a $\mathrm{RN}$ during their pre and post nursing education. Other areas identified were conflict resolution, information technology, managing challenging 
behaviour, and coping with rostered and rotating shift work. How health political processes and systems functioned were also identified by the respondents as not being adequately covered in their pre-registration nursing education. The survey also found interest in professional development increased by age of respondents with approximately $42 \%$ in the 50-54 age group with plans for future study, this increased to approximately $48 \%$ in the 55 59 age group. Of those in the 60-64 age group, approximately 52\% had plans for study, with the 65 and over age group at approximately 55\% compared to the 25-29 age group at approximately $37 \%$.

\section{The Future Nursing Workforce: Supply Projections 2010-2035}

The Future Nursing Workforce: Supply Projections 2010-2035 (NCNZ, 2013) presented nursing workforce projections based on information about the 2010 nursing workforce to inform and provide tools for nursing workforce decision makers. The NCNZ commissioned Business and Economic Research Limited to carry out the projections, using economic modelling. They developed four possible 'what if 'scenarios to demonstrate how decisions made about workforce supply could influence the future nursing workforce. The focus of the scenarios (Table 18) are: i) population growth; ii) the ageing population; iii) to increase international nurses; and iv) to decrease the number of NZ nursing graduates. In relation to the aged care workforce, apart from scenario one and two, there is no specific reference to aged care. However, from reading the results of scenario three and four, it is likely possible that there would be an effect on aged care. For example in scenario three in which the number of international nurses are increased, it is likely there would be a rise in international nurses employed into aged care.

The outcome of the modelled scenarios show the need for a strategy with well-defined priorities in order to grow and enable the nursing workforce to act in response to the changing needs in the health of the NZ population. 


\section{Table 18: Scenario results and possible effect on aged care Registered Nurse}

workforce

\begin{tabular}{|c|c|c|}
\hline Scenario & Actual Scenario & Possible Effect in Aged Care \\
\hline $\begin{array}{l}\text { Population } \\
\text { Growth }\end{array}$ & $\begin{array}{l}\text { Grow the supply of nurses to meet } \\
\text { population growth }\end{array}$ & $\begin{array}{l}\text { The greatest demand for ENs } \\
\text { working in rest home residential } \\
\text { care would between } 2025 \text { and } \\
2030\end{array}$ \\
\hline $\begin{array}{l}\text { Ageing } \\
\text { population }\end{array}$ & $\begin{array}{l}\text { Increase number of graduate nurses to } \\
\text { meet population health needs. Between } \\
2015 \text { and } 2020 \text { increasing numbers by } \\
2.5 \% \text { per annum, then, to } 3 \% \text { per annum } \\
\text { between } 2020 \text { and } 2025 \text {. With a further } \\
3.5 \% \text { per annum between } 2025 \text { and } \\
2030 \text { and again between } 2030 \text { and } 2035 \text {. }\end{array}$ & $\begin{array}{l}\text { Registered Nurses (RN) } \\
2010=3,090 \text { RN (approx.) } \\
2035=8,000 \text { RN } \\
\text { Highest increase in RNs being } \\
\text { employed into aged care will be } \\
\text { between } 2020 \text { and } 2025 .\end{array}$ \\
\hline $\begin{array}{l}\text { Increase } \\
\text { international } \\
\text { nurses }\end{array}$ & $\begin{array}{l}\text { The number of graduate nurses overall } \\
\text { stays the same. } \\
\text { In } 2020 \text {, number of graduate nurses is } \\
1,580 \text {. } \\
\text { There is a labour constraint by } 2020 \text { due } \\
\text { to the growing population. This } \\
\text { constraint is met by growing numbers of } \\
\text { internationally qualified nurses from: } \\
2010=25 \% \text { RN workforce } \\
2035=33 \% \text { RN workforce }\end{array}$ & $\begin{array}{l}\text { There is no specific mention of } \\
\text { the possible effects on aged care } \\
\text { RN workforce under the results of } \\
\text { this scenario. }\end{array}$ \\
\hline $\begin{array}{l}\text { Decrease } \\
\text { number of New } \\
\text { Zealand nurse } \\
\text { graduates }\end{array}$ & $\begin{array}{l}2014-2019 \text { enrolments in Bachelor of } \\
\text { Nursing programmes remain unchanged. } \\
2020-2029 \text { enrolments in NZ schools } \\
\text { of nursing decline by } 0.25 \% \text { per annum. } \\
2030-2035 \text { continue to decline. } \\
\text { Number of nurses graduating declines } \\
\text { by } 0.5 \% \text { per annum on average. }\end{array}$ & $\begin{array}{l}\text { There is no specific mention of } \\
\text { the effect on RN and EN aged } \\
\text { care workforce under this } \\
\text { scenario. }\end{array}$ \\
\hline
\end{tabular}

\section{Clarifying Nursing Education Funding Issues}

Clarifying Nursing Education Funding Issues (NZNO, 2010), by Anne Brinkman, provides a background on funded nursing education from 1993 to 2010. It captures how post registration nursing education had been established and funded over the 17 year period by the Clinical Training Agency, then Health Workforce New Zealand. The aims of the document were to improve collaboration between nursing practice and education through providing an historical viewpoint, information on the current setting, and recommending guiding principles.

The changes in nursing funding over time for postgraduate education were in areas such as rural and primary health, mental health, the introduction of the NETP programmes, and supporting the development of postgraduate papers towards Masters and NPs. There were 
no specific references in this document about aged care other than to outline what was expected to be gained through aged care nurses completing a postgraduate certificate in 1996 to1997. Nurses in aged care completing a postgraduate certificate at that time were expected to develop their knowledge in areas such as; decision making, team leadership, collegial support, professional judgement, research, ward management and innovative practice.

The amount of funding provided by the Clinical Training Agency had increased over time, although the majority of funding was allocated to medicine. As an example, in 2007/2008, of the total Clinical Training Agency budget, funding allocated to nursing was $\$ 11,100,498$ $(9.86 \%)$ whereas for medicine (vocational and non-vocational).The allocation was $\$ 78,243,109(69.5 \%)$.

To provide some direction for successful future nursing education, the NZNO proposed a framework of seven guiding principles. The principles were that educational funding needs to be: i) appropriate, and founded on the health needs of the population (national, regional and local) and on what nurses need to learn to enable the provision of confident and competent nursing care; ii) acceptable, and culturally appropriate so nurses can provide culturally acceptable care. As well as being culturally appropriate, nurses need to develop political competence so they can be better advocates for their patients; iii) affordable, to make best use of limited education and health funding and needs to be managed more efficiently on a national basis; iv) accessible, with less rigidity and better resources to enable nurses to have easier access; v) relevant and flexible so education is appropriate to the changing health needs of the population; vi) supported, so as nurses can be released from the workplace to enable increased learning opportunities; and vii) evaluated, to determine if learning outcomes have been achieved.

\section{Education Programme Standards for the Registered Nurse Scope of Practice}

The Education Programme Standards for the Registered Nurse Scope of Practice (NCNZ, 2010) outlines educational programme standards for the RN scope of practice. These are the seven standards by which tertiary education providers, who run undergraduate nursing programmes must follow to ensure nursing students complete a NCNZ approved programme to gain their registration (NCNZ, 2010). Content of the curriculum is covered in Standard Two and maintains that the curriculum must be based on national health priorities. This suggests that if the standards are adopted, and aged care becomes more of a national health priority, then it will hold more significance within the nursing curriculum. Standard Two also covers clinical experience and maintains clinical experience be held in 
a variety of settings, one of which includes aged residential care. Although only undergraduate education is covered in this document, undergraduate education is a prerequisite to postgraduate education. Undergraduate education also relates to nursing workforce development and aged care.

\section{New Zealand Nurses Organisation Education Policy Framework}

The New Zealand Nurses Organisation Education Policy Framework (NZNO, 2011) outlines NZNO's policies, rationales and recommendations on nursing education. The seven principles, outlined by Brinkman in the document Clarifying Nursing Funding Issues (NZNO, 2010), are utilised in this document. The policy covers post-registration as well as postgraduate nursing education. The NZNO made recommended actions (Table 19) for postgraduate education from this policy.

\section{Table 19: NZNO recommended actions for postgraduate education}

\section{Recommended Actions}

\begin{tabular}{|c|c|}
\hline $\begin{array}{l}\text { New Zealand } \\
\text { Nurses } \\
\text { Organisation }\end{array}$ & $\begin{array}{l}\text { In its policy documents, media statements and other work, } \\
\text { promotes the importance of ensuring postgraduate education } \\
\text { for nurses. } \\
\text { Articulates support for clear workforce data collection and } \\
\text { analysis by the MoH and the provision of appropriate, } \\
\text { accessible and equitable funding for postgraduate education. }\end{array}$ \\
\hline $\begin{array}{l}\text { Education } \\
\text { Providers }\end{array}$ & $\begin{array}{l}\text { Work with clinical providers to facilitate robust research } \\
\text { into NETP and NESP outcomes, in particular inclusion of } \\
\text { postgraduate courses during the programme. } \\
\text { Promote sound, supported career planning for/with new } \\
\text { graduates and other nurses. }\end{array}$ \\
\hline Clinical Providers & $\begin{array}{l}\text { - Work in collaboration with the NCNZ and clinical providers } \\
\text { to ensure NETP education provision meets the new graduate } \\
\text { students and consumers. } \\
\text { - Promote sound, supported career planning for/with new } \\
\text { graduates and other nurses }\end{array}$ \\
\hline $\begin{array}{l}\text { Ministry of } \\
\text { Health }\end{array}$ & $\begin{array}{l}\text { Continues to provide funding for postgraduate nursing } \\
\text { education and work toward ensuring this provision is } \\
\text { equitable. } \\
\text { - Provide funding for identified postgraduate studies in } \\
\text { specialties where there is no education programme in new } \\
\text { Zealand } \\
\text { - Provide funding for appropriate interdisciplinary } \\
\text { postgraduate programmes. }\end{array}$ \\
\hline
\end{tabular}

Source: New Zealand Nurses Organisation (2011). The New Zealand Nurses Organisation Policy Framework (p.19). Wellington, NZ.

Of note in the section on postgraduate education, the NZNO affirm they do not support postgraduate education as being a requirement of the NETP programme for RNs and 
recommends clinical providers research the outcomes of NETP and NESP with regard to the postgraduate education component. The NZNO supports the $\mathrm{MoH}$ postgraduate education nursing funding for developing nurses to take up roles in advanced and specialist clinical nursing positions, in leadership, management, research and education. It also supports funding from the $\mathrm{MoH}$ for postgraduate programmes not provided in $\mathrm{NZ}$ for nurses in specialty areas such as infection control.

Overall the NZNO supports postgraduate education and funding from the MoH. However, of note, the section on postgraduate study does not address specific areas of nursing such as older persons. Although, in the section on curricula content, the NZNO does affirm their belief in curricula needing to be focused on the future with "growing emphasis on primary health care, age related care and long-term conditions' management in the community" (p. 14).

\section{New Zealand Nurses Organisation Employment Survey 2013}

The New Zealand Nurses Organisation Employment Survey 2013 (NZNO, 2013) reports on specific and broad themes, and areas of relevance for those involved in planning for the nursing workforce. This includes managers, policy makers and the NZNO. Using a webbased survey, this was the third biannual such survey undertaken by the NZNO; the previous surveys were conducted in 2009 and 2011. In addition to the questions used in the previous two surveys, new questions were added concerning health and safety, changes in employment law and care capacity management. From a random sample, a total of 4571 survey requests were emailed resulting in a 1448 (32\%) return rate, the respondents included RNs, ENs, NPs and midwives. Of the 1448 responses, 110 (8\%) nurses identified they were employed in continuing care/residential care. There is no breakdown separating the number of RNs and the number of ENs. Questions asked about nursing workforce development generally on the following subjects: i) respondent profiles; ii) pay and employment agreements; iii) working patterns; iv) workload and staffing; v) job change and career progression; vi) organisational change and restructuring; vii) continuing professional development; viii) health and occupational health and safety; and ix) morale. The results which made particular reference to aged care, were on working patterns and workload and staffing,

Results from questions on workload and staffing, showed less than $50 \%$ of respondents thought they were sufficiently staffed to meet patients' needs, with those working in aged care more likely to report to their employer that there were insufficient nursing staff on shift to provide safe care. From the survey results for aged care, 26 respondents identified 
this would happen several times a week, with 14 reporting every shift. Results from questions on working patterns compared percentages of hours worked by those employed by a DHB and those employed in aged care. Of note, the numbers of respondents working more than 38 hours a week in aged care, was significantly higher than those working in a DHB by approximately 10 percent. However, the number of DHB staff working 25 to 32 hours a week was higher by one to two shifts a week, or approximately seven percent. It was also identified that the number of nurses working in aged care over the age of 65 had increased, but it was not stated in the report how much of an increase this was.

Overall, results from questions on continuing professional development revealed over half of the regulated nursing workforce were well qualified and had a postgraduate qualification. The biggest barriers to respondents completing professional development were problems attending courses during work time (approximately 34\%), the cost of fees (approximately 32\%), and commitments (approximately 28\%). These results were not broken down into areas of employment. One of the recommendations to come from the results covered workload, stress, and the lack of job satisfaction. It was recommended support and leave for professional development, safer staffing levels, and improved shift rostering be guaranteed.

\section{The New Zealand Nursing Workforce 2012-2013}

The New Zealand Nursing Workforce 2012 -2013 (NCNZ, 2013) is a biennial report on the profile of the NZ, nursing workforce. The Nursing Council had released similar reports, in 2000, 2002, 2010 and 2011. The purpose of this report was to provide current and reliable data for development of policy, planning and research. Data for the report comes from the information NPs, RNs and ENs provide annually when renewing their annual practicing certificates.

The report showed that at the end of March 2013 there were a total of 47,751 nurses practicing in NZ. Of those, 45,313 were providing direct services to the public, with $46 \%$ of the workforce aged 50 years or over, indicating the nursing workforce is aging. Ethnic groups showed nurses identifying as NZ European were the highest at 67\%, NZ Māori at seven percent and Pacific Peoples at three percent. There were 107 practising NPs, and 44,782 practising RNs. The NPs workforce had an increase of 12, from 89 in 2011. Of the 107 NPs, there were 100 female and 7 male. Most NPs worked in DHB acute settings (38), the next highest were in PHC/community settings (37) followed by DHB community setting (29). Only two NPs worked in rest home/residential care. 
The RN workforce consisted of 44,782, an increase of 496 nurses since the 2011 report. A total of 18,630 RNs were employed in acute settings at DHBs, with 4,516 employed in community settings at DHBs and 3,500 employed in other areas of DHBs. A total of 6,323 RNs are employed in PHC/community settings and 4,259 in rest home/ residential care. The ethnic breakdown for rest home/residential care showed 2,224 identified as NZ European, 458 as other European, 228 as NZ Māori, six as Cook Island Māori, and 178 identified as Pacific Peoples (includes Samoan, Tongan, Niuean, Fijian, Tokelauan and other Pacific). The highest number of nurses other than NZ European, where those who identified as Filipino at 742.

It was reported $44 \%$ of the $\mathrm{RN}$ workforce had a postgraduate qualification. In reporting statistics for RN and postgraduate education, the document refers to postgraduate qualifications only by practice setting, as opposed to employment setting, such as rest home/residential care. For this reason, it is hard to determine the actual numbers of RNs working in rest home/residential care as they were merged into continuing care elderly. The number of RNs working in continuing care/elderly with a postgraduate qualification is reported as $26.2 \%$ (which is low in comparison to other practice settings), PHC (41.9\%), practice settings in DHBs such as surgical are at 29\%, theatre (33.8\%), medical $(30.4 \%)$, assessment and rehabilitation (36.2\%), district nursing (41.4\%), obstetrics/maternity $(52.4 \%)$, and mental health $(47.5 \%)$.

\section{Competencies for the Nurse Practitioner Scope of Practice}

The Competencies for the Nurse Practitioner Scope of Practice, (NCNZ, 2012) outlines the NP's scope of practice, required qualifications, domains of competence, competencies and indicators. A scope of practice for NPs was first established by NCNZ in 2003 (DHBNZ, 2006), and at the time this document was released, there was the option of the NP role with or without prescribing rights. The 2012 document was in response to HWAC (2001) and included two recommendations for workforce initiatives for nursing. The first was to develop regulations for NPs to prescribe, including in aged care. The document covered the qualifications and competencies for these "expert Nurses who work within a specific area of practice incorporating advanced knowledge and skills" (p. 2).

\section{The College of Nurses Aotearoa Strategic Plan 2013-2016}

The College of Nurses Aotearoa Strategic Plan 2013-2016 (College of Nurses Aotearoa, 2013 ) is a three year plan and direction to members of the College of Nurses Aotearoa. The purpose of the College is to provide a medium for nurses to enable them to critically 
review educational, professional and research matters relating to nurses and to the attainment of reasonable outcomes for health consumers. The document contains three strategic directions: i) to align nursing workforce development with community need; ii) influence policy/health leadership; and iii) develop a sustainable future. There are key objectives for each of the three strategies.

In relation to the strategy on workforce development, there are five objectives. None of which refer specifically to aged care. These objectives do refer to the support and workforce development of PHC nursing, NP development, supporting Maori nurses, identifying future leaders within the College of Aotearoa membership and externally; and removing barriers to maximise the use of the nursing workforce.

\section{Literature Review for the New Zealand Qualifications Review}

The Literature Review for the New Zealand Qualifications Review: Aged Care, Disability, Health and Social Services paper was commissioned by Careerforce in 2013. Careerforce are an industry training organisation for the health and community support sector in NZ. They work nationally with employers to develop qualifications recognised by the New Zealand Qualifications Authority (Careerforce, 2015). In 2013 the New Zealand Qualifications Authority carried out a review of qualifications aiming to lessen the number of level 1 to level 6 qualifications due to changes in the health, disability, aged support and social services sector and to ensure those qualifications would be more applicable to workers and employers in the future. The purpose of the document was to expand on previously identified topics and themes, one of which concerned the gaps in qualifications and pathways.

Although the focus of this paper is on the unregulated workforce, it is worth noting from the section in the document on aged care, NZ's aging population has a predicted increase in demand within the aged care workforce of 50\% to 75\% between 2015 and 2026 (these figures include caregivers, nurses, medical staff and therapists). Interestingly, attention was also drawn to two key factors. The first was the need for future managers of aged care facilities to have better skills and knowledge. The second factor was the need for career pathways to be developed within the aged care workforce. This suggests caregivers will have more responsibility and there will need to be an increase in caregivers completing qualifications. 


\section{Consultation on the Scope of Practice and Qualifications Prescribed for Nurse Practitioners: Analysis of Submissions}

The Consultation on the Scope of Practice and Qualifications prescribed for Nurse Practitioners: analysis of Submissions (NCNZ in 2014) released the findings of 30 submissions on an earlier consultation documentation concerning NPs. The submissions released were from government, professional, education and nine individual nurses. There were no identified submissions from older people services or aged residential care. However, some members of the Primary Health Reference Group within one DHB were from aged residential care and it could be inferred that the individual submission may have been from nurses working in aged residential care. It is significant to note there was only engagement from two tertiary education providers given there are seven providers delivering NP postgraduate education. The majority of those who submitted a response were in support of all the NCNZ's proposals. However, fewer (16 out of 28) agreed with non prescribing NPs having to complete the prescribing process within two years.

\section{Nursing Council New Zealand Annual Report 2014}

The Nursing Council of New Zealand Annual Report 2014 (NCNZ in 2014) reports on activities over 2013 and 2014. Of note was information provided in the report about the growing number of NP registrations since its introduction in 2002, of which there were 138 NPs with 129 practiscing at the time of the report. The report does not specifically provide information about numbers of NP's practising in aged care. The document also reports on the consultation of the NPs scope of practice which was done to align with changes made to the Medicines Amendment Act 2013. This will likely have an impact in the future on tertiary education providers in regard to numbers of nurses enrolling into prescribing practicum papers and the possibility of adjusting programmes for prescribing.

\section{The New Zealand Nursing Workforce: A Profile of Nurse Practitioners, Registered} Nurses and Enrolled Nurses 2014 - 2015

The New Zealand Nursing Workforce: A profile of Nurse Practitioners, Registered Nurses and Enrolled Nurses 2014 - 2015 (NCNZ, 2015) is the sixth report the Nursing Council have published outlining NZ's nursing workforce. The report presents statistics and information on NPs, RNs and ENs. The total nursing workforce at this time was 50,356 or 10,508 per 100,000 New Zealanders. Forty three percent of nurses were 50 years. The largest ethnic group is NZ European 67\%, with NZ Māori, Indian and Filipino each at seven percent and Pacific three percent. 
Of the NP workforce, there were 142 practising compared to 107 since the 2013 report, in showing an increase of 33 percent. This equates to three BPs per 100,000 New Zealanders. In comparison to all nurses, the mean age of NPs is 51.8 years, whereas for all nurses it is 45 years. There were six NPs working in aged care. Employment settings and ethnicities show, of the six NPs working in rest home/residential, one is NZ European, three are other European, one is Asian ethnicity and one identifies as other.

The RN workforce is made up of 47,488 nurses, this shows an increase of 2,706 RNs from the last report in 2013.The numbers of RNs equate to 104 per 10,000 New Zealanders. Employment settings of RNs showed there were 4,469 (9.4\%) working in rest home /residential care. Ethnicities of those RNs working in rest home/residential care, showed the largest group were NZ/Pākeha (2,123), followed by Filipino (906), Indian (618), other European (430), NZ Māori (234), Pacific (175) (Pacific included Samoan, Tongan, Nieuan, Tokoloan, Fijian, other Pacific) and Cook Island Māori (7). Of note, 40\% of Filipino RNs were employed in Acute settings in DHBs and (41\%) in rest home residential care.

The highest numbers with a post registration qualification were those practicing in the surgical setting with 5,542 (31\%) followed by the medical setting at 4,724 (33.6\%) and continuing care at 4,412 (26.3\%). Practice setting areas with the lowest post registration qualification numbers were youth health 203 (48\%), family planning / sexual health 208 (56.3\%), and intellectually disabled 214 (45.8\%).

\section{New Zealand Nurses Organisation Employment Survey 2015}

New Zealand Nurses Organisation Employment Survey 2015 (NZNO, 2015) reports results of the biennial survey collected from NZNO members via a web based application. The survey questions cover topics such as employment issues, demographic details, and perceptions of working life. The same questions were used as those in the 2013 survey with more in depth questions around employment law change, health and safety, and care capacity demand management. Of 5000 invitations to participate in the survey, 1175 (23.5\%) responses were returned, a decrease of nine percent since 2013 (NZNO, 2015). Of the 1175,86 (7.3\%) were from continuing care/elderly (as categorised by field of practice), a decrease of $0.7 \%$ since 2013 . Of note is that continuing care/elderly was the fourth highest in respondent numbers compared to primary health, 142 (12\%), medical, 99 (8.4\%) and surgical $90(7.6 \%)$. 
Survey results regarding education, qualifications and continued professional development showed $41 \%$ of nurses working in continuing care/elderly were not given paid release time for professional development, and 55\% had no fees paid for professional development, compared to $29 \%$ of RNs working in private surgical hospitals. Overall, the most common type of preferred professional development, was similar to 2013 with in-service education $(84.8 \%)$, short courses $(55.6 \%)$ and seminars $(49 \%)$. Postgraduate education as a

preference featured as; postgraduate certificate (12.5\%), postgraduate diploma (7.2\%), and masters (4.3\%). As actual percentages were not provided in 2013, and due to the nine percent decrease in respondents, it is difficult to compare 2015 preferred types of professional development with 2013 results. As occurred in 2013, there remain some older nurses who feel disadvantaged with funding applications due to their age, with no other information specifically provided to explain this. It also appears, of those nurses who have received funding, release time to attend study days has been decreased by their employer.

The most common barriers to professional development were difficulties attending in work time $(52 \%)$, followed by cost to self in fees $(44.2 \%)$, other time commitments $(39.1 \%)$ and difficulties taking time off work in own time to attend (35.9\%). Results around frequency of unsafe care in continuing care/elderly showed the numbers of those who reported unsafe care every shift was approximately $22 \%$, compared to DHB inpatient at nine percent. According to the results, the morale of nurses has declined slightly since the 2013 survey, due to the financial climate, higher patient acuity, restructuring, and heavier workloads.

\section{Summary}

Just over half (9) of the documents by professional bodies in this second cluster, support the need for NPs in the nursing workforce as well as increasing numbers of NPs. Overall the numbers of nurses working in aged care remain lower compared to other settings, and education and training was considered important for the nursing workforce. Some documents did not refer to aged care at all, while other nursing settings were prolific by comparison.

\section{Conclusion}

It is well known the NZ population is aging and along with it so is the health and disability workforce. Government policy and professional body documents reviewed in this chapter all search for, suggest, propose and recommend better ways of approaching the growing demand on the future health and disability workforce. Starting with the New Zealand Health Strategy in 2000, the then Minister of Health, raised the issue that future workforce 
issues would need to be addressed and specifically referred to the older person in aged residential care. The need for training and support for the health workforce was also indicated with the proposed establishment of the HWAC to address how these needs would be met.

Both government policy and professional body documents raised the issue that, as people age their health needs become more complex, and for nursing, this means there will be a need for nurses to increase their knowledge in order to provide more advanced care. It was identified that this would be even more necessary in PHC due to the ageing in place priority from the New Zealand Positive Aging Strategy released in 2001. Documents reviewed identify that as older persons are living in their own homes for longer, this will increase pressure and demand on PHC services and health care workers resulting in the need for an increase in the nursing workforce and nurses with advanced practice.

While progress has been made in the area of advanced nursing practice, there has been limited developments in aged care. Nurse Practitioners were first addressed in Government policy in 2002, and it was raised that older persons and PHC would benefit from having NPs to provide advanced care, leadership and knowledge. At that time it was optional for NPs to complete prescribing, it is now compulsory for NPs to register with a prescribing qualification.

A common theme throughout both clusters of documents has been for the education and health sector to increase collaboration. This is to ensure undergraduate and postgraduate nursing education programmes are appropriate for the health workforce. It was also raised that funding structures for workforce education and training need to be reviewed. This did happen as the Clinical Training Agency's funding structure and processes were reviewed in 2010, resulting in the Clinical Training Agency's disestablishment and the establishment of HWNZ. Despite the change, the medical workforce continue to receive the majority of funding for postgraduate education and training.

Government policy and professional body documents regularly refer to the need for increasing the workforce in aged care. This begins with the Health of New Zealand Strategy (2000) and the Impact of Aging in New Zealand on the Demand for Health and Disability Support Services and Workforce Implications (2004). Both of these documents report the unpopularity of caring for older people in long term care and the issues faced with recruitment and retention. Over time these issues have not changed. Of the total nursing workforce in 2000, 2,153 (6.8\%) nurses were employed into rest homes compared to 2015 where the total was, $5,287(10.5 \%)$ showing a small increase of $3.7 \%$. This 
highlights that over 15 years little progress has been made in regards to increasing recruitment and retention of nurses in aged care. Little progress has also been made with the number of NPs employed in rest home/residential care. Currently only six NPs are employed nationally even though it has been recognised throughout the document review of the need to increase NP numbers in the field of older persons in residential care. The following chapter describes findings from the focus groups and interviews with nurses and nurse managers concerning postgraduate education. 


\section{Chapter 5 Registered Nurses and Nurse Managers in Aged Care Perspectives on Postgraduate Education}

\section{Introduction}

Chapter five presents findings from the 20 RNs who participated in the two focus groups, and the 13 one-on-one interviews. Participants came from four different aged care facilities. Following the introduction the demographics and professional characteristics of the 20 participants are presented. This is followed by findings from the focus groups and interviews. Similarities and differences in views on engagement of postgraduate education for nurses working in aged care are presented through looking at the different perspectives of the participants. To maintain confidentiality the facilities are referred to as Facility A, Facility B, Facility C and Facility D. The RNs are referred to as RN1 to 15 with the nurse manager participants as NM1 to 5. The participants are identified by number and facility, for example, RN1from Facility A is referred to as RN1A.

The original aim to carry out three homogenous focus groups with participants from all facilities in each group did not eventuate. Due to an initial very low response rate and the time factor to complete this research, data collection was changed to hold separate homogenous focus groups at each facility. However, on the two occasions homogenous focus groups were arranged, when I arrived at the facility, nurses who had and who had not completed postgraduate education also arrived for the focus group. Given earlier issues with participation, and after considering the ethical issues, I conducted the focus groups with all present. My reflections on the impact of having these groups as heterogeneous are provided in Chapter six. Table 20 summarises where the participants for the focus groups and interviews came from in relation to facilities and postgraduate education. The length of time for the two focus groups was similar with the first group at Facility A lasting 47 minutes and the group at Facility $\mathrm{C}$ lasting 42 minutes.

Although the aim was to interview participants before or after work, this was difficult to arrange. As a consequence 11 of the 13 interviews were carried out during working hours resulting in some of the interviews being of a shorter length than the others. It also meant that others working in the aged care facility potentially knew who participated in the research. The brevity of the interview is discussed in Chapter six. The interviews at each facility were either in the Nurse Managers' office, senior nurses' office, whanau room or a training room. On occasions there were some minor interruptions with staff knocking on the door needing equipment, or in the case of one of the Nurse Managers, the phone 
ringing and needing to be answered. The audio recording was paused during these times. The interviews varied in time with the shortest being nine minutes and the longest at 32 minutes, the average was 16 minutes.

Table 20: Summary of participants by facility, data collection format and engagement in postgraduate education

\begin{tabular}{|l|l|l|l|}
\hline Title & Facility & Data Collection & Postgraduate Experience \\
\hline RN 1 & A & Focus group & Working toward postgraduate qualification \\
\hline RN 2 & A & Focus group & Working toward postgraduate qualification \\
\hline RN 3 & A & Focus group & No postgraduate qualification \\
\hline RN 4 & A & Interview & No postgraduate qualification \\
\hline RN 5 & A & Interview & No postgraduate qualification \\
\hline NM 1 & A & Interview & No postgraduate qualification \\
\hline RN 6 & B & Interview & Working toward postgraduate qualification \\
\hline NM 2 & B & Interview & Completed postgraduate qualification \\
\hline NM 3 & B & Interview & Completed postgraduate qualification \\
\hline RN 7 & B & Interview & No postgraduate qualification \\
\hline RN 8 & B & Interview & No postgraduate qualification \\
\hline RN 9 & C & Focus Group & Working toward postgraduate qualification \\
\hline RN 10 & C & Focus Group & No postgraduate qualification \\
\hline RN 11 & C & Focus Group & No postgraduate qualification \\
\hline RN 12 & C & Focus Group & No postgraduate qualification \\
\hline NM 4 & C & Interview & No postgraduate qualification \\
\hline RN 13 & D & Interview & No postgraduate qualification \\
\hline RN 14 & D & Interview & No postgraduate qualification \\
\hline RN 15 & D & Interview & No postgraduate qualification \\
\hline NM 5 & D & Interview & Completed postgraduate qualification \\
\hline
\end{tabular}

\section{The Participants}

All 20 participants provided demographic and professional characteristics (Table 21).

Nineteen (95\%) participants were female and seven (35\%) had engaged in postgraduate education. Of the seven participants who had engaged in postgraduate education, two had received funding, three had done their postgraduate education before funding was available, one had studied overseas and one had self funded. The two participants who had received postgraduate funding spoke positively about it. Although the numbers are small, there were some differences in those who had and had not completed postgraduate education. Neither of the two nurses aged 65 or over had completed postgraduate education, and only one of the eight Asian nurses had undertaken postgraduate education. The main areas the nurses who had done postgraduate education worked were rest home and hospital $(n=3)$. Ethnicities varied with $65 \%$ of participants from overseas. The biggest group were Asian at eight (40\%). 
Table 21. Demographic and professional characteristics of participants

\begin{tabular}{|l|l|r|r|r|}
\hline Variable & Value & $\begin{array}{r}\text { Postgrad } \\
\text { education } \\
\mathrm{n}=7\end{array}$ & $\begin{array}{c}\text { No Postgrad } \\
\text { education } \\
\mathrm{n}=13\end{array}$ & \multicolumn{1}{c|}{ Total } \\
\hline Gender & Female & $7(100 \%)$ & $12(92 \%)$ & $19(95 \%)$ \\
& Male & & $1(8 \%)$ & $1(5 \%)$ \\
\hline Age & $25-34$ & $1(14 \%)$ & $5(38 \%)$ & $6(30 \%)$ \\
& $35-44$ & $2(29 \%)$ & $2(15 \%)$ & $4(20 \%)$ \\
& $45-54$ & $2(29 \%)$ & $1(8 \%)$ & $3(15 \%)$ \\
& $55-64$ & $2(29 \%)$ & $3(23 \%)$ & $5(25 \%)$ \\
& $\geq 65$ & $0(0 \%)$ & $2(15 \%)$ & $2(10 \%)$ \\
\hline Ethnicity & New Zealand European & $1(14 \%)$ & $4(31 \%)$ & $5(25 \%)$ \\
& New Zealand Māori & $1(14 \%)$ & $1(8 \%)$ & $2(10 \%)$ \\
& Pacific* & $2(29 \%)$ & $1(8 \%)$ & $3(15 \%)$ \\
& Asian $*$ & $1(14 \%)$ & $7(54 \%)$ & $8(40 \%)$ \\
& Other* & $2(29 \%)$ & $0(0 \%)$ & $2(10 \%)$ \\
\hline Year of first & $\leq 1979$ & $1(14 \%)$ & $3(23 \%)$ & $4(20 \%)$ \\
nursing & $1980-1989$ & $2(29 \%)$ & $1(8 \%)$ & $3(15 \%)$ \\
registration & $1990-1999$ & $1(14 \%)$ & $2(15 \%)$ & $3(15 \%)$ \\
& $2000-2009$ & $2(29 \%)$ & $5(38 \%)$ & $7(35 \%)$ \\
& $2010-2014$ & $1(14 \%)$ & $2(15 \%)$ & $3(15 \%)$ \\
\hline Years & $\leq 4$ years & $1(14 \%)$ & $5(38 \%)$ & $6(30 \%)$ \\
working in & 5 years - 14 years & $3(43 \%)$ & $3(23 \%)$ & $6(30 \%)$ \\
aged care & 15 years - 24 years & $3(43 \%)$ & $2(15 \%)$ & $5(25 \%)$ \\
& $\geq 25$ years & $0(0 \%)$ & $3(23 \%)$ & $3(15 \%)$ \\
\hline Area of aged & Rest home, hospital and dementia & $2(29 \%)$ & $4(31 \%)$ & $6(30 \%)$ \\
care & Rest home and hospital & $3(43 \%)$ & $6(46 \%)$ & $9(45 \%)$ \\
& Rest home and dementia & $2(14 \%)$ & $2(10 \%)$ \\
& Hospital only & $1(8 \%)$ & $2(10 \%)$ \\
& Dementia only & $0(0 \%)$ & $1(5 \%)$ \\
\hline
\end{tabular}

*As per Health Workforce funding, Pacific includes the two participants who identified as Fijian Indian.

The years of nursing experience of the participants since first registration ranged from one to 40 years. The years the participants had worked in aged care ranged from one year through to more than 25 years. The participants who had worked in aged care for approximately one year were included in interviews and one had engaged in postgraduate study. Three who had worked in aged care over 25 years had engaged in no postgraduate study. The participants who had mainly engaged in postgraduate education were those in the five to eight year group, and in the 15 to 20 year group. Whilst three out of four of the participating facilities catered for rest home, hospital and dementia care, $9(45 \%)$ of the participants worked in the rest home and hospital areas only. One participant worked specifically in the area of dementia only and another worked in the hospital only, with six $(30 \%)$ working in all three areas. Two $(10 \%)$ participants worked in the area of rest home and dementia care but neither had engaged in any postgraduate education. 


\section{Overview of Postgraduate Education and the Aged Care Sector}

All participants shared their views about the place of postgraduate education in aged care and also about aged care itself, irrespective of whether they had engaged in any postgraduate education. Five themes emerged from the analysis. These were: i) Nursing knowledge is important for improving quality of older persons care; ii) Postgraduate education's place in career prospects and progression; iii) Systems and influences in relation to the role of external agencies in providing postgraduate opportunity; iv) Workplace influences the uptake of postgraduate education; and v) Personal factors influence choices and timing of the uptake of postgraduate education. Table 22 provides a summary of the participants' current level of postgraduate education, future plans for postgraduate education, as well as their careers.

Table 22: Level of postgraduate education and future career plans of participants

\begin{tabular}{|c|c|c|}
\hline $\begin{array}{l}\text { Level of postgraduate } \\
\text { education }\end{array}$ & Future study plans & Career plans where stated \\
\hline $\begin{array}{l}\text { No postgraduate education } \\
\text { qualification } \\
\mathrm{n}=13\end{array}$ & $\begin{array}{l}\text { Comments ranged from } \\
\text { being "unsure" and doing } \\
\text { "none". Three of } \\
\text { participants were } \\
\text { considering pursuing } \\
\text { postgraduate study in } \\
\text { palliative and aged care. A } \\
\text { timeframe was not } \\
\text { provided. }\end{array}$ & $\begin{array}{l}\text { Five participants stated they } \\
\text { would be retiring and had } \\
\text { no other future career plans. } \\
\text { One participant was } \\
\text { interested in pursuing a } \\
\text { career in nursing } \\
\text { management. }\end{array}$ \\
\hline $\begin{array}{l}\text { Working towards } \\
\text { Postgraduate Certificate } \\
\mathrm{n}=3\end{array}$ & $\begin{array}{l}\text { Two participants indicated } \\
\text { they would be continuing } \\
\text { with postgraduate study. }\end{array}$ & $\begin{array}{l}\text { These participants were } \\
\text { aiming to pursue their } \\
\text { careers in public health, } \\
\text { aged residential care and } \\
\text { one participant was aiming } \\
\text { to be a Nurse Specialist. }\end{array}$ \\
\hline $\begin{array}{l}\text { Postgraduate Certificate } \\
n=2\end{array}$ & $\begin{array}{l}\text { Both participants wished to } \\
\text { further their postgraduate } \\
\text { education, one participant } \\
\text { aiming to complete } \\
\text { Masters. }\end{array}$ & $\begin{array}{l}\text { One participant was } \\
\text { considering a career in } \\
\text { management. }\end{array}$ \\
\hline $\begin{array}{l}\text { Postgraduate Diploma } \\
n=1\end{array}$ & None stated & $\begin{array}{l}\text { This participant was } \\
\text { preparing for retirement }\end{array}$ \\
\hline $\begin{array}{l}\text { Working towards Masters } \\
\mathrm{n}=1\end{array}$ & None stated & $\begin{array}{l}\text { This participant was } \\
\text { planning to continue to } \\
\text { work in care of the older } \\
\text { adult. }\end{array}$ \\
\hline
\end{tabular}




\section{Nursing knowledge: Important for improving quality of older persons care}

Nursing knowledge resulting in better quality of care and improved practice was referred to by $13(65 \%)$ participants. This was something that evolved from RNs in aged care engaging in postgraduate education. Participants felt that with more advanced nursing knowledge and keeping up to date with current trends in nursing, residents would receive better, skilled and competent care. NM5D considered nursing knowledge was not only a benefit to residents but also to the resident's family:

For the residents the care is going to be a lot more up to date, also for residents families, knowing that it's not just a rest home that someone goes to at the end of their days. That they are going to get really good care, really good care plans, different cares are going to be looked at, it's research evidence based it's not just that we have always done it this way.

RN8B who had not completed any postgraduate education, thought although nursing knowledge gained from postgraduate education was valuable, it did not necessarily have to be of a postgraduate nature to be an advantage to residents, "Any education will always be beneficial to residents".

Sharing gained nursing knowledge with others in the workplace by those who had engaged in postgraduate education, was considered of value in improving residents' care. NM2B spoke of one RN who had engaged in postgraduate education "She was really good at supporting all the other staff, she blossomed when she started doing her postgraduate training because she was bringing it all back to work and seeing where she could use it". RN3A also spoke of RNs engaged in postgraduate education sharing knowledge through questioning other nurses in their practice. This comment was echoed by NM2B who had observed questioning of practice. "I noticed what she [the RN engaged in postgraduate education] was doing in guiding the other RNs so that she would be giving them ideas, have you thought about? Have you done this?” NM3B also spoke enthusiastically about the influence of nurses engaged in postgraduate education and sharing nursing knowledge "I've always seen them [nurses engaged in postgraduate education] grow and from there they're able to grow others and do it with passion".

Providing a "higher level of care" was described by NM3B in relation to nurses engagement in postgraduate education, delivering care to residents at Facility B. Similarly both RN5A and RN13D spoke of residents potentially receiving "optimum care” from 
RNs engaged in postgraduate education and RN6B spoke about how postgraduate education would "improve standards of care".

Improvement in nursing practice was both observed and not observed by participants. Participants who had observed improvement spoke of those RNs who had engaged in postgraduate education as having "in depth knowledge", "thinking outside the square" and having a "different perspective”. NM3B commented on improvement of practice through thinking outside the square "From what I have observed, it changes their mind-set to think beyond, oh, this is my resident, this is all I have to do, they [the RNs engaged in postgraduate study] start to look at ways to improve the person's life in whatever way they can”. Similarly, RN8B had observed a change in thinking. In contrast, NM4C commented she had not noticed any direct advantage to the residents, but more of a benefit to the RN in the area of decision making and managing medications.

NM2B thought more overseas nurses needed to improve their practice through postgraduate education, as many complete the Competency Assessment Programme (CAP) course (Overseas nurses must successfully complete a CAP course in order to nurse in NZ) and do not see the need for any further education. Nurse Managers also considered there was a need for more NPs not only for the benefit of residents but also for the nursing staff. Nurse Managers spoke of NPs working alongside and mentoring some RNs already engaged in postgraduate study.

\section{Postgraduate Education: Career prospects and progressions}

Over half $(55 \%)$ of participants brought up career prospects or progression of career in both a positive and a negative way in relation to engaging in postgraduate education. Positives were the importance postgraduate education has on career pathways, and negatives focused on RNs not staying in aged care once completing postgraduate education. RN8B believed postgraduate education to be a natural progression, "It's a follow on from what you do prior to coming in [starting work in aged care as a graduate nurse]. Similarly, RN9C from Focus Group Two believed that postgraduate education built on and improved knowledge already previously learnt; "I think it's just enhancing the knowledge that you already have and then gaining more knowledge through more studies”. Being aware of the right time to undertake postgraduate education was raised by NM3B as something she felt was related to career paths. This participant thought that once a nurse knows what career path to take, that is the time they will engage in postgraduate education. 
Career progression was a definite advantage identified by NM4C for RNs engaged in postgraduate education; "They [RNs] will be better at their job because they will be applying what they're learning, better opportunities will open doors for them and it will boost their confidence as well". NM1A spoke of postgraduate education as being a requirement now if nurses want to progress along a career pathway, "To further their career, I think the expectation now is that you need postgrad to go further”. Similarly NM2B brought up career progression as well as keeping up with current trends in nursing. Both Nurse Managers from Facility B spoke of their own experiences with engaging in postgraduate education and how it helped them progress with their careers. NM2B voiced, "It helped me in giving me confidence to move on", and NM3B spoke of completing postgraduate education so she could be successful in attaining a particular role.

The association between postgraduate education and career advancement into management positions was also raised as a perception from RN13D and specifically commented on by NM4C “It's like there is this connotation that if you take postgraduate studies, you are aiming for promotion, you want to step up on your career. So I think this is the culture, in my perspective, in here”.

Both ends of the age spectrum were discussed in relation to career pathways by different RNs from different facilities. One RN who had not completed any postgraduate education, felt strongly that although postgraduate education is important, it is more appropriate for younger nurses wanting to advance their career in aged care, rather than for older nurses. However, an RN from a different facility who has not completed any postgraduate education thought that aged care nursing was perceived to be for nurses at the end of their career.

Gaining a postgraduate qualification and then leaving aged care was an issue brought up by participants from focus group two, as well as by two RNs and a Nurse Manager from different facilities. RN5B voiced "they [RNs) do postgrad and the next thing they're gone”. RN11C from focus group two thought RNs in aged care gain postgraduate qualifications “To move on". RN9C from focus group two shared "I want to further my education I don't know how long I will be here, maybe I will be here for two years, for three years". NM5D thought the reason RNs leave following gaining postgraduate qualifications was, "Because they want to go further up the ladder and they probably don't want to be particularly staying in one residential facility for the rest of their days". Similarly RN7B thought that RNs who engaged in postgraduate education moved elsewhere as they were not getting job satisfaction following completing education "The 
reason is, so they can seek employment elsewhere, to be honest, I don't think it [aged care] offers enough".

\section{System Influences: The role of external agencies in providing postgraduate opportunities}

Opportunities to engage in postgraduate study concerned access to information and funding, finances and perceived relevance of what was available in postgraduate education. Information processes about knowledge surrounding the availability of HWNZ postgraduate nursing funding from the local DHB was identified as being a barrier by three (15\%) of the 20 participants. Although information about HWNZ postgraduate nursing funding is distributed to all aged care facilities during annual funding rounds by the local DHB (Chapter Two), interviews revealed that how RNs are informed about it varies by facility. Two participants shared that nursing staff from their facilities, were lacking in knowledge about the availability of and processes around postgraduate nursing funding. RN6B commented nurses "were aware of postgrad studies but not aware of the funding and all about it". Similarly NM5D currently had one RN self-funding postgraduate education and voiced 'I don't think the staff were aware of the support they could get from the DHB with regards to their papers".

Finding information about postgraduate pathways and papers was not always easy. RN6B experienced "I was going on the internet and it takes a long time and then in the end you are thinking no, I can't find any [information about postgraduate nursing]”. Similarly, RN7B found "How much filters through to them [referring to nursing staff] to know what is there [postgraduate papers] and what's valuable or what will make a difference to them, I don't think they understand'. Thoughts on the relevance of postgraduate papers in relation to aged care was mixed. RN11C from Focus Group Two thought "It [postgraduate study] would be good for specific areas like a dementia unit, but for general hospital level, the scope is way too broad. Whereas both RN3A and NM3B were positive about the relevance of postgraduate papers, NM3B noted "A lot of our nurses tend to go for the Palliative care papers, I think that might be an easy transition for them to realize, actually studying's good".

\section{Workplace Factors: Influences on the uptake of postgraduate education}

During the interviews and focus groups, participants spoke of factors that affect the uptake of postgraduate education in the workplace. Factors included support from the facility, Nurse Manager and colleagues, promotion of postgraduate education, heavy workloads and 
more positively, how postgraduate education has resulted in nurses engaged in education are more motivated in the workplace. Support in the workplace to undertake postgraduate education varied across the facilities. Participants spoke of both positive and negative supportive influences relating to their workplace coming from i) the organisation who own the facility; ii) people in senior roles such as Nurse Managers and Clinical Coordinators; and iii) nursing colleagues.

NM5C spoke of how positive support from the organisation had been since the organisation had a better understanding of the benefits postgraduate education has for the nursing staff, residents and the facility. This support involved "giving extra study [study leave] recognising what they are doing [the nursing staff] and then recognising our nurses in general, we have different awards each month for what people achieve". Whereas three other Nurse Managers spoke of their organisation as having limited support for education for nurses. Although the Nurse Managers were personally supportive, they noted there were financial constraints, NM2B voiced "I have to pinch and scrimp to pay Peter to pay Paul to get people off on training, but I certainly would allow them time off, and that may have to be annual leave”. Facility organisational financial constraints were also experienced by all participants in Focus Group Two at Facility C where one participant expressed "The facility as a company provide us with a lot of incentive, extra time to do studies, it is very difficult even for them to pay us to go to training”.

Of the participants who were Nurse Managers, all supported postgraduate education at their facility in varying degrees. NMA1 shared enthusiastically "I support them fully, I give them time, I check how their assignments are going, I celebrate when they do well". Whereas, those in Focus Group Two considered there were variable levels of support from their Nurse Manager, with some strongly voicing postgraduate education was highly "encouraged" and others expressing it was just "mentioned". Six of the 13 participants who were interviewed, one of whom had completed postgraduate education, spoke very positively about support from their Nurse Managers. RN5A found "they [Nurse Manager and Clinical Leader] will give you time, if you were doing assignments, I've noticed that they will re adjust the roster to help you out, other RNs are willing to switch duties to help". Similar support was voiced by the other five RNs.

Participants were also positive about other nurses in the workplace not engaged in postgraduate education being supportive of those who were. RN4A spoke "We are very supportive of each other" and elaborated "she [the RN undertaking study] can just give her load [workload] to someone [another RN] who is available and someone can just cover 
for her. Similarly RN3A voiced "If it is too much for them [those doing postgraduate studies] to work we can take off some work and then someone can cover so we can [not able to distinguish words] help them".

The way in which postgraduate education has been promoted in the workplace differs between each facility, in most cases it was discussed by Nurse Managers at staff meetings with five out of eight RNs interviewed speaking very positively about it. RN5A voiced "I missed out on the first year, the senior nurse told me when the next one [referring to the annual local DHB HWNZ postgraduate nursing funding round] was coming up, so she's all for it, she also offered her support”. The opposite was felt by Focus Group Two members from facility C. This group felt similarly to RN11C that "a Nurse Manager can encourage as much as they can but it depends on the nurses if they are really interested". The nurses themselves sometimes actively promoted postgraduate study to others. NM5D reported " $I$ have found the staff are really quite excited about doing postgrad study now to what they were when I first arrived." This comment is in contrast to NM4D "I am putting out flyers all the time when the funding is out, but no one has come and said to me that they want postgraduate studies”. Although postgraduate education was not always promoted and encouraged, RN8B voiced "they [the Nurse Manager and those nurses with a senior role] do push education, they push for you to do this and that but you just don't have the time.

Four interviewed participants as well as those in Focus Group Two highlighted the issue of studying and having a heavy workload at work. One of the participants voiced "If you were not as tired and exhausted from your day job then you possibly would think if you had a little time maybe I do have time to do papers[postgraduate papers]. But if your workload is as big as what we are going through, then you wouldn't even bother". Countering this perspective, another focus group participant shared that study "boosts your self esteem and motivation". On the other hand, NM5D considered that nurses engaged in postgraduate education were more recognised and their knowledge base was valued "I think they are acknowledged more for what they do and what they know from their knowledge base". RN7B commented on how more motivated staff were who were engaged in study, "educated staff are stimulated and the job becomes more interesting, less tedious.

\section{Personal Factors: Choices and timing regarding up taking of postgraduate education}

Time was highlighted by 14 (70\%) of participants as an element relating to the uptake of study by both those who had engaged in postgraduate education and those who had not. Some participants spoke of finding the right time to commence postgraduate education. 
When some participants spoke of time they also spoke of it with regard to managing family, work and study, "I think, time, especially when you are doing a full time job, you have stress from your work, you have a short time to do your assignment, having to focus on your job as well, so it's too much and also if you have a family at home” (RN4).

Likewise NM3 spoke strongly of time being an obstacle, "I think barriers are children, personal life, having to work paying bills, and if they are going to do postgraduate papers it's extra on top of a 40 hour week, let alone family life".

The seven participants who had or who still were currently engaged in postgraduate study, found juggling work, family and study to be stressful and time consuming. They managed this in a variety of ways. From taking a year off work, to being organised and consciously making time, being supported by the workplace, through being given paid study leave to attend study days, to being able to swap shifts and being given extra time off such as days off in lieu. This did vary by each facility. RN4A who had not engaged in postgraduate education, observed that the RNs in her facility, who had undertaken postgraduate education, were under a lot of pressure, however, they were motivated to complete their studies, "they are very into it, they are very focused". One participant who is engaged in study spoke very strongly about countering stigma as a reason some nurses working in aged care choose to engage in postgraduate study, "I think it's the stigma, if you meet the other nurses out there, they put down aged care, they kind of look down upon you, like you don't know anything” (RN6). Being able to say you are engaged in postgraduate study gets different reactions.

Self-belief in being able to manage and achieve postgraduate study was a factor brought up by participants. NM1A spoke of nurses having a lack of confidence to engage in postgraduate education. "I think a lot of them don't think they can do it or, have the ability and don't have the confidence”. Similarly NM2B thought that age was a consideration for some nurses in deciding to engage in postgraduate education "I think of the age of people in aged care, [The RNs] most of them would be in their mid-forties to higher and starting to do postgraduate then, I think you question your ability”. It was also expressed that sometimes nurses were fearful of engaging in postgraduate education. In contrast and speaking very positively from a personal experience NM5D expressed, "it's quite exciting to know that your brain still works and you are not just wife and a mother and a nurse that goes to work every day, that you are actually quite clever”. 


\section{Summary}

This chapter has presented an overview of the findings from two focus groups and 13 interviews of which participants provided both negative and positive comments. There were differing perceptions and views between RNs as well as RNs and Nurse Managers. The findings which highlighted the importance and role of personal, professional, organisational and systems factors will be discussed in the following chapter. 


\section{Chapter 6 Discussion and Conclusion}

\section{Introduction}

This study was designed to explore the role of postgraduate education in aged care. It was achieved through a review of policy and organisational documents, conducting focus groups and interviews, with RNs and nurse managers from residential care facilities in an urban region of NZ. Objectives of this research included: i) to identify the role of postgraduate education for advancing nursing practice in aged residential care; ii) to ascertain the role of postgraduate nursing education for aged care nurses' careers; iii) to identify enablers and barriers to completing postgraduate study; iv) to discover ways of working with those enablers and barriers to empower future nurses through their postgraduate education; and v) to investigate and explore aged care nurses' experiences of postgraduate nursing education through the nurse observing his/her self-experiences and those of other nurses. This chapter presents and then discusses the three key findings of this study. These findings are: i) enablers to nurses engaging in postgraduate education; ii) barriers to nurses engaging in postgraduate education; and iii) the significance of postgraduate education for aged care. Strengths and limitations of the research are then reflected on, followed by recommendations and implications for aged care managers, RNs working in aged care, DHB funding coordinators and, finally the conclusion.

\section{Overview of Findings}

The need for a qualified nursing workforce that includes NPs was identified as early as 2000. The document review identified that having a skilled aged care workforce was necessary for meeting the future needs of the aging population in NZ. Participants in the focus groups and interviews could see the benefits and change postgraduate education made in improving the level of nursing practice for all nurses working in aged care. Nurse Managers in particular noted the importance of and need for more NPs in aged care.

The sample of 20 participants from the four facilities had characteristics similar to those identified by the NCNZ's (2014) description of RNs working in aged care (Table 23). The main difference is in regards to ethnicity. There were only $25 \%$ of NZ European in this study compared with $40 \%$ in the NCNZ national data. This difference is partly due to the large number of internationally qualified nurses known to go to aged care. This study also had almost twice the proportion of Māori and more than three times the percentage for Pacific peoples than the Nursing Council report reveals. 
Table 23: NCNZ Percentage of RN's age and rest home/residential care setting compared to participants in this study

\begin{tabular}{|l|l|l|l|}
\hline & & Study Data & NCNZ Data \\
\hline Age & $<25$ & 0 & $1.6 \%$ \\
& $25-34$ & $30 \%$ & $29.6 \%$ \\
& $35-44$ & $20 \%$ & $16.4 \%$ \\
& $45-54$ & $15 \%$ & $19.6 \%$ \\
& $55-64$ & $25 \%$ & $24.1 \%$ \\
& $65>$ & $10 \%$ & $8.4 \%$ \\
\hline Ethnicity & NZ European & $25 \%$ & $47.5 \%$ \\
& NZ Māori & $10 \%$ & $5.2 \%$ \\
& Pacific peoples & $15 \%$ & $3.5 \%$ \\
& Asian & $40 \%$ & $38.6 \%$ \\
& Other & $10 \%$ & $3.9 \%$ \\
\hline Year gained nursing registration & $<1979$ & $20 \%$ & $14.6 \%$ \\
& $1980-1989$ & $15 \%$ & $18.9 \%$ \\
& $1990-1999$ & $10 \%$ & $22.4 \%$ \\
& $2000-2009$ & $35 \%$ & $28.4 \%$ \\
& $2010-2015$ & $20 \%$ & $15.5 \%$ \\
\hline
\end{tabular}

Source: NCNZ (2015). The NZ Nursing Workforce: A Profile of Nurse Practitioners, Registered Nurses and Enrolled Nurses 2014-2015. Wellington: Author.

Data from this study is largely consistent with the national data concerning when nurses first gained their registration. However, of note is the difference in <1979, 1990 to 1999 and 2010 to 2015 category where percentages in this study are higher.

The sample had considerable working experience in aged residential care, this ranged from less than 12 months to more than 25 years. Current data from NZNO (2015) although not covering age and years of nursing experience, did collect data indicating $30 \%$ of the general nursing workforce had more than 30 years nursing experience, as well as this, $37.5 \%$ of the general nursing workforce have remained with same employer for more than 10 years. In this study, two participants did not meet the inclusion criteria as they had been nursing less than two years (Chapter three). Of the two, one was engaged in postgraduate education.

Thirty five percent of study participants had completed or were in the process of completing postgraduate education, this is almost $10 \%$ higher than the national average of $26 \%$. This difference may be attributed to nurses who have undertaken postgraduate study being more interested in being involved in research. Of the seven participants who have engaged in postgraduate study, six were between 35 years and 64 years with one between 25 and 34 years. Of those older than 65 years, none had engaged in postgraduate education. Of the seven participants who had engaged in postgraduate education, six had worked in aged care between five and 24 years. Of the 13 participants who had not completed any 
postgraduate study, five had worked in residential aged care less than four years. This indicates that nurses may review the need for postgraduate education when they have had four to five years nursing in aged care.

Participant's ethnicities in this study, compared to numbers of those who had completed or were in the process of completing postgraduate education, showed the highest percentage are shared between Pacific and Asian with both at 29 percent. NZ European, NZ Māori and Asian ethnicities are all at 14 percent. Current data from NCNZ does not provide percentages or numbers of those RNs with a postgraduate qualification by practice setting and ethnicity to be able to compare data from this study with current NCNZ data.

\section{Significance of Postgraduate Education for Aged Care}

Postgraduate education plays a significant role in advanced nursing practice within the aged care sector. Participants in this research spoke about RNs who had completed postgraduate study as providing an increased level of care, having in depth knowledge, being up to date with nursing knowledge and having better assessment skills. Nurse Managers came across as being proud of their RNs achievements, seeing a difference in how the individual's practice changed, their confidence grew and also in how this manifested to other nurses at the facility ultimately for the better of the residents.

New Zealand government policy documents, and documents from professional bodies such as the NZNO and NCNZ, considered education and training to be significant for the NZ health workforce. In 2000, the Minister of Health was the catalyst for reviewing health workforce development with the release of the New Zealand Health Strategy. Between 2000 and 2015, government policy documents on health workforce development have been recommending the need for advancing nursing practice from nurse specialist through to NPs in all areas of nursing, especially in primary health care and aged care (DHBNZ, 2006, 2009; HWAC 2002a, 2002b; MoH, 2000, 2001, 2002, 2004a.). Despite this, interviews from the nurses involved in this research indicate that the policy and strategic goals are not being met.

In 2004, the MoH released a background paper outlining responses from international literature regarding the impact of the future demand on health services from the rising aging population, and how this could be managed. From this, it was identified that one area in health that needed to change was to increase the number of specialist practitioners to manage conditions related to aging. Specialist practitioners included advanced practice geriatric nurses and NPs mostly employed in rest homes (MoH, 2004). This research 
revealed only one nurse identifying specialist practises as an option for the future. One nurse also identified their Masters level desire with the others just wishing to engage in standard postgraduate education, or no education.

In summary, postgraduate education is significant for aged care as the population ages and will continue to do so placing a higher demand on the health sector. To manage this now and in the future there is a need for advanced nursing practice in the care of the older person. Government policy and professional nursing bodies have been recommending this since 2000 when the New Zealand Health Strategy was released. Participants could see the difference postgraduate education made to the nursing practice of those who had completed a postgraduate qualification, and Nurse Managers could also see the benefit of having NPs providing advanced nursing practice in caring for the older person.

\section{Enablers to Engaging in Postgraduate Education}

The findings show that support was the key enabler for participants to engage in postgraduate education. Support was varied and not always straightforward. It was noted by participants in both a positive and negative way and therefore is both an enabler and a barrier. Support was provided by facility owners, nurse managers and work colleagues, and was frequently commented on as a 'necessity' by the participants. The role of providing various types of support is in keeping with international research which commonly refers to nurses not only needing employer support but also academic support (Black \& Bonner, 2011; Clerehan et al., 2011; Hoffman \& Hester, 2012; Sweeney \& Dalton, 2007; Tame 2009).

Facility owners have an obligation to support education for all nursing staff, as RNs are required to complete 60 hours of professional development over three years in order to retain their annual practicing certificate (NCNZ, 2015). A 30 point course at a NZ university would achieve this, as such a course is expected to take 300 hours. Education for the nurses in this research, includes attending in-service education in the residential care facility they work in, at the local DHB, and postgraduate education at universities and polytechnics.

Support for nurses to engage in postgraduate education from residential care owners by providing some form of remuneration for gaining a postgraduate qualification, was also considered to be important for nurses. The participants argued it would be acknowledgement of the work RNs had put in to study and that they would feel more valued as employees. Johnson and Copnell (2002) identified that not being provided with 
any remuneration for gaining postgraduate qualifications was considered a barrier by $70 \%$ of nurse respondents in their study. However, nurses in a Malaysian based study by Chiu (2005), found although there was a lack of monetary remuneration, professional and personal growth was considered more important to nurses. A system of financial reward linked to postgraduate qualifications was considered in the review of nursing education commissioned by the Minister of Health (MoH, 2009), however this has not been initiated in any of the facilities involved in this study.

The issue of time was raised as a significant barrier. The Report of the Safe Staffing/Healthy Workplaces Committee of Enquiry (Safe Staffing Healthy Workplaces Unit, 2006) recommended nurses need 'protected time' for gaining clinical knowledge and skills in the workplace. The education to achieve these gains could be delivered internally or externally to the workplace and includes postgraduate education. Similarly, the NZNO (2010) consider planned release time from the workplace as necessary to enable nurses to benefit from learning opportunities. However, the experiences of the majority of nurses in this research who had completed postgraduate education, was that planned protected time for gaining knowledge and skills was not often provided. The RN's shared that they often had to attend study days during days off or take annual leave and strongly believed that it should not be the case. Participants who were Nurse Managers, did say they were able to give their RNs engaged in postgraduate education paid study leave some of the time, however it was not consistent due to acuity in the workplace. There appeared to be a mix within each facility of releasing their RNs to attend study days during days off, taking annual leave to attend study days as well as getting actual paid study leave. Some of the facilities were better at providing paid study leave than others. This finding is supported by Black and Bonner (2011) who found that release days for distance education postgraduate study is not supported by employers. Sweeney and Todd (2007) further identified, that although nurses expected support from their employers in being given study leave, they were instead required to use annual leave. Funding time off should not be a barrier as HWNZ postgraduate nursing funding does provide clinical release to employers and reimburses the cost per hour for the time the nurse is released $(\mathrm{MoH}, 2011)$. This should enable RNs to attend study days without having to use days off or annual leave. This is the case for all nursing postgraduate papers.

Support from Nurse Managers was crucial in enabling RN's engagement in postgraduate education. Participants identified that it provided encouragement and motivation. Similarly Tame (2009) found that the culture of postgraduate education was very much driven by the Manager, with nearly all participants seeing the Manager as the 'gate keeper'. This was 
also very much in keeping with Nurse Managers from the aged care facilities engaged in this research, as it appeared from what the Nurse Managers shared, and what the RNs stated, the more input from the Nurse Manager in providing support, the higher the number of RNs engaged in postgraduate education. Nurse Managers were provided support in a variety of ways. The extent to how this occurred differed across the facilities. Support from Nurse Managers included the distribution of postgraduate information at staff meetings, discussing postgraduate education with nurses at appraisals, following up with those who had shown an interest, making roster changes, arranging lieu days and annual leave days to allow time to work on assignments and prepare for exams, and generally showing an interest in progress and offering encouragement and guidance.

There were some differences between how RNs and Nurse Managers perceived how support was being provided. In one facility the RN felt there was no real encouragement to pursue postgraduate education whereas the Nurse Manager spoke of the opposite.

Nurse Managers spoke enthusiastically and positively about the support they provided, and were pleased to see the growth in their RNs. In contrast, Zahran (2013) found some Nurse Managers, although supportive, could not see any difference in the practice of the nurses who engaged in or had a Masters Level qualification. Overall, there were few studies in the literature about Nurse Managers and the type of support they provide to RNs engaged in postgraduate education. In contrast, there are a number of studies which refer to employer based support.

Many of the participants shared they had noticed the way nurses engaging in postgraduate study had changed and how this had impacted on other nurses' practice as well. This finding, that other nurses noted the benefits of doing postgraduate study for both patients and for themselves, is significant. Those studying were respected and valued for their new knowledge, and viewed as leaders. In some cases they were viewed as role models and mentors by those nurses who were just beginning their own postgraduate journey.

Support for engagement in postgraduate education was also found to come from work colleagues. Nurse Managers and RNs spoke of colleagues swapping shifts with nurses engaged in postgraduate study so they could attend class. When participants were being interviewed about this, it became very clear that supporting each other was unquestionable. There was a great sense of collegiality between those RNs engaged in postgraduate study and those who were not. However, Tame (2009) found the opposite, where nurses engaged in postgraduate education spoke of work colleagues as not being supportive. 
Easing the financial burden of postgraduate study through gaining Health Workforce New Zealand (HWNZ) funding enables nurses to pursue postgraduate education and is additionally a support mechanism. However, a small number reported that, the way information about the funding is distributed was considered to be a barrier. In some cases participants spoke of facilities receiving information about HWNZ postgraduate nursing funding from the local DHB, but once the information reached the facility, it was not overtly accessible. In one case a participant had no knowledge it even existed.

The Nurse Managers varied in the way they distributed information about postgraduate nursing funding.This ranged from leaving information in staff rooms, putting information on notice boards and discussing it with staff during staff meetings. In my position in a DHB as the Co-ordinator of HWNZ postgraduate funding, I was personally surprised to learn that the information I sent to the Nurse Managers did not reach all the nursing staff. I am now more aware of the marketing and distribution of postgraduate information. People in roles such as myself need to spend time working alongside and fostering relationships with aged care facilities to ensure information reaches the facility management and the nursing staff. Achieving this includes; promotion and recruitment of nurses to take up the opportunity of HWNZ funding, liaising with employers, and supporting nurses in accessing information and resources to enable them to engage in and continue with their chosen postgraduate pathway $(\mathrm{MoH}, 2011)$. The responsibility does not lie solely with the DHB but also with the respective Nurse Managers. Nursing staff need to be well informed and supported from the DHB HWNZ Coordinator. International literature revealed little regarding how information about postgraduate study is disseminated to nursing staff by funding agencies, employers or Nurse Managers.

Ease of access to locating information about postgraduate pathways and papers, including flexibility within these, are further enablers to the engagement in postgraduate education. A small number of RNs also considered lack of information to be barriers. It was found that RNs needed guidance in order to get a clearer understanding of what is available and the appropriate papers to take. The issue of flexibility within postgraduate pathways and papers became evident. While the literature did not specifically reveal any evidence outlining the ease of access to information concerning postgraduate pathways, Johnson and Copnell (2002) did find minimal evidence indicating there was an absence of flexibility within postgraduate programmes.

Although the focus of this study was not to explore the type of papers the participants would like to engage in, HWAC (2005) noted of the need to focus on integration of 
knowledge to practice. In proposing strategies for health workforce development, HWAC recommended the need for robust links between educational bodies, regulatory bodies, and employers in the health and disability workforce to enable the development of relevant programmes. Although the absence of flexibility per se was not raised as an issue by the participants, two (10\%) RNs did identify the low number of postgraduate papers offered by tertiary education providers that were relevant to aged care.

The implementation of the NP role into aged care was recommended in the Health of Older Persons Strategy (MoH, 2002). The fact that none of the RNs who were studying currently or who were not engaged in any postgraduate study, brought up the subject of $\mathrm{NP}$, may reflect that nurses other than those in management do not have a good understanding of the work of the NP. They did not appreciate that they were potentially on an NP pathway themselves. However, NPs working in the care of the older persons have been shown to be a valuable resource for residents and nursing staff within NZ as revealed in the evaluation findings of a pilot involving a NP working across primary health and three older persons facilities (MoH, 2013). A further positive outcome from the evaluation was the amount of formal and informal education the NP was able to provide to the nursing staff. This was beneficial as nursing staff became aware that they could further their careers.

In summary, support featured strongly from participants as an enabler to engaging in postgraduate education. This identified support from owners of facilities, Nurse Managers and colleagues as the main providers. This was also highlighted in international research. Funding for postgraduate education was also considered a support and a barrier as information did not always reach all participants. More support and guidance in deciding on postgraduate pathways was indicated by a small number of participants, this was also alluded to by the HWAC in its recommendations for stronger links between educational bodies and employers in the health and disability workforce. Support and the benefit of having NPs working in the care of the older person was identified as being valuable by Nurse Managers in providing mentoring to nursing staff. This was also found to be the case in a recent New Zealand pilot study (MoH, 2013).

\section{Barriers to Engaging in Postgraduate Education}

Three factors stood out which participants considered as barriers to nurses engaging in postgraduate education. These factors include time management, financial commitments, and lack of confidence in being able to manage and succeed in postgraduate study. The 
NZNO Employment Survey (NZNO, 2013) reported the biggest barrier to being able to complete requirements for professional development, which includes postgraduate education, was, being able to attend education in work time. Secondly was the cost to themselves in fees, and third were time commitments. In contrast to the NZNO, my research found by far the biggest barrier according to the participants was a lack of time. Lack of time, refers to time management, of which the participants perceived as the difficulties of being able to manage home, family, work commitments and additionally, postgraduate study. Difficulties managing family commitments, travel, and fulltime work as well as study was also highlighted in the NZNO Employment Survey (2013a).

In this current research, the issue of managing time was brought up by both those who had completed postgraduate study and those who had not. Both RNs and Nurse Managers spoke strongly about lack of time as being a barrier. Time having a negative effect, and being a barrier to postgraduate education was also highlighted in the international literature (Clerehan et al., 2011; Olsson et al; 2013; Scott et al., 2013). However, in the study by Johnson and Copnell (2009) there was very little evidence of issues with time management. The complexities of managing time in relation to postgraduate study, is not only an issue for NZ nurses but also for nurses internationally. All the participants in this research had family and home commitments, a life outside of work, there was a strong sense that home and family was their first priority, followed by work and lastly the possibility of postgraduate study, but there was always the issue of time and how these nurses could possibly factor in postgraduate study.

Finances were considered to be a barrier by three participants. Participants who identified this had, and had not, been engaged in postgraduate education. They spoke of finances being a barrier due to the cost of postgraduate papers when they had other personal and family financial commitments. Although the possibility of applying for a student loan was raised, I gained a sense that this was not an ideal solution for them. Those participants who had identified finances as being a barrier did not bring up the subject of applying for HWNZ postgraduate nursing funding, yet the benefits are many and include, paying for the cost of the paper, clinical release time (payment to the employer for releasing the nurse to study days related to the postgraduate paper), travel and accommodation (within certain criteria), and Māori and Pacific Peoples Cultural support (MoH, 2011). Compared to this research, there was a greater emphasis internationally of lack of finances being a barrier (Black \& Bonner, 2011; Boore, 1996; Johnson \& Copnell, 2002; Scott et al., 2013; Warren \& Mills, 2009; Watson \& Wells, 1987). One reason for this could be that nurses in other countries do not have the same type of funding support as that provided to NZ nurses. 
A lack of confidence, or lack of self-belief, in being able to engage in postgraduate study was identified by Nurse Managers and a small number of RNs as a barrier. A small number of RNs perceived being of an older age as a reason for lack of confidence or self-belief, as it was perceived being older affected believing in yourself to have the ability to manage postgraduate study. The participants did not elaborate on what age 'older age' was. This was not significantly evident in the international literature, however Watson and Wells (1987) found there was a link between age and the intent to engage in postgraduate education. Nurses aged between 25 to 34 and 30 to 44 were more likely to take it up. This is similar to NZ where an employment survey of all nurses conducted by the NZNO in 2013, found there was an increase in those showing an interest in study between the ages of 30 to 34 . As the age of the nurse increased, so did their interest in further study. This increase was from the age of 55 and carried on to 65 and over. However, compared to younger co-workers, some older nurses felt that, due to their age, they had been disadvantaged in applying for funding (NZNO, 2015). Given people are working longer, age should not be a barrier.

In summary there were three main barriers to enabling postgraduate education. The biggest of these is with management of time. This had also been identified by NZNO and in international literature. Lack of finances was also considered a barrier for a small number due to the cost of the papers. This suggests the benefits of HWNZ postgraduate funding. Lack of confidence and low self-belief due to age was also thought to be a barrier and was not significantly evident within the international literature. However there was a difference compared to NZNO which found that the interest in study increased with age.

\section{Strengths and Limitations of Research}

This study fills an important gap in knowledge, as there are very few NZ studies researching nursing and the care of the older person. No NZ research was found where postgraduate education fits within aged care. One of the strengths of the research is the sample. I successfully recruited and gained the perspectives and experiences from three groups of nurses working in residential aged care with different experiences of postgraduate education and different roles. Although two of the sample had been working in aged care for less than a year, this strengthens the findings as both participants had permanent jobs, with one enrolled in study. In addition, I was able to recruit participants from four different facilities. Although the culture of each workplace was different there were some similarities in perceptions and experiences that united the groups. 
There are a number of limitations to the research. The first limitation was that the focus groups were heterogeneous. I was unable to have homogenous focus groups as had been planned, due to limited recruitment of participants. Not having homogenous groups meant the participants did not have a commonality which limited fuller discussion of their views, as I needed to keep others involved in the discussion in order to involve those who had different backgrounds.

The second limitation of this study is that focus groups and participants were only able to give a short amount of time for each interview. Even though I arranged to conduct interviews at times that would catch morning staff finishing and afternoon commencing shift, this was not always successful, with some participants being interviewed while on shift. For this reason interviews were shorter as staff were keen to get back to their residents. This meant I was unable to get as many thoughts, experiences, and more richer in depth information from participants.

A third limitation of this research was the poor audio recording for the first focus group. I was unable to clearly hear what the group had to say about their thoughts and experiences. Some of the focus group was able to be transcribed, and I was able to use my field notes for data, but at times, I was unable to record the actual words people said. However, I consider I still managed to capture the main ideas and messages shared, as I established immediately after the focus group that the recording was problematic. Although I had good field notes, the main impact from this was that I had fewer direct quotations which I could use. The fourth and final limitation was a mistake in the original demographics template for accurately capturing the ages of participants. Age ranges were displayed as, 20 to 25 and 25 to 30 group. This meant, those who may have been aged 25 could have put themselves in either of the age groups, resulting in inaccurate age range data. This was addressed when reporting the data by displaying the age ranges as 25 to 34 and 35 to 44 , and also once this issue was identified, the participants then agreed to write down their age.

\section{Recommendations}

Five recommendations have been drawn from this research. The recommendations are for Nurse Managers, nurses, tertiary education providers, nurse coordinators managing HWNZ postgraduate funding and lastly for further research.

A key driver for postgraduate education uptake must also happen at the strategic level of the rest home providers. Without postgraduate education being a key priority within health care provider strategy the onus of postgraduate education falls on the shoulders of the 
individual RNs as an addition to their work load. There is a disconnect between government strategy for aged care education and what is being delivered by aged care providers. While some providers are delivering good support for postgraduate education others are not.

Nurse Managers in this research distributed HNWNZ postgraduate funding information to nursing staff through staff meetings, individual performance appraisal meetings and putting information up on notice boards. While this is positive, it is vital that Nurse Managers go further than that and follow up regularly on those nurses showing interest in pursuing postgraduate education. I recommend Nurse Managers support their RNs, throughout the RNs postgraduate journey, most importantly through following up on any interest shown in postgraduate study, holding regular meetings throughout the year to monitor progress, and celebrating any successes. As an example passing an assignment. This will not only encourage nurses to pursue postgraduate education but it could go far in ensuring, a positive postgraduate education culture in the aged care facility.

Tertiary education providers play an important role in delivering postgraduate education. In this research a small number of participants highlighted the difficulty in accessing information about postgraduate papers and pathways and described this as a barrier. Although it is acknowledged that tertiary education providers do provide information through many different types of media to capture a wide audience, in this case it has not been successful. From this research, I recommend education providers continue to foster the positive relationships they do have with the aged residential care sector, but also build on them through improving and encouraging access for nurses in aged care, with many who have English as a second language, to engage in postgraduate education. One way to achieve this is to hold more information sessions throughout the year about what postgraduate education is, what papers are available and how they relate to aged care. This could be achieved through working with DHB HWNZ Coordinators with sessions held at DHBs at central aged care facilities.

A barrier brought up in this research was about some participants not being aware HWNZ postgraduate funding existed or not knowing how to access it. Although I send out information about HWNZ postgraduate funding and visit aged residential care nurses to provide information and answer questions, it appears I have not always been successful in reaching some nurses. From this research I recommend DHB HWNZ postgraduate nursing funding coordinators to continue to follow up with aged residential care Nurse Managers with regard to the distribution of funding information. The postgraduate nursing funding 
Coordinators should also visit aged residential care facilities regularly and continue to build up existing relationships with Nurse Managers as well as the RNs, to enable nurses to engage in postgraduate education.

Both enablers and barriers were brought up in this research by RNs working in aged care. Both those who had and had not engaged in postgraduate education spoke of time, lack of finances and lack of self belief as barriers. Many participants spoke of time being a barrier with regard to fitting in family and home commitments, work, and study. While the issue of time can be considered a barrier, with the support from family, friends and the workplace, postgraduate study can be achievable. With regard to finances being a barrier, HWNZ postgraduate funding is available and goes some way toward helping with the cost of postgraduate study. I recommend the following to those nurses in aged care who may be interested in postgraduate education to; i) set up good support systems with family, friends and with employers; ii) to take up the opportunity of HWNZ postgraduate funding; and iii) to remember a one trimester paper is completed in 12 weeks.

Further research needs to be conducted in the area of the Registered Nurse and postgraduate education in aged care and nursing generally. Due to my research having a small sample size and being conducted in one region of NZ, it is difficult to be able to say my results can be considered a representation of other regions of NZ. Also as there is no $\mathrm{NZ}$ research on this topic, there is no opportunity for me to compare my results to other NZ studies. If this study was repeated, I recommend i) a bigger sample size to get a wider group of participants; ii) conducting homogenous focus groups to see if this would make any change to the outcome; iii) conducting the study on a wider scale to see if ethnicity results from this research were unique to this area on $\mathrm{NZ}$ or not, as compared to national data from NCNZ, this study showed a larger representation of those identifying as Asian and Pacific; and iv) in order to elicit the positive impact of postgraduate education in aged care further research needs to be undertaken in those organisations that have embraced postgraduate education.

\section{Conclusion}

This research has shown that postgraduate education has a significant role to play for nurses working in aged care through improving and advancing nursing practice. However to achieve this, the right supports need to be in place from facility owners, Nurse Managers and colleagues. Government policy has been recommending advancing nursing practice in the aged care sector through Nurse Specialists and NPs in order to help meet the demand 
for the nursing workforce since the year 2000. Findings from this study suggest the importance and need for support from Nurse Managers as vital to nursing staff interested in, and those engaging in, postgraduate study.

Postgraduate education is key to ensuring increased numbers of NPs in the care of the older persons. Future demand for aged care nurses will grow as the population ages. More importantly, postgraduate education has the potential to raise the profile of the nurse working with older persons. As more nurses working in this setting are supported in their engagement in postgraduate education, this can only help in the provision of up-to-date care for the older person in the future. 


\section{Appendices}

\section{Appendix A: Information sheet}

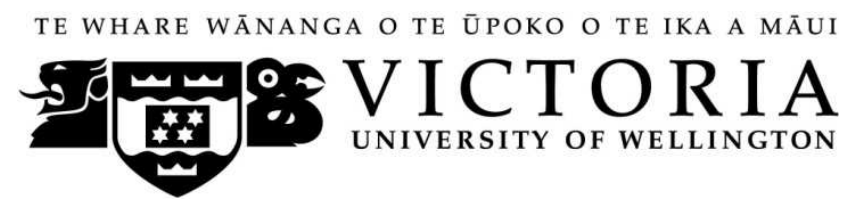

Victoria University of Wellington

Graduate School of Nursing, Midwifery and Health

\section{Information Sheet for a Study on the Role of Postgraduate Education for Registered Nurses Working in the Aged Care Sector}

Date: $26 / 01 / 2015$

Researcher: Susan Tansley: Graduate School of Nursing, Midwifery \& Health, Victoria University of Wellington.

I am a Masters student in Nursing at the Graduate School of Nursing, Midwifery \& Health. As part of this degree I am undertaking a research project leading to a thesis. The research has been approved by Victoria University of Wellington Human Ethics Committee (approval 23/10/2014). I am also employed as the Nurse Coordinator for Health Workforce New Zealand Postgraduate Nursing Funding at Hutt Valley and Wairarapa District Health Board as well as Nurse Coordinator for the Nursing Entry to Practice Programme at Hutt Valley District Health Board. My workplace supports the undertaking of this research.

The purpose of my research is to explore the perspectives of Registered Nurses who are employed in aged care and their views and experiences of postgraduate education as there is a significant gap in research on postgraduate education for nurses working in aged care. The methodology I am using is case study with mixed methods and involves a planned document review and three separate focus groups for collecting data from Registered Nurses and Managers of rest homes.

The three focus groups are:

1. Registered Nurses who have not undertaken any postgraduate study

2. Registered Nurses who have completed any postgraduate study

3. Managers of rest homes

I am inviting Registered Nurses working in the aged care sector in the Hutt Valley to participate in this study. This will involve attending and participating in one of the above focus groups. You will need to sign a consent form to participate. Ground rules will be determined at the beginning of each focus group. During the focus group session, I will ask questions to the group and the group will then discuss their ideas and thoughts around each question. The focus groups will be audio recorded and will last approximately 90 minutes, light refreshments will be provided. The dates and venues will be advised. Demographics and professional characteristics will also be collected from those participating. Demographics will cover age and ethnicity. Professional characteristics will cover; year and country of registration; length of time working in aged care; area of 
residential care the nurse is employed in; the nurses postgraduate nursing levels and future career plans.

The information collected will be confidential and the identity of the participants will be protected. All material collected will be confidential to the group. The names of the nurses' workplaces or personal identifying information will not be sought. Participants can withdraw at any time without giving a reason, or ask that something that is said not be reported verbatim in the research. Just let me know at the time. Information provided up to the point of withdrawal will remain part of the data for the research.

The only people who will have access to the material collected will be my supervisor, $\mathrm{Dr}$ Katherine Nelson and I. The material collected will be kept in a locked cupboard and will be destroyed two years after the end of the project. Feedback will be available for those who participate in the study at the conclusion of the study. It is also anticipated that the research will be presented at Victoria University School of Nursing Midwifery and Health and a journal article will be written about the research. The research project will be submitted for examination to Victoria University of Wellington and deposited within the University library where it will be available electronically.

The closing date for the return of the consent form will be 13/02/2015.

If you have any questions or would like further information about the research project please do not hesitate to contact me or my supervisor, Dr Katherine Nelson, at Victoria University of Wellington. Contact details:

\section{Principal Investigator}

Susan Tansley, Nurse Coordinator Health Workforce New Zealand Postgraduate Nursing Funding and Nursing Entry to Practice (NETP) Programme, Practice Development Unit, Pilmuir House, Hutt Valley DHB, Private Bag 31 907, Lower Hutt. Ph.: XXXXXXXX. Email: $\underline{X X X X X X X X X X X X}$

\section{Supervisor}

Dr Katherine Nelson, Senior Lecturer, Graduate School of Nursing \& Midwifery, Victoria University of Wellington. Ph.: XXXXXXXXXX Email: XXXXXXXXXXXXX 


\section{Appendix B: Ground rules}

\section{Ground Rules for Focus Groups}

1. Give everyone a chance to talk and contribute to the discussion, everyone's thoughts and experiences are important. There are no right or wrong answers.

2. When contributing to the discussion it is helpful to provide positive as well as negative comments. All comments will be valued.

3. It is important that you stay focused on the question being asked, please refer to the question frequently to help keep you engaged.

4. Throughout the focus group session, the facilitator will attempt to obtain a closure on each topic. No one should feel they have important ideas not discussed.

5. All participants are asked to agree to keep what is discussed in the group as confidential. What is shared in the room stays in the room. 


\section{Appendix C: Interview questions for focus groups and interviews}

\section{Focus Groups and Interview Questions}

1. Where do you think postgraduate education sits in aged care?

2. How would you describe the culture in your place of work around nurses and postgraduate study?

3. How does your place of work support nurses who take up postgraduate study?

4. What have you observed of other nurses in your workplace who engage in postgraduate education?

5. What do you think would be the benefits, or, you have observed as being of benefit, to nurses engaging in postgraduate education?

6. What do you think are the barriers, or, you have observed as being barriers to engaging in postgraduate education?

7. What do you think are the reasons why nurses working in aged care engage in postgraduate education?

8. What do you think are the potential benefits to the residents of nurses completing postgraduate education?

9. What benefits to the residents have you observed from nurses engaging in postgraduate education?

Question 10: this question was specifically added for Nurse Managers

10. Describe your own experiences of postgraduate education. 


\section{Appendix D: Demographics and professional characteristics template}

\section{Demographics and Professional Characteristics}

Please complete the questions below

\begin{tabular}{|c|c|}
\hline $\begin{array}{l}\text { Age } \\
\text { Please circle the age group that applies to you. }\end{array}$ & $\begin{array}{l}20-25 \\
25-30 \\
35-40 \\
45-50 \\
55-60 \\
65-70 \\
70+\end{array}$ \\
\hline $\begin{array}{l}\text { Ethnicity } \\
\text { Please circle the ethnicity you identify with. }\end{array}$ & $\begin{array}{l}\text { NZ European } \\
\text { NZ Maori } \\
\text { Cook Island Maori } \\
\text { Samoan } \\
\text { Tongan } \\
\text { Niuean } \\
\text { Fijian } \\
\text { Chinese } \\
\text { Indian } \\
\text { Other (please state) }\end{array}$ \\
\hline $\begin{array}{l}\text { Nursing Registration } \\
\text { Please indicate the year in which you gained Nursing } \\
\text { registration. }\end{array}$ & \\
\hline $\begin{array}{l}\text { Country of Registration } \\
\text { Please indicate in which country you gained your nursing } \\
\text { registration. }\end{array}$ & \\
\hline $\begin{array}{l}\text { Length of Time Working in Aged Care } \\
\text { Please indicate how many years you have been working in } \\
\text { aged care. }\end{array}$ & \\
\hline $\begin{array}{l}\text { Area of Aged Care } \\
\text { Please circle which area of aged care you are employed in. }\end{array}$ & $\begin{array}{ll}\text { 1. } & \text { Rest home level } \\
\text { 2. } & \text { Hospital level } \\
\text { 3. } & \text { Dementia care level }\end{array}$ \\
\hline $\begin{array}{l}\text { Level of Postgraduate Education } \\
\text { Please circle which level of postgraduate education you } \\
\text { are currently at. }\end{array}$ & $\begin{array}{ll}\text { 1. } & \text { Working towards Postgraduate } \\
\text { Certificate } \\
\text { 2. Postgraduate Certificate } \\
\text { 3. Working towards Postgraduate } \\
\text { Diploma } \\
\text { 4. Postgraduate Diploma } \\
\text { 5. Working towards Masters } \\
\text { 6. Masters } \\
\text { 7. No postgraduate education } \\
\\
\text { qualification }\end{array}$ \\
\hline $\begin{array}{l}\text { Future Career Plans } \\
\text { Please indicate what plans you have for your future } \\
\text { nursing career. } \\
\text { (Please use back of page if there is not enough room). }\end{array}$ & \\
\hline
\end{tabular}




\section{Appendix E: Ethics approval}

\begin{tabular}{l|l}
\hline TO & Susan Tansley \\
\hline COPY TO & Kathy Nelson \\
\hline FROM & Dr Allison Kirkman, Convener, Human Ethics Committee \\
\hline
\end{tabular}

\begin{tabular}{|c|c|}
\hline DATE & 23 October 2014 \\
\hline PAGES & 1 \\
\hline SUBJECT & $\begin{array}{l}\text { Ethics Approval: } 21242 \\
\text { The Role of Postgraduate Education for Registered Nurses } \\
\text { Working in the Aged Care Sector }\end{array}$ \\
\hline
\end{tabular}

Thank you for your application for ethical approval, which has now been considered by the Standing Committee of the Human Ethics Committee.

Your application has been approved from the above date and this approval continues until 27 September 2015 . If your data collection is not completed by this date you should apply to the Human Ethics Committee for an extension to this approval.

Best wishes with the research.

Allison Kirkman

Human Ethics Committee

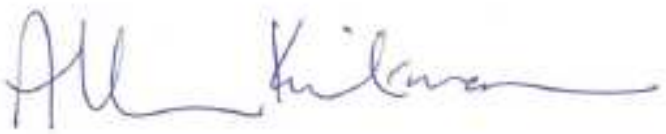




\section{Appendix F: Consent form}

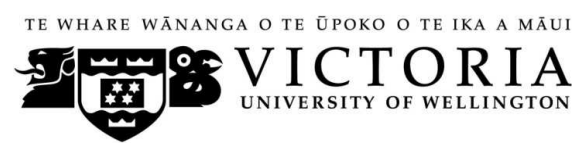

\section{Victoria University of Wellington \\ Graduate School of Nursing, Midwifery and Health \\ Consent form}

\section{Title: The Role of Postgraduate Education for Registered Nurses Working in the Aged Care Sector}

\section{Name of Researcher: Susan Tansley}

- I confirm that I have read and understand the information sheet dated: 3/11/2014 for the above study. I have had the opportunity to consider the information, ask questions and have had these answered satisfactory.

- I understand that my participation is voluntary and that I am free to withdraw at any time without giving any reason, but that any contribution I have made to the group meetings will remain part of the research.

- I understand that any information I provide as part of this study will be kept confidential by the principal researcher and supervisor, but that others who are involved in the group meetings will know my identity and what I have shared.

- I understand that the published results or presentations will not use my name and that no opinions will be attributed to me that will identify me.

- I understand that the field notes and audio recordings of the group meetings will be stored in a secure place and destroyed two years after the end of the study.

- I agree to abide by the ground rules that are decided by the group.

- I am aware I will have the opportunity to review notes following each of the group meetings.

- I understand at the end of this study feedback will be sent to me if I would like it. I would like feedback sent to me once the study is completed Yes $\square \quad$ No $\square$ I would like a certificate of participation for my portfolio $\quad$ Yes $\square \quad$ No $\square$

- I agree to take part in the above study.

Signed:

Date:

Name of participant (please print) 


\section{Appendix G: Transcriber agreement}

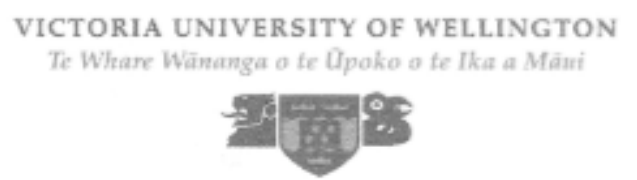

Confidentiality Agreement for Transcriber

The Role of Postgraduate Education for Registered Nurses Working in the Aged Care Sector

Researcher: Susan Tansley: Graduate School of Nursing, Midwifery \& Health, Victoria University of Wellington

I have read the information sheet outlining this study. I have discussed with the researcher the nature of the research and have had any questions that I have had answered to my satisfaction. My role as the research transcriber has been outlined to me by the researcher.

At all times the research information (recordings and transcripts) will be inaccessible to other persons. The researchers have assured me that they will debrief me following transcribing to address any issues that transcribing bring up for me.

Most importantly, I understand and agree to store the recordings securely while in my care and keep the information I hear and type in the course of transcribing confidential to the researcher and myself.

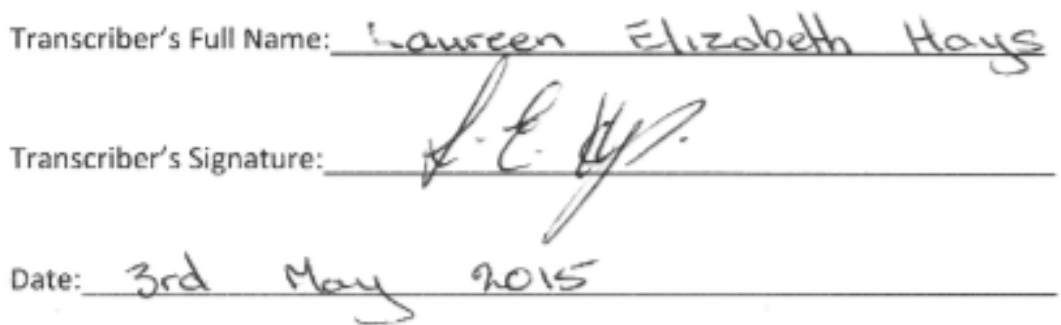




\section{Reference List}

Barnhill, D., McKillop, A., \& Aspinall, C. (2012). The impact of postgraduate education on registered nurses working in acute care. Nursing Praxis in New Zealand, 28(2), 27-36.

Black, K.E., \& Bonner, A. (2011). Employer based support for registered nurses undertaking postgraduate study via distance education. Nurse Education Today, 31(2), 163-167.

Boore, J. (1996). Postgraduate education in nursing: A case study. Journal of Advanced Nursing, 23(3), 620-629.

Careerforce, (2015). Retrieved $5^{\text {th }}$ December, 2015, from http://www.careerforce.org.nz/about/

Careerforce, (2000). Literature Review for the New Zealand Qualifications Review: Aged Care, Disability, Health and Social Services Sector. Retrieved $5^{\text {th }}$ December, 2015, http://careerforce.org.nz/wordpress/wp-content/uploads/Literature_Review_final_draft.pdf

Chiu, L. (2005). Motivation for nurses undertaking a post-registration qualification in Malaysia. International Nursing Review, 52(1), 46-51.

Clendon, J. (2011). Enhancing preparation of undergraduate students for practice in older adult settings. Contemporary Nurse, 38(1-2), 94-105.

Clerehan, R., McCall, L., \& Alshahrani, K. (2011). Saudi Arabian nurse's experiences of studying masters degrees in Australia. International Nursing Review, 59(2), 215-221.

College of Nurses Aotearoa New Zealand Inc. (2013). Strategic Plan 2013-2016.

Retrieved $25^{\text {th }}$ May, 2015, from http://www.nurse.org.nz/strategic-plan.html

Creswell, J.W. (2014). Research Design:Qualitative, quantitative, and mixed methods approaches $\left(4^{\text {th }}\right.$ Ed.). California:Sage publications.

Cronin, C. (2014). Using case study research as a rigorous form of inquiry. Nurse Researcher, 21(5), 19-27.

Curtis, E., \& Redmond, R. (2007). Focus groups in nursing research. Nurse Researcher, $14(2), 25-37$. 
District Health Boards New Zealand. (2005). Future Workforce 2005-2010. Retrieved $4^{\text {th }}$ November, 2014, from http://www.dhbnz.org.nz/Site/Future_workforce

District Health Boards New Zealand. (2006). Future workforce: Nursing workforce Strategy. Retrieved $4^{\text {th }}$ November, 2014, from

http://www.dhbnz.org.nz/Site/Future_workforce

District Health Boards New Zealand. (2009). Future workforce: Our health workforce today and in the future. Retrieved $4^{\text {th }}$ November, 2014, from http://www.dhbnz.org.nz/Site/Future_workforce

Doody, O., Slevin, E., \& Taggart, L. (2013a). Focus group interviews in nursing research: Part 1. British Journal of Nursing, 22(1), 16-19.

Doody, O., Slevin, E., \& Taggart, L. (2013b). Preparing for and conducting focus groups in nursing research: Part 2. British Journal of Nursing, 22(3), 170-173.

Freeman, T. (2006). 'Best practice' in focus group research: Making sense of different views. Journal of Advanced Nursing, 56(5), 491-497.

Grant Thornton New Zealand Limited (2010). Aged residential service care review. Retrieved $16^{\text {th }}$ October, 2014, from http://nzaca.org.nz/publication/documents/ARSCR.pdf

Health Workforce Advisory Committee. (2002a). The New Zealand health workforce: A stocktake of issues and capacity 2001. Retrieved $12^{\text {th }}$ September 2014 from https://www.health.govt.nz/system/files/documents/publications/hwacstocktake2001-introduction.pdf

Health Workforce Advisory Committee. (2002b). The New Zealand Health Workforce Framing Future Directions: A discussion document. Wellington, New Zealand.

Health Workforce Advisory Committee. (2003). The New Zealand health workforce future directions: Recommendations to the Minister of Health. Retrieved $16^{\text {th }}$ October, 2014, from https://www.health.govt.nz/system/files/documents/publications/hwac-futuredirections-recommendations.pdf

Health Workforce Advisory Committee. (2006). Strategic principles for workforce development in New Zealand. Retrieved $16^{\text {th }}$ October, 2014, from 
https://www.health.govt.nz/system/files/documents/publications/hwac-workforcestrategic-framework.pdf

Higginbottom, G.M.A. (2004). Sampling issues in qualitative research. Nurse Researcher, 12(1), 7-14.

Hoffman, J., \& Hester, J. (2012). The academic transitional experiences of master's students at the University of the Western Cape. Journal of the Democratic Nursing Organisation of South Africa, 35 (1).

Howard-Brown, C., \& McKinlay, E. (2014) ARC NETP Programme Evaluation Final Report. Retrieved $16^{\text {th }}$ February, 2015, from http://www.health.govt.nz/publication/aged-residential-care-nurse-entry-practice-arcnetp-programme-evaluation-report

Jacobs, S.H., \& Boddy, J.M. (2008). The genesis of advanced nursing practice in New Zealand: Policy, practice and education. Nursing Praxis in New Zealand, 24(1), $11-22$.

Johansen, E., \& Harding, T. (2013). 'So I forgot to use 1.5 line spacing! it doesn't make me a bad nurse': The attitudes to and experiences of a group of Norwegian postgraduate nurses to academic writing. Nurse Education in Practice,13(5), 366370.

Johnstone, A., \& Copnell, B. (2002). Benefits and barriers for registered nurses undertaking postgraduate diplomas in paediatric nursing. Nurse Education Today, 22(2), 118-127.

Kimchi, J., Polivka, B., \& Sabol Stevenson. J. (1991). Triangulation: Operational definitions. Nursing Research, 40(8), 364-366.

Kitzinger, J. (1995). Introducing focus groups. British Medical Journal, 311(7000), 299302.

Krueger, R.A., \& Casey, M,A. (2009). Focus groups: A practical guide for applied research $\left(4^{\text {th }}\right.$ Ed. $)$. California: Sage publications.

Lederman, L.C. (1990). Assessing educational effectiveness: The focus group interview as a technique for data collection. Communication Education, 39(2), 117-127. 
LoBiondo-Wood, G., \& Haber, J. (2002). Nursing research methods, critical appraisal and utilization ( $5^{\text {th }}$ ed.). St Louis, Missouri: Mosby Inc.

McBrien, B. (2008). Evidence-based care: Enhancing the rigour of a qualitative study. British Journal of Nursing, 17(20), 1286-1289.

McDonald, S., Willis, G., Ourie, W.F. \& Hedgecock, B. (2009). Graduate nurse's experience of postgraduate education within a nursing entry to practice programme. Nursing Praxis in New Zealand, 25(3), 17-26.

McIntosh, M.J., \& Morse, M. (2015). Situating and constructing diversity in semistructured interviews. Global Qualitative Nursing Research, 2, 1-12.

Ministry of Health. (2000). New Zealand Health Strategy. Retrieved $15^{\text {th }}$ October, 2014, from

http://www.health.govt.nz/system/files/documents/publications/newzealandhealthst rategy.pdf

Ministry of Health. (2002a) Health of older people strategy. Retrieved $16^{\text {th }}$ October, 2014, from http://www.health.govt.nz/publication/health-older-people-strategy

Ministry of Health. (2002b). Health of older people in New Zealand: A statistical reference. Retrieved 16th October, 2014, from http://www.health.govt.nz/publication/health-older-people-new-zealand-statisticalreference

Ministry of Health. (2004a). Impact of population aging in New Zealand on the demand of health and disability support services and workforce implications. Retrieved $16^{\text {th }}$ October, 2014, from http://www.health.govt.nz/publication/impactpopulation-ageing-new-zealand-demand-health-and-disability-support-servicesand-workforce

Ministry of Health. (2004b). Aging New Zealand and health and disability projections 2001- 2021. Retrieved $17^{\text {th }}$ October, 2014, from http://www.health.govt.nz/publication/ageing-new-zealand-and-health-anddisability-services-2001-2021

Ministry of Health. (2006a). Health of older people information strategic plan: Directions to 2010 and beyond. Retrieved $17^{\text {th }}$ October, 2014, from 
http://www.health.govt.nz/publication/health-older-people-information-strategicplan-directions-2010-and-beyond

Ministry of Health. (2006b). Health workforce development: An overview. Retrieved $28^{\text {th }}$ January, 2015, from http://www.health.govt.nz/publication/health-workforcedevelopment-overview

Ministry of Health. (2009). A nurse education and training board for New Zealand. Retrieved $5^{\text {th }}$ October, 2014, from http://www.moh.govt.nz/notebook/nbbooks.nsf/8b635a98811e8aed85256ca8006d4 e51/9943a4089f23ef13cc2576150007745f/\$FILE/nurse-education-training-boardnz-aug09-v2.pdf

Ministry of Health. (2011a). Workforce for the care of older people: Phase 1 report.

Retrieved $17^{\text {th }}$ October, 2014, from

http://www.health.govt.nz/system/files/documents/pages/care-of-older-peoplephase1-report.pdf

Ministry of Health. (2011b). Postgraduate nursing training specifications. Retrieved $5^{\text {th }}$ October, 2014, from http://www.health.govt.nz/our-work/healthworkforce/investment-and-purchasing\#nursing

Ministry of Health. (2013). Evaluation of the Nurse Practitioner in aged care. Retrieved $25^{\text {th }}$ January, 2016, from https://www.health.govt.nz/publication/evaluation-nursepractitioner-aged-care

Ministry of Health. (2014a). Health Practitioners Competence Assurance Act. Retrieved $6^{\text {th }}$ December, 2015, from http://www.health.govt.nz/our-work/regulation-healthand-disability-system/health-practitioners-competence-assurance-act/nonregulatedhealth-professions

Ministry of Health. (2014b). Voluntary bonding scheme. Retrieved $5^{\text {th }}$ October, 2014, from http://www.health.govt.nz/our-workforce/voluntary-bonding-scheme

Ministry of Health. (2014c). Service specification nursing entry to practice 2/B46.

Retrieved $5^{\text {th }}$ October, 2014, from http://www.health.govt.nz/our-work/healthworkforce/investment-and-purchasing\#nursing 
Ministry of Health. (2015a). Evaluation of the new graduate employment scheme through the very low cost access initiative: final evaluation report. Retrieved 9th February, 2016, from http://www.health.govt.nz/search/results/vlca\%20evaluation

Ministry of Health. (2015b). Health of Older People Update. Retrieved $26^{\text {th }}$ January, 2016, from http://www.health.govt.nz/our-work/life-stages/health-olderpeople/health-older-people-strategy-update

Ministry of Health. (2015c). New Zealand health strategy update. Retrieved $28^{\text {th }}$ January, 2016, from http://www.health.govt.nz/about-ministry/what-we-do/new-zealandhealth-strategy-update

Ministry of Health. (2015d). Update of the New Zealand Health Strategy all New Zealanders Live Well, Stay Well, Get Well Consultation Draft. Retrieved $28^{\text {th }}$ January, 2016, http://www.health.govt.nz/publication/new-zealand-health-strategyconsultation

Ministry of Health. (2016). Investment and purchasing. Retrieved $23^{\text {rd }}$ February, 2016, from http://www.health.govt.nz/our-work/health-workforce/investment-andpurchasing\#nursing

Ministry of Social Development. (2001). The positive aging Strategy. Retrieved $15^{\text {th }}$ October 2014, from. http://www.msd.govt.nz/about-msd-and-ourwork/publications-resources/planning-strategy/positive-ageing/index.html

New Zealand Nurses Organisation. (2010). Clarifying nursing education funding issues. Retrieved $16^{\text {th }}$ November, 2015, from http://www.nzno.org.nz/resources/nzno_publications

New Zealand Nurses Organisation. (2006). Strategic plan. 2006-2011 Retrieved $8^{\text {th }}$ November, 2014, from http://www.nzno.org.nz/resources/nzno_publications

New Zealand Nurses Organisation. (2013a). NZNO employment survey 2013 our nursing workforce: For close observation. Retrieved $26^{\text {th }}$ January, 2016, from http://www.nzno.org.nz/resources/nzno_publications

New Zealand Nurses Organisation. (2013b). Education policy framework. Retrieved $20^{\text {th }}$ January, 2015, from http://www.nzno.org.nz/Portals/0/publications/Education\%20Policy\%20Framewor k\%202013.pdf 
New Zealand Nurses Organisation. (2015). NZNO Employment survey 2015 our nursing workforce: Condition deteriorating. Retrieved $26^{\text {th }}$ January, 2016, from http://www.nzno.org.nz/Portals/0/publications/Employment\%20Survey,\%202015\% 20NZNO\%20(d)\%20ffv2.pdf

Nursing Council of New Zealand. (2000). The New Zealand nursing workforce. Retrieved $26^{\text {th }}$ January, 2016, from http://www.nursingcouncil.org.nz/Publications/Reports

Nursing Council of New Zealand. (2010) Education programme standards for the RN scope of practice. Retrieved $15^{\text {th }}$ August, 2014, from http://www.nursingcouncil.org.nz/Education

Nursing Council of New Zealand. (2013a). The future nursing workforce: Supply projections 2010-2035. Retrieved $15^{\text {th }}$ August, 2015, from http://www.nursingcouncil.org.nz/Publications/Reports

Nursing Council of New Zealand. (2013b). Consultation on the scope of practice and qualifications prescribed for Nurse Practitioners: Analysis of submissions. Retrieved $19^{\text {th }}$ January, 2016, from http://www.nursingcouncil.org.nz/News/Futurechanges-to-the-nurse-practitioner-scope-of-practice

Nursing Council of New Zealand. (2014). The New Zealand nursing workforce: A profile of Nurse Practitioners, Registered Nurses and Enrolled Nurses 2012-2013. Retrieved $10^{\text {th }}$ August, 2014, from http://www.nursingcouncil.org.nz/Publications/Reports

Nursing Council of New Zealand. (2014). Annual Report 2014. Retrieved $19^{\text {th }}$ January, 2016, from http://www.nursingcouncil.org.nz/Publications/Reports

Nursing Council of New Zealand. (2015). The New Zealand nursing workforce. Retrieved $26^{\text {th }}$ January, 2016, from http://www.nursingcouncil.org.nz/Publications/Reports

Olsson, M., Persson, M., Kaila, P., Nilsson Wikmar, L., \& Bostrom, C. (2013). Students expectations when entering an interprofessional master's degree. Journal of Allied Health, 42(1), 3-9.

Polit, D.F., \& Beck, C.T. (2008). Nursing research generating and assessing evidence for nursing practice $\left(8^{\text {th }}\right.$ ed.). Philadelphia: Lippincott Williams \& Wilkins.

Powell, R.A., \& Single, H.M. (1996). Focus groups. International Journal for Quality in Health Care, 8(5), 499-504. 
Roberts, K., \& Taylor, B. (2002). Nursing research processes an Australian perspective. $\left(2^{\text {nd }}\right.$ ed.). Victoria Australia: Nelson Thomson Learning.

Safe Staffing healthy Workplaces Committee. (2006). Report on the Safe Staffing/healthy Workplaces Committee of Inquiry. Retrieved $28^{\text {th }}$ August, 2014, from http://www.centraltas.co.nz/assets/SWS/SSHW/SSHW-Committee-of-Inquiry.pdf

Sandelowski, M. (1986). The problem of rigor in qualitative research. Advances in Nursing Science, 8(3), 26-37.

Sandelowski, M. (1995). Qualitative analysis: What it is and how to begin. Research in Nursing and Health, 18(4), 371-375.

Sandelowski, M. (2010). What's in a name? Qualitative description revisited. Research in Nursing \& Health, 33(1), 77-84.

Schneider, Z., Whitehead, D., \& Elliot. D. (2008). Nursing \& midwifery research methods and appraisal for evidence-based practice (3rd ed.). Australia: Elsevier.

Scott, K., White, K., \& Roydhouse. K. (2013). Advancing the educational and career pathway for clinical trials nurses. The Journal of Continuing Education, 44(4), 165170.

Simsen, B.J., Holroyd, E., \& Sellick, K. (1996). Postgraduate education expectations: A survey of Hong Kong graduate nurses. Journal of Advanced Nursing, 24(4), 827835.

Statistics New Zealand. (2016). 'Ethnicity' webpage. Retrieved $7^{\text {th }}$ February 2016 from http://www.stats.govt.nz/methods/classifications-and-standards/classificationrelated-stats-standards/ethnicity.aspx

Sweeney, J., \& Dalton, C. (2007). Intellectual disability nurse's interest in undertaking postgraduate education. Learning Disability Practice, 10(2), 30-37.

Tame, S. Perioperative nurses' perceptions and experiences of continuing professional education. Journal of Perioperative Practice, 19(8), 257-262.

Then, K.L., Rankin, J.A., \& Ali, E. (2014). Focus group research: What is it and how can it be used? Canadian Journal of Cardiovascular Nursing, 24(1), 16-22.

Te Pou. (2016) Te Pou. Retrieved $23^{\text {rd }}$ February 2016 from http://www.tepou.co.nz 
Warren, J.I. (2009). Motivating registered nurses to return for an advanced degree. Journal of Advanced Nursing, 40(5), 200-207.

Watkins, D. (2011). Motivation and expectations of German and British nurses embarking on a master's programme. Nurse Education Today, 31(1), 31-35.

Watson, P.G., \& Wells, N. (1987). Nurses attitudes toward the advantages of master's degree preparation in nursing. Journal of Nursing Education, 25(2), 63-68.

Williamson, G.R. (2005). Illustrating triangulation in mixed-methods nursing research. Nurse Researcher, 12(4), 7-18.

Yin, R.K. (2009). Case study research design and methods. United States of America: Sage Inc.

Zahran, Z. (2013). Masters level education in Jordan: A qualitative study of key motivational factors and perceived impact on practice. Nurse Education Today, 33(9), 1051-1056. 